\title{
Searching for the key to the self : evaluation of the 'I am the key' program for mental health promotion
}

Citation for published version (APA):

Mann, M. C. (2003). Searching for the key to the self : evaluation of the 'I am the key' program for mental health promotion. [Doctoral Thesis, Maastricht University]. Universiteit Maastricht. https://doi.org/10.26481/dis.20030321mm

Document status and date:

Published: 01/01/2003

DOI:

$10.26481 /$ dis. $20030321 \mathrm{~mm}$

Document Version:

Publisher's PDF, also known as Version of record

\section{Please check the document version of this publication:}

- A submitted manuscript is the version of the article upon submission and before peer-review. There can be important differences between the submitted version and the official published version of record.

People interested in the research are advised to contact the author for the final version of the publication, or visit the DOI to the publisher's website.

- The final author version and the galley proof are versions of the publication after peer review.

- The final published version features the final layout of the paper including the volume, issue and page numbers.

Link to publication

\footnotetext{
General rights rights.

- You may freely distribute the URL identifying the publication in the public portal. please follow below link for the End User Agreement:

www.umlib.nl/taverne-license

Take down policy

If you believe that this document breaches copyright please contact us at:

repository@maastrichtuniversity.nl

providing details and we will investigate your claim.
}

Copyright and moral rights for the publications made accessible in the public portal are retained by the authors and/or other copyright owners and it is a condition of accessing publications that users recognise and abide by the legal requirements associated with these

- Users may download and print one copy of any publication from the public portal for the purpose of private study or research.

- You may not further distribute the material or use it for any profit-making activity or commercial gain

If the publication is distributed under the terms of Article $25 \mathrm{fa}$ of the Dutch Copyright Act, indicated by the "Taverne" license above, 


\title{
Searching for the Key to the Self
}

\author{
Evaluation of the 'I Am The Key' program \\ for Mental Health Promotion
}




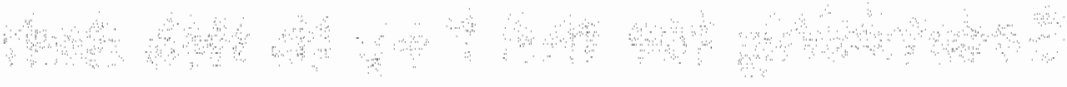
a. 


\title{
Searching for the Key to the Self
}

\author{
Evaluation of the 'I Am The Key' program \\ for Mental Health Promotion
}

\author{
Proefschrift \\ ter verkrijging van de graad van doctor \\ aan de Universiteit Maastricht, \\ op gezag van de Rector Magnificus, \\ Prof. Dr. A.C. Nieuwenhuizen Kruseman, \\ volgens het besluit van het College van Decanen, \\ in het openbaar te verdedigen \\ op vrijdag 21 maart 2003 om 12:00 uur \\ door \\ Michal Cohen Mann
}




\section{Promotors}

Prof. dr. Clemens Hosman

Prof. dr. Nanne De Vries

\section{Beoordelingscommissie}

Prof. dr. Bart van den Borne

Dr. Susan Bögels

Prof. dr. Nathan Deen

Prof. dr. Ingrid Josephs

Prof. dr. Gerjo Kok

(C) Mann, Michal: Searching for the Key to the Self

Evaluation of the 'I Am The Key' program for Mental Health Promotion

\section{Colofon}

Layout and cover design: E. C. Mann

Priming. Unigraphic, Maastricht

Cover illustration; Rinat Hoffer

ISBN $90-5681-154-1$

The studies presented in this dissertation were conducted under auspices of the Maastricht Research Institute for Prevention and Care (Health) at Maastricht University, The Netherlands. Health is part of the Netherlands School of Primary Care Research (CaRe), which has been acknowledged since 1995 by the Royal Dutch Academy of Art and Science (KNAW). Financing for the studies here presented was generously provided by the Dutch Health Research and Development Council (Zorg Onderzoek Nederland, ZON/MW). The materials used in the project were sponsored by a grant of 'Kinder postzegels', and the department of Health Education and Health Promotion of the Maastricht University, The Netherlands. 
In memory of my beloved father, Joseph Mann 



\section{Contents}

$\begin{array}{ll}\text { Introduction } & 9\end{array}$

Self-esteem in a broad spectrum approach for mental health promotion $\quad 21$

Internalizing and externalizing problems in normal children: Relationships with self-esteem, self-perceived competence and parenting stress $\quad 47$

The 'I Am The Key' (IATK) program $\quad 63$

Searching for the key to the self: An evaluation of the short-term effects of 'I Am

The Key', a Generic School Mental Health Promotion Program

A follow-up study of the effectiveness of "I Am The Key", a generic school

counseling program

Generall Discussion

References

147

Summary

161

Acknowledgements

165

Appendix

170 
"If sometimes you feel yourself little, useless, offended and depressed, always remember your root: you were once the strongest and most resilient sperm out of hundreds of millions" (Anonymous) 
Chapter 1

Introduction 

"Know thyself" (Anonymous: inscribed on the temple of Apollo at Delphi)

\section{Introduction}

All the branches, leaves, flowers, and fruits of a tree can be simultaneously nourished and vitalized by one act: watering the roots. The roots are the central point of the tree: the linchpin to its continued existence. In many ways, the roots resemble the inner center of our diversified lives: the self. Thoughts, feelings, speech, actions, and relationships all originate deep within the self. Self-esteem serves as one of the main pillars of the self and is accepted as such throughout psychology. Enhancing the self in general, and self-esteem in particular, is likely to promote a process of self-growth. Improved self-esteem could contribute to an individual's healthy emotional and social development.

This thesis describes the implementation and evaluation of the "I Am The Key' (IATK) program, a program that aims to promote self-esteem in 10-12 year old children. The goal of the program is to foster self-esteem and to prevent the risk of internalizing problem behavior such as depression and externalizing problem behavior such as aggression.

According to a recent report of the WHO (2001), more than $25 \%$ of individuals all over the world develop at least one mental or behavioral disorder during their lifetime, among which are symptoms of depression and aggression (Almeida-Filho, Mari, Franca, Fernandes, \& Andreoli, 1997; Regier et al., 1988; Wells, Bushnell, Hornblow, R, \& Oakley-Brown, 1989; WHO, 2001). About 10\% of all individuals suffer from depressive disorders (Goldberg \& Lecrubier, 1995). In 1993 the Harvard School of Public Health in collaboration with the World Bank and WHO assessed the Global Burden of Disease (GBD) and introduced a new metric the Disability Adjusted Life Year (DALY) to quantify the burden of diseases. In the World Health Report of 2001 unipolar depression disorders was ranked in the fourth place for the total population and second place for 15-44-year-olds as a leading cause of DALYs in 2000. These depressive disorders cause massive disruption in 
the lives of those directly affected and their families. In most cases, even after recovery, quality of life continues to be poor, because of social factors like continued stigma and discrimination. Coincidentally, aggressive behavior and violence are also widespread phenomena worldwide, according to a European report (Connect, 2001). Violence in society is alreadly reflected in the behavior of primary schoolchildren and has come to be recognized as a major social problem, which does not only affect well-being, happiness, and achievements, but which can also undermine society's democratic values.

The worldwide and European situation as described above applies in The Netherlands as well. Statistical reports in The Netherlands on the prevalence of symptoms of depression and aggression in schoolchildren are relatively scarce. Depression research mainly surveys the adult population, its prevalence within the Dutch population is between 5 and $9 \%$ depending on the different age groups. The prevalence of depression has a curvilinear relationship with age, with the age group 35-44 having the highest rate (Bijl, Van Zessen, \& Ravelli, 1997). While depression research mainly focuses on adults, research on aggression in The Netherlands covers children and adolescents as well. Several studies indicate problems of bullying, sexual harassment, and violence among high school subjects, 13-17 years old (Bongers, 1994). According to research findings on violence in The Netherlands between 1960 and 1995 (Komen, 1997), aggressive behavior, youth criminality, and delinquency have increased over the years and became more severe among children and adolescents.

In the USA more information is available. In the last report of the National Center for Edication Statistics USA (1997), two clear and alarming trends were identified. The level of aggression and delinquency, and the total number of crimes committed (sexual abuse, robbery, armed physical attack, vandalism, theft, and physical attack without weapons) increased from elementary education upwards. Unfortunately, the prevalence of depression is alarming too. According to the Substance Abuse and Mental Health Services Administration Report (2000), in the USA alone nearly 3 million youngsters aged 12 to 17 thought about suicide during the year 2000 and over a million actually tried to kill themselves. These findings can be linked to high depression rates, because it is often the depressive disorders 
that lead to suicide (WHO, 2001). Suicide, especially among young adults, is a leading cause of death.

The above-mentioned prevalence of symptoms of aggression and depression in modern society, increasing worldwide, illustrates the need for prevention in mental health. Interestingly, Mrazek and Haggerty (1994) describe the well-documented need for studies on the efficacy of universal prevention in schools. They define universal prevention as those "interventions that are targeted to the general public or to a whole population group that has not been defined on the basis of increased risk" (pp. 24). Universal interventions might focus on the role of selfesteem as a risk and protective factor in mental health, based on the idea that fostering self-esteem could influence the development of a range of mental disorders and promote individual's well-being (see Chapter 2). To this end, Harter"s (1999) work on the construction of the self, which summarizes the determinants and inner mechanisms of self-esteem following an extensive research review on the construction of the self (see Chapters 2 and 5), can form the basis for making such interventions. The current study uses this approach in an attempt to prevent mental health problems by fostering self-esteem.

Below, a brief overview is prowided of the terminology of self and selfesteem. "Then, the rolle of self-esteem in health, health education, and in mental thealth promotion is examined. Finally, the research design is introduced and an outline of the content of the thesis is given.

\section{Definitions of 'self variables'}

The self is a multidimensional concept, which is divided into three main parts: the cognitive aspect ('self-concept'); the emotional aspect ('self-esteem'); and the behawioral aspect ('self-efficacy') (see Chapter 2).

This study focuses on the cognitive and emotional dimensions of the self. Self-esteem and self-concept are general concepts, while self-efficacy focuses on specific behavior. According to Bandura (1986, pp. 391), perceived self-efficacy is defined as people's judgments of their capabilities to organize and execute courses 
of action required to attain designated types of performances. Perceived selfefficacy is not concerned with the skills one has, but with the judgment one has of what one can do with the skills one possesses. Thus, the concept of self-efficacy relates to one's beliefs about the capabilities of one's behavior in a particular situation. Self-efficacy does not refer to a global trait of an individual, but will vary greatly depending on the task and context which confronts him or her (Bandura, 1986; Strecher, DeVillis, Becker, \& Rosenstock, 1986).

The self-concept is defined as the sum of an individual's beliefs and knowledge about his/her personal attributes and qualities. It is classed as a cognitive sehema that organizes abstract and concrete views about the self and that controls the processing of self-relevant information (Kihlstrom \& Cantor, 1983; Markus, 1977). Other concepts such as self-scheme, self-image, and self-perception are used in this dissertation as synonyms equivalent to self-concept. Self-esteem is the evaluative and affective dimension of self-concept, and is here considered as equivalent to self-regard, self-estimation, and self-worth (Harter, 1999). It refers to a person's global appraisal of his/her positive or negative value, based on the scores a person gives him- or herself in different roles and domains of life (Markus \& Nurius, 1986; Rogers, 1981).

\section{Self-esteem and healthy mental development}

According to Tudor (1996), self-concept, identity, and self-esteem are among the key elements of mental health. Therefore it is important to understand how selfesteem develops. According to Harter's evidence-based theory (1999), self-esteem is a product of two internal judgments: self-perceived competence in domains of importance and overall sense of support. The development of self-esteem during childhood and adolescence depends on factors such as coping with selfdiscrepancies between competing self-concepts, such as the ideal and the real self, especially in domains of importance. The larger the discrepancy between the value a child assigns to a certain competence area and the perceived self-competence in that area, the lower the feeling of self-esteem (Harter, 1999). Moreover, the overall 
sense of support of significant others, especially parents and peers, is influential for the development of self-esteem. Children who feel that others accept them, and that they are unconditionally loved and respected, report a higher sense of self-esteem (Bee, 2000). Conversely, children with a high discrepancy and a low sense of social support report a lower sense of self-esteem. These results suggest that efforts to improve self-esteem in children require both supportive social surroundings and the formation and acceptance of realistic personal goals in relevant personal domains (Harter, 1999).

Pre-pubescence and adolescence are crucial periods in self-esteem development. The evolving nature of self-esteem was highlighted by Erikson in his theory on the stages of psychosocial development in children, adolescents, and adults. Special attention in this theory was given to the process of identity development during adolescence. As long as the process of crystallization of identity continues, individuals are occupied with their self-esteem and self-concept (Erikson, 1968). If this process is not negotiated successfully the individual remains confused, not knowing who he or she really is. Identity problems such as unclear identity, diffused identity, and foreclosure, together with low self-esteem, can be the cause and the core of many mental and social problems, as studied and reviewed by Marcia (1993).

As the roots must have fertile ground for the tree to grow and develop, so must self-esteem have an optimal environment for the development of individual mental health. Several social factors and processes might have an impact on mental health. Social antecedents, both within the family and in one's social surroundings, could be considered as risk and protective factors that may influence mental wellbeing (see Chapters 2 and 3). For instance within the family, protective factors can include secure attachment, social support such as parental support, and positive relationships within the family. Relevant risk factors include death, physical or mental illness in the family, marital problems and divorce, child abuse, and neglect. These events could elevate parenting stress. Recent research indicates that parenting stress, stressful life events and lack of social support from family members were found to be significantly associated with psychopathology (Mesman \& Koot, 2000). Therefore, it is proposed that positive self-esteem together with strong social 
support could have a protective and promoting effect on mental health, limiting the negative impact of life events such as severe stressors.

\section{The role of self-esteem in health education and promotion}

Health promotion, according to the Ottawa Charter, refers to the process of enabling people to exert control over, and to improve the factors affecting their health (WHO, 1986a). Self-esteem has a role in health promotion as it has protective functions which affect physical and mental health (see Chapter 2). In the context of negative messages and stressors, people have a need to think positively about themselves and to defend and to improve their self-worth. Self-esteem represents a motivational force that influences perceptions and coping behavior (see Chapter 2). It is also an element of empowerment, one of the key goals of health promotion (WHO, 1986b). According to Rappoport (1984) empowerment is a psychological sense of control and a concern with actual social influence. Improving positive selfesteem is considered as a crucial element of empowerment (Brown, 1998). Enhancing self-esteem and feelings of control could affect achievements and performance. Many mental health programs that aim to build a strong sense of identity and empowerment focus on the enhancement of self-esteem (Hage \& Nosanow, 2000; McLendon, 2000).

\section{The dual nature of self-esteem in health education models}

In the introduction to his book on the determinants of health. Commers (2002) states: "Ancient sources of wisdom as well as insights from modern physics remind us that our understanding of cause and effect is largely illusory. Every 'cause' is in some sense also an 'effect', and every effect is in fact the outcome of an infinite and unpredictable set of causes" (pp. 12). The same goes with self-esteem. Within health behavioral models, self-esteem can function both as a determinant of health behavior and as one of its outcomes. Poor self-esteem can trigger poor coping behavior or risk behavior that subsequently increases the likelihood of certain diseases, including mental disorders. On the other hand, the presence of poor coping behavior and ill-health can generate or reinforce a negative self-image. 
The Precede-Proceed model of Green \& Kreuter (1991) for the planning of health education and health promotion recognizes this dual role of self-esteem. The model directs health educators to specify characteristics of health problems and to take multiple determinants of health and health related behavior into account. It integrates an epidemiological, behavioral, and environmental approach. The staged Precede-Proceed framework supports health educators in identifying and influencing the multiple factors that shape health status and in evaluating the changes produced by interventions. Self-esteem plays a dual role in the PrecedeProceed model, as an outcome variable and as a determinant. On the one hand Green and Kreuter (1991, pp. 27) suggest self-esteem as one of the outcomes of health behavior and health status, and as one of the quality of life indicators. On the other hand, empirical studies over 15 years indicate that self-esteem is an important psychological determinant contributing to health and quality of life (Evans, 1997).

Self-esteem could serve as a predisposition for health behaviors and as its outcome. Therefore, self-esteem could have a rolle in generic mental health promotion interventions (see Chapter 2).

\section{Mental Health Promotion}

Sartorius, the former WHO Director of Mental Health, defined mental health promotion as a means by which individuals, groups or large populations can enhance their competence, self-esteem, and sense of well-being (Sartorius, 1988). This view is supported by Tudor (1996) in his monograph on mental health promotion, where he also presents self-concept and self-esteem as two of the core elements of mental health and, therefore, as an important focus of mental health promotion.

Self-esteem is a non-specific risk factor and protective factor in the development of mental disorders and social problems (see Chapter 2). Therefore, a global preventive approach built around the 'self' is advocated. Generally, by changing common risk and protective factors (e.g. self-esteem, coping skills, and social support), and adopting a generic preventive approach, the development of a 
range of mental disorders can be influenced and individual well-being promoted. This could occur even before the onset of any specific problem has presented itself. Given its multi-outcome perspective; we have termed this strategy the "broad spectrum approach" (BSA) in prevention and promotion (Mann, Hosman, Schaalma, \& De Vries, submitted a).

In developing the BSA, 'self-esteem' is considered one of the important elements of such a proposed strategy. By fostering self-esteem and hence treating a common risk factor, one can actively contribute to the prevention of an array of physical diseases, mental disorders, and social problems challenging society today.

\section{Research questions and the study design}

\section{Research questions}

This research intends to evaluate the relation between self-esteem and problem behavior in children. If self-esteem is associated with problem behavior, it could be fruitful to intervene on this characteristic. The I Am The Key (IATK) program (Mann, 1997) aims to foster self-esteem. Therefore, we evaluate the short-and longterm effects of the IATK program on self-esteem and symptoms of depression and aggression. The impact of the program on male and female children ranking high, medium, and low on self-esteem and problem behavior is discussed.

\section{Research design}

I Am The Key is a broad spectrum approach program that aims to foster self-esteem and prevent the risk of mental disorders and social problems (see Chapter 4). The program was developed and implemented by the author in Israel (Mann, 1987) and translated from Hebrew into English (Mann, 1997). The program was translated into Dutch in 1999, at which time it was implemented further in the Jeroen Bosch school in Arnhem, The Netherlands, as part of a small-scale pilot study (see Chapter 4). In 2000, the program was implemented in 16 schools in the south of Limburg, The Netherlands. To determine the effects of the program, an evaluation study was undertaken using a nested randomized design. This evaluation study consisted of a 
pre-test, a post-test, and a follow-up measure. The pre- and post-test measures were performed immediately before and after the implementation of the program in schools. The pre-test also served as a cross-sectional study on problem behavior in normal schoolchildren (see Chapters 3 and 5). The follow up was conducted eight months after the post-test (see Chapter 6). The population included at least two classes of pupils aged 11-12 per target school. Within schools, classes were randomized, with one class assigned to the experimental group (i.e. participating in IATK) and the remaining class serving as the control.

\section{Outline of the thesis}

Chapter 2 describes the importance of 'self-esteem" as a protective factor and a nonspecific risk factor in physical and mental health. Evidence is presented which illustrates that self-esteem can lead to better health and social behavior and that a broad range of mental disorders and social problems are associated with poor selfesteem. Such mental disorders and social problems include both internalizing problems (e.g. depression, suicidal tendencies, eating disorders, and anxiety) and externalizing problems (e.g. violence and substance abuse). This chapter concentrates on self-esteem as a potential risk and protective factor in mental and physical health from a developmental and educational point of view. The consequences for theory development, program development, and health education research are addressed. Focusing on self-esteem is considered an important element of mental health promotion and of a broad spectrum approach in prevention.

Chapter 3 describes the results of a cross-sectional study on internalizing and externalizing problems in normal children which also served as a base-line measurement for the evaluation of the IATK program. The relationship between self-esteem, self-perceived competence, and parenting stress on the one hand, and internalizing and externalizing problem behaviors on the other, was investigated in a sample of 709 elementary schoolchildren. 
The fourth chapter provides the description and theoretical foundation to the IATK program. It gives an outline of the curriculum's main themes, methods, and strategies. The pilot results are discussed as well.

The IATK program was implemented in 16 schools in the south of The Netherlands, in a mested randomized design. Within every school there were experimental and control classes. The fifth and sixth chapters present the short-term and long-term effect studies. The program"s effects on mental health promotion variables (self-esteem and behavioral conduct) and mental and social problems (delinquency, depression, and aggression) are discussed.

Finally a general discussion of the whole research is presented in Chapter 7. 
Chapter 2

Self-esteem in a broad spectrum approach for mental health promotion

A revised version of this chapter was submitted in January 2003 as: Michal Mann, Clemens MH Hosman. Herman P Schaalma, \& Nanne $K$ de Vries. Self-esteem in a broad spectrum approach for mental health promotion. 
$\therefore \quad \therefore$

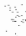


"The most basic task for one's mental, emotional and social health, which begins in infancy and continues until one dies, is the construction of his/her positive selfesteem" (Macdonald, 1994).

\begin{abstract}
Self-evaluation is crucial to mental and social well-being, as it influences aspirations, personal goals, and interaction with others. This paper stresses the importance of self-esteem as a protective factor and a non-specific risk factor in physical and mental health. Evidence is presented illustrating that self-esteem can lead to better health and social behavior, and that poor self-esteem is associated with a broad range of mental disorders and social problems, both internalizing problems (e.g. depression, suicidal tendencies, eating disorders, and anxiety) and externalizing problems (e.g. violence and substance abuse).

We discuss the working mechanism of self-esteem in these relations. It is argued that an understanding of the development of self-esteem, its ourcomes, and its active protection and promotion, are critical to the improvement of both mental and physical health. The consequences for theory development, program development, and health education research are addressed. Focusing on self-esteem is considered a core element of mental health promotion and a fruitful basis for a broad spectrum approach (BSA) in prevention.
\end{abstract}




\section{Introduction}

The belief: and evaluations people hold about themselves determine who they are, what they can do, and what they can become (Burns, 1982). These powerful, imner influences provide an internal guiding mechanism, steering and nurturing the indiwidual through life, and governing their behavior. Peoples concepts and feelings about themselves are generally labeled as their self-concept and selfesteem. These together with their ability to deal with life's challenges and to control what happens to them, are widely documented in literature (Bandura, 1977; Bowlby, 1980; Harter, 1999; Rutter, 1992; Seligman, 1975).

Self-concept is defined as the sum of an individual's beliefs and knowledge about his/her personal attributes and qualities. It is classed as a cognitive schema that organizes abstract and concrete views about the self, and that controls the processing of self-relevant information (Kihlstrom \& Cantor, 1983; Markus, 1977). Other concepts, such as self-image and self-perception, are equivalents to selfconcept. Self-esteem is the evaluative and affective dimension of the self-concept, and is considered as equivalent to self-regard, self-estimation, and self-worth (Harter, 1999). It refers to a person's global appraisal of his/her positive or negative value, based on the scores a person gives him/herself in different roles and domains of life (Markus \& Nurius, 1986; Rogers, 1981). Positive self-esteem is not only seen as a basic feature of mental health, but also as a protective factor that contributes to better health and positive social behavior through its role as a buffer against the impact of negative influences. It is seen to actively promote healthy functioning as reflected in life aspects such as achievements, success, satisfaction, and the ability to cope with diseases, such as cancer and heart disease. Conversely, an unstable self-concept and poor self-esteem play a critical role in the development of an array of mental disorders and social problems, such as depression, anorexia nervosa, bulimia, anxiety, violence, substance abuse, and high-risk behaviors. These conditions not only result in a high degree of personal suffering, but also impose a considerable burden on society. As will be shown, prospective studies have highlighted the nature of low self-esteem as a risk factor and positive self-esteem as 
a protective factor. To summarize, self-esteem is considered as an influential factor both in physical and mental health and therefore could be an important focus in health promotion, in particular mental health promotion.

Health promotion refers to the process of enabling people to increase control over, and to improve their own health (WHO, 1986a). Subjective control as well as subjective health, each aspects of the self, are considered as significant elements of the health concept. Recognizing the existence of different views on the concept of mental health promotion, Sartorius, the former WHO Director of Mental Health, preferred to define it as a means by which individuals, groups, or large populations can enhance their competence, self-esteem, and sense of well-being (Sartorius, 1988). This view is supported by Tudor (1996) in his monograph on mental health promotion, where he also presents the self-concept and self-esteem as two of the core elements of mental health and, therefore, as an important focus of mental health promotion.

This article aims to clarify how self-esteem is related to health and mental health, both empirically and theoretically, and to offer arguments for enhancing self-esteem and self-concept as a major aspect of health promotion, mental health promotion, and broad spectrum approach (BSA) in prevention.

The first section presents a review of the empirical evidence on the consequences of high and low self-esteem in the domains of mental health, health, and social outcomes. This section also addresses the question of the bi-directional nature of the relationship between self-esteem and mental health. The second section discusses the role of self-esteem in health promotion from a theoretical perspective. How are differentiations within the self-concept related to self-esteem and mental health? How does self-esteem relate to the currently prevailing theories in the field of health promotion and prevention? What are the mechanisms that link self-esteem to health and social outcomes? Several theories used in health promotion or prevention offer insight into such mechanisms. We discuss the role of positive self-esteem as a protective factor in the context of stressors, the developmental role of negative self-esteem in mental and social problems, and the role of self-esteem in models of health behavior. 
Finally, implications are discussed for designing a health-promotion strategy that could generate broad spectrum outcomes through addressing common risk factors such as self-esteem. In this context, schools are discussed as an ideal setting for such broad spectrum interventions. Some examples are offered of school programs that have successfully contributed to the enhancement of self-esteem and the prevention of mental and social problems.

\section{Positive self-esteem and the implications for physical and mental health}

The question of whether positive self-esteem is connected to physical and mental well-being is addressed in the following section, which assesses the role of positive self-esteem in areas of life such as school achievement, coping with stress, and physical diseases.

\section{Self-esteem and mental well-being}

Empirical studies over the last 15 years indicate that self-esteem is an important psychological factor contributing to health and quality of life (Evans, 1997). Recently, several studies have shown that subjective well-being significantly correlates with high self-esteem, and that self-esteem shares significant variance in both mental well-being and happiness (Zimmerman, 2000). Self-esteem has been found to be the most dominant and powerful predictor of happiness (Furnham \& Cheng, 2000). Indeed, while low self-esteem leads to maladjustment, positive selfesteem, internal standards, and aspirations actively seem to contribute to 'wellbeing' (Garmezy, 1984; Glick \& Zigler, 1992). According to Tudor (1996), selfconcept, identity, and self-esteem are among the key elements of mental health.

\section{Self-esteem, academic achievements, and job satisfaction}

The relationship between self-esteem and academic achievement is reported in a large number of studies (Filozof et al., 1998; Hay, Ashman, \& van Kraayenoord, 
1998; Marsh \& Yeung, 1997). In the critical chilldhood years, positive feelings of self-esteem have been shown to increase children's confidence and success at school (Coopersmith, 1967), with positive self-esteem being a predicting factor for academic success e.g. reading ability (Markus \& Nurius, 1986). Results of a longitudinal study among elementary schoolchildren indicate that children with high self-esteem have higher cognitive aptitudes (Adams, 1996). Furthermore, research has revealed that core self-evaluations measured in childhood and in early adulthood are linked to job satisfaction in midlle adulthood (Judge, Bono, \& Locke, 2000).

\section{Self-esteem and coping with stress in combination with coping with physical disease}

The protective nature of self-esteem is particularly evident in studies examining stress and/or physical disease in which self-esteem is shown to safeguard the individual from fear and uncertainty. This is reflected in observations of chronically ill individuals. It was found that a greater feeling of mastery, efficacy, and high selfesteem, in combination with having a partner and many close relationships, all have direct protective effects on the development of depressive symptoms in the chronically ill (Penninx et al., 1998). Self-esteem has also been shown to enhance an individual's ability to cope with disease and survival. Research on pre-transplant psychological variables and survival after bone marrow transplantation (Broers et al., 1998) indicates that high self-esteem prior to surgery was related to longer survival. Chang and Mackenzie (1998) have found that the level of self-esteem was a consistent factor in the prediction of the functional outcome of a patient after at stroke.

To conclude, many studies on the outcomes of positive self-esteem are correlational by nature, although there are some prospective studies as well. Positive self-esteem is associated with mental well-being, adjustment, happiness, success, and satisfaction. It is also associated with recovery after severe diseases. Research results show beneficial outcomes of positive self-esteem; however, the evolving nature of self-esteem could also result in negative outcomes. 


\section{Identity development and the sources of negative self-esteem}

The evolving nature of self-esteem was conceptualized by Erikson in his theory on the stages of psychosocial development in children, adolescents, and adults (Erikson, 1968). According to Erikson, individuals are occupied with their selfesteem and self-concept as long as the process of crystallization of identity continues. If this process is not negotiated successfully, the individual remains confused, not knowing who he really is. Identity problems, such as unclear identity, diffused identity, and foreclosure, together with low self-esteem, can be the cause and the core of many mental and social problems (Marcia et al., 1993).

The development of self-esteem during childhood and adolescence depends on a wide variety of intramindividual and social factors. Approval and support, especially from parents and peers, and self-perceived competence in domains of importance are main determinants of self-esteem (see Harter, 1999 for a review). Attachment and unconditional parental support are critical during the phases of selfdevelopment. This is a reciprocal process, as individuals with positive self-esteem can better internalize the positive view of significant others. For instance, in their prospective study among young adolescents, Garber and Flynn (2001) found that negative self-worth develops as an outcome of low maternal acceptance, maternal history of depression, and exposure to negative interpersonal contexts, such as negative parenting practices, early history of child maltreatment, negative feedback from significant others on one's competence, and family discord and disruption.

Other sources of negative self-esteem are discrepancies between competing self-concepts, such as between the ideal and the real self, especially in domains of importance. The larger the discrepancy between the value a child assigns to a certain competence area and the perceived self-competence in that area, the lower the feeling of self-esteem (Harter, 1999). Furthermore, discrepancies can exist between the self as seen by oneself and the self as seen by significant others. This could refer to contrasts that might exist between self-perceived competencies and the lack of approval or support by parents or peers, as implied by Harter (1999).

Finally, negative and positive feelings of self-worth could be the result of a cognitive, inferential process, in which children observe and evaluate their own 
behaviors and competencies in specific domains (self-efficacy). The poorer they value their competencies, especially in comparison to those of their peers or to the standards of significant others, the more negative their self-esteem. Such selfmonitoring processes can be negatively or positively biased, by a learned tendency to negative or pasitive thinking (Seligman, Reivich, Jaycox, \& Gillham, 1995).

\section{Negative outcomes of poor self-esteem}

The outcomes of negative self-esteem can be manifold. Poor self-esteem can result in a cascade of diminishing self-appreciation, creating self-defeating attitudes, psychiatric vulnerability, social problems, or risk behaviors. The empirical literature highlights the negative outcomes of low self-esteem. However, in several studies there is a lack of clarity regarding causal relations between self-esteem and problems or disorders (Flay \& Ordway, 2001). This is an important observation, as there is reason to believe that self-esteem should be examined not only as a cause but also as a consequence of problem behavior. For example, on the one hand, a child could have a negative view about himself and that might lead to depressive feelings. On the other hand, depression or lack of efficient functioning could lead to feeling bad, which might decrease self-esteem. Although the directionality can work both ways, this article concentrates on the evidence for self-esteem as a potential risk factor for mental and social outcomes. Three clusters of outcomes can be differentiated. The first are mental disorders with internalizing characteristics, such as depression, eating disorders, and anxiety. The second are poor social outcomes with externalizing characteristics including aggressive behavior, violence, and educational exclusion. The third is risky health behavior such as drug abuse and not using condoms.

\section{Self-esteem and internalizing mental disorders}

Self-esteem plays a significant role in the development of a variety of mental disorders. According to the Diagnostic and Statistical Manual of Mental Disorders (DSM IV, APA, 1984), negative or unstable self-perceptions are a key component in the diagnostic criteria of major depressive disorders, manic and hypomanic 
episodes, dysthymic disorders, dissociative disorders, anorexia nervosa, bulimia nervosa, and in personality disorders, such as borderline, narcissistic, and avoidant behavior. Negative self-esteen is also found to be a risk factor, leading to maladjustment and even escapism. Lacking trust in themselves, individuals become unable to handle daily problems which, in turn reduces the ability to achieve maximum potential. This could lead to an alarming deterioration in physical and mental well-being. A decline in mental health could result in internalizing problem behavior such as depression, anxiety, and eating disorders. The outcomes of selfesteem for these disorders are elaborated on below.

\section{Depressed moods, depression, and suicidal tendencies}

The clinical literature suggests that low self-esteem is related to depressed moods (Patterson \& Capaldi, 1992), depressive disorders (Dori \& Overholser, 1999; Rice, Ashby, \& Slaney, 1998), hopelessness, suicidal tendencies, and previously attempted suicide (Overholser, Adarns, Lehnert, \& Brinkman, 1995). Correlational studies have consistently shown a significant negative relationship between selfesteem and depression (Beck, Steer, Epstein, \& Brown, 1990; Patton, 1991). Campbell, Chew and Scratchley (1991) found an individual's appraisal of events to be clearly related to their self-esteem. Low self-esteem subjects rated their daily events as less positive, and negative life events as being more personally important than high self -esteem subjects. Subjects with high self-esteem made more stable and global internal attributions for positive events than for negative events, leading to reinforcement of their positive self-image. Subjects low in self-esteem, however, were more likely to associate negative events to stable and global internal attributions, and positive events to external factors and luck (Campbell, Chew, \& Scrathley, 1991). There is a growing body of evidence that indicates, that individuals with low self-esteem invariably report a depressed state and that there is a link between dimensions of attributional style, self-esteem, and depression (Abramson, Metalsky, \& Alloy, 1989; Hammen \& Goodman-Brown, 1990; Harter, 1999; Kovacs \& Beck, 1986; Renouf, 1990; Romney, 1994). 
Some indications of the causal role of self-esteem result from prospective studies. In longitudinal studies, low self-esteem during childhood (Reinherz et al., 1993), adolescence (Teri, 1982), and early adulthood (Wilhelm, Parker, DewhurstSavellis, \& Asghari, 1999), was identified as a crucial predictor of depression later in Hife. Shin (1993) even found that when accumulative stress, social support, and self-esteem were introduced subsequently in regression analysis, of the latter two, only self-esteem accounted for significant additional variance in depression. In addition, Brown, Bifluco and Andrews (1990) showed that positive self-esteem, although closely associated with inadequate social support, plays a role as a buffer factor. There appears to be a pathway from not living up to personal standards, to low self-esteem and to being depressed (Baumeister, 1990; Harter, 1986, 1990; Higgins, 1987, 1989). Alternatively, another study indicated that when examining the role of life events and difficulties, it was found that total stress interacted with low self-esteem in predicting depression, whereas self-esteem alone made no direct contribution (Miller, Kreitman, Ingham, \& Sashidharan, 1989). To conclude, results of cross-sectional and longitudinal studies showed that low self-esteem is predictive of depression.

The potentially detrimental impact of low self-esteem in depressive disorders stresses the significance of Seligman's recent work on 'positive psychology". His research indicates that teaching children to challenge their pessimistic thoughts whilst increasing positive subjective thinking (such as bolstering self-esteem), can reduce the risk of pathologies such as depression (Seligman, 1995; Seligman \& Csikszentmihalyi, 2000; Seligman et al., 1995).

\section{Other internalizing disorders}

Although self-esteem is most frequently associated with depression, relations have also been found with other internalizing disorders, such as anxiety and eating disorders. Research results indicate that self-esteem is inversely correlated with anxiety and other signs of psychological and physical distress (Beck, Brown, Steer, Kuyken, \& Grisham, 2001). For example, Ginsburg et al. (1998) observed a low level of self-esteem in highly socially anxious children. Self-esteem was shown to 
serve the fundamental psychological function of buffering anxiety, with the pursuit of self-esteem as a defensive avoidance tool against basic human fears. This mechanism of defense has become evident in research with elementary (Ginsburg et al, 1998) and high-schoolchildren (Fickova, 1999). In addition, empirical studies have shown that bolstering self-esteem in adults reduces anxiety (Solomon, Greenberg, \& Pysczynski, 2000).

The critical role of self-esteem during school years is clearly reflected in studies on eating disorders. At this stage in life, weight, body shape, and dieting behavior become intertwined with identity. Researchers have reported low selfesteem as a risk factor in the development of eating disorders in female schoolchildren and adolescents (Fisher, Pastore, Schneider, Pegler, \& Napolitano, 1994; Shisslak et al., 1998; Smolak, Levine, \& Schermer, 1996), as did prospective studies (Vohs et al., 2001). Low self-esteem also seems predictive of the poor outcome of treatment in such disorders, as has been found in a recent four-year prospective follow-up study among adolescent in-patients with bulimic characteristics (van der Ham, van der Strien, \& van Engelan, 1998). The significant influence of self-esteem on body-image has led to programs in which the promotion of self-esteem is used as a main preventive tool in eating disorders (Scarano, Gina, Kaodner, \& Cynthia, 1994; St Jeor, 1993; Vickers, 1993).

To sum, there is a systematic relation between self-esteem and internalizing problem behavior. Moreover, there is enough prospective evidence to suggest that poor self-esteem might contribute to deterioration of internalizing problem behavior while improvement of self-esteen could prevent such deterioration.

\section{Self-esteem, externalizing problems, and other poor social outcomes}

For more than two decades, scientists have studied the relationship between selfesteem and externalizing problem behaviors, such as aggression, violence, youth delinquency, and dropping out of school. The outcomes of self-esteem for these disorders are described below. 


\section{Violence and aggressive behavior}

While the causes of such behaviors are multiple and complex, many researchers have identified self-esteem as a critical factor in crime prevention, rehabilitation, and behavioral change (Gilbert, 1995; Kressly, 1994). In a recent longitudinal questionnaire study among high-school adolescents, low self-esteem was one of the key risk factors for problem behavior (Jessor, Turbin, \& Costa, 1998).

Recent studies confirm that high self-esteem is significantly associated with less violence (Fleming, Mullen, Sibthorpe, \& Bammer, 1999; Horowitz, 1999), while a lack of self-esteem significantly increases the risk of violence and gang membership (Schoen, 1999). Results of a nationwide study of bullying behavior in Ireland show that children who were involved in bullying as either bullies, victims, or both, had significantly lower self-esteem than other children (Schoen, 1999). Adolescents with low self-esteem were found to be more vulnerable to delinquent behavior. Interestingly, delinquency was positively associated with inflated selfesteem among these adolescents after performing delinquent behavior (Schoen, 1999). According to Kaplan's self-derogation theory of delinquency (1975), involvement in delinquent behavior with delinquent peers can increase children's self-esteem and sense of belonging. It was also found that individuals with extremely high levels of self-esteem and narcissism show high tendencies to express anger and aggression (Baumeister, Bushman, \& Campbell, 2000; Papps \& O'Carroll, 1998). To conclude, positive self-esteem is associated with less aggressive behavior. Although most studies in the field of aggressive behavior; violence, and delinquency are correlational, there is some prospective evidence that low selfesteem is a risk factor in the development of problem behavior. Interestingly, low self-esteem as well as high and inflated self-esteem, are both associated with the development of aggressive symptoms.

\section{School dropout}

Dropping out from the educational system could also reflect rebellion or antisocial behavior resulting from identity diffusion. For instance, Muha (1991) has shown that while self-image and self-esteem contribute to competent functioning in 
chilldhood and adolescence, low self-esteem can lead to problems in social functioning and school dropout. The social consequences of such problem behaviors may be considerable for both the individual and the wider community. Several prevention programs have reduced the dropout rate of students at risk (Alice, 1993; Andrews, 1999). All these programs emphasize self-esteem as a crucial element in dropout prevention.

\section{Self-esteem and risk behavior}

The impact of self-esteem is also evident in risk behavior and physical health. In a longitudinal study, Rouse (1998) observed that resilient adolescents had higher selfesteem than their non-resilient peers, and that they were less likely to initiate a variety of risk behaviors. Positive self-esteem is considered as a protective factor against substance abuse. Adolescents with more positive self-concepts are less likely to use alcohol or drugs (Carvajal, Clair, Nash, \& Evans, 1998), while those suffering from low self-esteem are at a higher risk for drug and alcohol abuse (Cervi, 1998; Loveland-Cherry, Leech, Laetz, \& Dielman, 1996; Wiatrek, 1998), and tobacco use (Crump, Lillie- Blanton, \& Anthony, 1997; Jones \& Heaven, 1998). Carvajal et al. (1998) showed that optimism, hope, and self-esteem are determinants of avoiding substance abuse by adolescents, mediated by attitudes, perceived norms and perceived behavioral control. Although many studies support the finding that improving self-esteem is an important component of substance abuse prevention (Devlin, 1995; Rodney, Mupier, \& Crafter, 1996), some studies found no support for the association between self-esteem and heavy alcohol use (Poikolainen, Tuulio-Henrikkson, Aalto-Setaelae, Marttunen, \& Loennqvist, 2001).

Empirical evidence suggests that positive self-esteem can also lead to behavior which is protective against contracting AIDS, while low self-esteem contributes to vulnerability to HIV/AIDS (Rolf \& Johnson, 1992; Somali et al., 2001). The risk level increases in cases where subjects have low self-esteem and where their behavior reflects efforts to be accepted by others or to gain attention, either positively or negatively (Reston, 1991). Lower self-esteem was also related to sexual risk-taking and needle sharing among homeless ethnic-minority women 
recovering from drug addiction (Nyamathi, 1991). Abel (1998) observed that single females whose partners did not use condoms, had lower self-esteem than single females whose partners did use condoms. In a study of gay and/or bisexual men, low self-esteem proved to be one of the factors that made it difficult to reduce sexual risk behavior (Paul, Stall, \& Davis, 1993).

To summarize, the literature reveals a number of studies showing beneficial outcomes of positive self-esteem, and conversely, negative outcomes of poor self-esteem, especially in adolescents. Prospective studies and intervention studies have shown that self-esteem can be a causal factor in depression, anxiety, eating disorders, delinquency, school dropout, risk behavior, social functioning, academic success, and satisfaction. However, the cross-sectional character of many other studies does not exclude that low self-esteem can also be considered as an important consequence of such disorders and behavioral problems.

To assess the implications of these findings for mental health promotion and preventive interventions, more insight is needed into the antecedents of poor self-esteem and the mechanisms that link self-esteem to mental, physical, and social outcomes.

\section{Mechanisms linking self-esteem and health behavior}

What are the mechanisms that link self-esteern to health and social outcomes? Several theories used in health promotion or prevention offer insight into such mechanisms. We discuss the role of positive self-esteem as a protective factor in the context of stressors, the developmental role of negative self-esteen in mental and social problems and the role of self-esteem in models of health behavior.

\section{Positive thinking about oneself as a protective factor in the context of stressors}

People have a need to think positively about themselves, to defend and to improve their positive self-esteem, and even to overestimate themselves. Self-esteem 
represents a motivational force that influences perceptions and coping behavior. In the context of negative messages and stressors, positive self-esteern can have various protective functions.

Research on optimism confirms that a somewhat exaggerated sense of selfworth facilitates mastery, leading to better mental health (Seligman, 1995). Evidence suggests that positive self evaluations, exaggerated perception of control or mastery, and unrealistic optimism are all characteristic of normal human thought, and that certain illusions may contribute to mental health and well-being (Taylor \& Brown, 1988). The mentally healthy person appears to have the capacity to distort reality in a direction that protects and enhances self-esteem. Conversely, individuals who are moderately depressed or low in self-esteem consistently display an absence of such enhancing illusions. Self-esteem could thus be said to serve as a defense mechanism that promotes well-being by protecting internal balance. The degree of such a defense, however has its limitations. The beneficial effect witnessed in reasonably well-balanced individuals becomes invalid in cases of extreme selfesteem and significant distortions of the self-concept. Seligman (1995) claimed that optimism should not be based on unrealistic or heavily biased perceptions. Earlier, Jahoda (1958) also included the 'adequate perception of reality' as a basic element of mental health.

A protective role of self-worth is also present in stress theories, in which positive thinking about oneself is considered to buffer the impact of stressors. The transactional model of stress and coping, as developed by Lazarus and Folkman (1984), is frequently used as a theoretical basis of preventive interventions in mental health. The model emphasizes cognitive appraisals which center on the evaluation of harm, threats and challenges, as well as on the options to cope with such threats. The transactional character refers to the cognitive process in which particular environmental conditions are appraised by a particular person with certain psychological characteristics. Self-esteem is considered as one of the factors that influence both the perception of threats and the evaluation of possible coping reactions. Positive self-esteem and self-confidence can buffer stress by mitigating the perceived threat and by enhancing the selection and implementation of efficacious coping strategies. As Lazarus and Folkman (1984) state, "Viewing 
yourself positively can also be regarded as a very important psychological resource for coping. We include in this category those general and specific beliefs that serve as a basis for hope and that sustain coping efforts in the face of the most adverse condition.... Hope can exist only when such beliefs make a positive outcome seem possible, if not probable” (pp. 159). A high level of self-esteem together with strong social support makes individuals less vulnerable to stressors (Brown et al., 1990; Rutter, 1992). Self-esteem can be seen as an internal moderator of stressors and sociall support as an external moderator (Capjan, 1974; Hobfool \& Waltisch, 1984). On a far more general level, this is reflected in Albee's (1985) well-known formula for the incidence of emotional illness in society, used as a theoretical fundament for primary prevention:

Incidence $=$

Organic causes and Stresses

Competence, coping-skills, self-esteem, and social support

Actions that increase the size of the numerator will increase the incidence of dysfunctional behavior in society, and activities that reduce, modify, or eliminate these factors will diminish the incidence of dysfunction. Efforts that reduce the size of the denominator will correspondingly increase the incidence, whereas actions that increase the size of the denominator, such as self-esteem, will reduce incidence.

\section{Identity, self-esteem and the development of externalizing and internalizing problems}

Erikson's theory on the stages of psychosocial development in children, adolescents, and adults $(1965,1968)$ and Herbert's flow chart (1987) focus on the vicissitudes of identity and the development of unhealthy mental and social problems. According to these theories, when a person is enduringly confused about his/her own identity, he/she may possess an inherent lack of self-reassurance which results in either a low level of self-esteem or in unstable self-esteem and feelings of insecurity. However, low self-esteem - likewise inflated self-esteem - can also lead to identity problems. 
Under circumstances of insecurity and low self-esteem, the individual evolves in one of two ways: he/she takes the active escape route or the passive avoidance route (Herbert, 1987). The escape route is associated with externalizing behaviors: aggressive behavior, violence and school dropout, the seeking of reassurance in others through high risk behavior, premature relationships, cults or gangs. Reassurance and security may also be sought through drugs, alcohol, or food. The passive avoidance route is associated with internalizing factors: feelings of despair and depression. Extreme avoidance may even result in suicidal behavior.

Whether identity and self-esteem problems express themselves following the externalizing active escape route or the internalizing passive avoidance route, is dependent on personality characteristics and circumstances, life events, and social antecedents (e.g. gender and parental support) (Hebert, 1987). Recent studies consistently show gender differences regarding externalizing and internalizing behaviors among others in a context of low self esteem (Benjet \& HernandezGuzman, 2001; Block \& Gjerde, 1986; Harter, 1999; Rolf, Masten, Cicchetti, Nuechterlein, \& Weintraub, 1990). Girls are more likely to have internalizing symptoms than boys, and boys are more likely to have externalizing symptoms than girls. Moreover, according to Harter (1999), in recent studies girls appear to be better than boys in positive self-evaluation in the domain of behavioral conduct. Self perceived behavioral conduct is there assessed as the individual view on how well behaved he/she is and how he/she views his/her behavior in accordance with social expectations (Harter, 1999). Negative self-perceived behavioral conduct is also found to be an important factor in mediating externalizing problems (Hoffman, 1999; Reda-Norton, 1995).

The internalization of parental approval or disapproval is critical during childhood and adolescence. Studies have identified parents' and peers' supportive reactions (e.g. involvement, positive reinforcement, and acceptance) as crucial determinants of children's self-esteem and adjustment (Shadmon, 1998). In contrast to secure, harmonious parent-child relationships, poor family relationships are associated with internalizing problems and depression (Kashubeck \& Christensen, 1993; Oliver \& Paull, 1995). 


\section{Self-esteem in health behavior models}

Self-esteem also plays a role in current cognitive models of health behavior. Health education research based on the Theory of Planned Behavior (Ajzen, 1991) has confirmed the role of self-efficacy as a behavioral determinant (Godin \& Kok, 1996). Self-efficacy refers to the subjective evaluation of control over a specific behavior. While self-concepts and their evaluations could be related to specific behavioral domains, self-esteen is usually defined as a more generic attitude towards the self. One can have high self-efficacy for a specific task or behavior, while one has a negative evaluation of self-worth, and vice versa. Nevertheless, both concepts are frequently intertwined since people often try to develop selfefficacy in activities that give them self-worth (Strecher et al., 1986). Self-efficacy and self-esteem are therefore not identical, but nevertheless related. The development of self-efficacy in behavioral domains of importance can contribute to positive self-esteem. On the other hand, the levels of self-esteem and selfconfidence can influence self-efficacy, as is assumed in stress and coping theories.

The Attitude-Social influence-self-Efficacy (ASE) model (De Vries, Dijkstra, \& Kuhlman, 1988; De Vries \& Mudde, 1998) and the Theory of Triadic Influence (TTI) (Flay \& Petraitis, 1994) are recent theories that provide a broad perspective on health behavior. These theories include distal factors that influence proximal behavioral determinants (De Vries, Mudde, Dijkstra, \& Willemsen, 1998), and specify more distal streams of inlluence for each of the three core determinants in the Planned Behavior Model (attitudes, self-efficacy, social normative beliefs). Each of these behavioral determinants is assumed to be moderated by several distal factors, including self-esteem and mental disorders.

The TTI regards self-esteem in the same sense as the ASE, as a distal factor. According to this theory, self-efficacy is influenced by personality characteristics, especially the 'sense of self', which includes self-integration, selfimage, and self-esteem (Flay \& Petraitis, 1994).

The Precede-Proceed model of Green \& Kreuter (1991) for the planning of health education and health promotion also recognizes the role of self-esteem. The model directs health educators to specify characteristics of health problems and to 
take multiple determinants of health and health-related behavior into account. It integrates an epidemiologicad, behavioral, and environmental approach. The staged Precede-Proceed framework supports health educators in identifying and influencing the multiple factors that shape health status and evaluating the changes produced by interwentions. Self-esteem plays a role in the first and fourth phase of the Precede-Proceed model, as an outcome variable and as a determinant. The initial phase of social diagnosis, analyizes the quality of life of the target population. Green and Kreuter (1991, pp. 27) present self-esteem as one of the outcomes of health behavior and health status, and as one of the quality of life indicators. The fourth phase of the model, which concerns the educational and organizational diagnosis, describes three clusters of behavioral determinants: predisposing, enabling, and reinforcing factors. Predisposing factors provide the rationale or motivation for behavior, such as knowledge, attitudes, beliefs, values, and perceived needs and abilities (pp. 154). Self-knowledge, general self-appraisal, and sellefficacy are considered as predisposing factors.

To summarize, self-esteem can function both as a determinant and as an outcome of healthy behavior within health behavior models. Poor self-esteem can trigger poor coping behavior or risk behavior that subsequently increases the likelihood of certain diseases among which are mental disorders. On the other hand, the presence of poor coping behavior and ill-health can generate or reinforce a negative self-image.

\section{Self-esteem in a broad spectrum approach to mental health promotion and prevention in schools}

Given the evidence supporting the role of self-esteem as a core element in physical and mental health, it is recommended that its potential in future health promotion and prevention programs be reconsidered.

The design of future policies for mental health promotion and the prevention of mental disorders is currently an area of active debate (Hosman, 2000). A key question in the discussion is which is more effective: a preventive approach focusing on specific disorders, or a more generic preventive approach? 
Based on the evidence supporting the role of self-esteem as a non-specific risk factor and protective factor in the development of mental disorders and social problems, we advocate a generic preventive approach built around the 'self'. In general, changing common risk and protective factors (e.g. self-esteem, coping skills, social support) and adopting a generic preventive approach can reduce the risk of the development of a range of mental disorders and promote individual wellbeing even before the onset of any specific problem has presented itself. Given its multi-outcome perspective, we have termed this strategy the 'broad spectrum approach' (BSA) in prevention and promotion.

Self-esteem is considered one of the important elements of the BSA. By fostering self-esteem and hence treating a common risk factor, one can actively contribute to the prevention of an array of physical diseases, mental disorders, and social problems challenging society today. This may also, at a later date, imply the prevention of a shift to other problem behavior or symptoms, which might occur when only problem-specific risk factors are addressed. For example, an eating disorder could be replaced by another type of symptom, such as alcohol abuse, smoking, social anxiety, or depression, when only the eating behavior itself is addressed and not more basic causes, such as poor self-esteem, high stress levels, and lack of social support. Although there is, as yet, no published research on such a shift phenomenon, the high level of comorbidity between such problems might reflect the likelihood of its existence. Numerous studies support the idea of comorbidity and showed that many mental disorders have overlapping associated risk factors such as self-esteem. There is a significant degree of comorbidity between and within internalizing and externalizing problem behaviors such as depression, anxiety, substance disorders, and delinquency (Angold, Costello, \& Erkanli, 1999; Harrington, Rutter, \& Fombonne, 1996; Swendsen \& Merikangas, 2000). By encompassing the individual as a whole, within the BSA, the risk of such an eventuality could be reduced.

The broad spectrum approach could have practical implications in the field. Schools are an ideal setting for implementing BSA programs, thereby aiming at preventing an array of problems, since they cover the entire population. They have the means and responsibility for the promotion of healthy behavior for such a 
common risk and protective factor, since schoolchildren are in their formative stage. A mental health promotion curriculum oriented towards emotional and social learning could include a focus at enhancing self-esteem. Weare (2000) stressed that schools need to aim at helping children develop a healthy sense of self-esteem as part of the development of their "intra-personal intelligence". According to Gardner (1993) 'intra-personal intelligence' is the ability to form an accurate model of oneself and the ability to use it to operate effectively in life. Self-esteem, then is an important component of this ability. Serious thought should be given to the implementation of these ideas in the field.

It is important to clearly define the nature of such a BSA program designed to foster self-esteem within the school setting. In our opinion, such a program should include important determinants of self-esteem, namely: competence and social support.

Harter (1999) stated that competence in domains of importance and social support, together provide a powerful explanation on the level of self-esteem. According to Harter's research on self-perceived competence (Harter, 1999), every child experiences some discrepancy between what he/she would like to be, the "ideal self'- and his/her actual perception of him/herself, 'the real self'. When this discrepancy is large and it deals with a personally relevant domain, this will result in lower self-esteem. Moreover, the overall sense of support of significant others (especially parents, peers and teachers) is also influential for the development of self-esteen. Children who feel that others accept them, and are unconditionally loved and respected, will report a lrigher sense of self-esteem (Bee, 2000). Thus children with a high discrepancy and a low sense of social support reported the lowest sense of self-esteem. These results suggest that efforts to improve selfesteem in children require both supportive social surroundings and the formation and acceptance of realistic personal goals in the personally relevant domains (Harter, 1999).

In addition to determinants such as competence and social support, we need to translate the theoretical knowledge on coping with imer self-processes (e.g. inconsistencies between the real and ideal self) into practice, in order to perform a 
systematic intervention regarding the self. Harter's work offers an important foundation for this. Based on her own and others" research on the development of the self, she suggests the following principles to prevent the development of negative self-esteem and to enhance self-worth:

- Reduction of the discrepancy between the real self and the ideal self.

- Encouragement of relatively realistic self-perceptions.

- Encouraging the belief that positive self-evaluations can be achieved.

- Appreciation for the individual's views about their self-esteem and individual perceptions on causes and consequences of self-worth.

- Increasing awareness of the origins of negative self-perceptions.

- Providing a more integrated personal construct while improving understanding of self-contradictions.

- Encouraging the individual and his/her significant others to promote the social support they give and receive.

- Fostering internalization of positive opinions of others (Harter, 1999).

\section{Examples of school health promotion programs that foster self- esteem}

Haney and Durlak (1998) wrote a meta-analytical review of 116 intervention studies for children and adolescents. Most studies indicated significant improvement in children's and adolescents' self-esteem and self-concept, and as a result of this change, significant changes in behavioral, personality, and academic functioning. Haney and Durlak reported on the possiblle impact improved self-esteem had on the onset of social problems. However, their study did not offer an insight into the potential effect of enhanced self-esteem on mental disorders.

Several mental health-promoting school programs that have addressed selfesteem and the determinants of self-esteem in practice were effective in the prevention of eating disorders (O'Dea \& Abraham, 2000), problem behavior (Flay $\&$ Ordway, 2001), and the reduction of substance abuse, anti-social behavior, and 
anxiety (Short, 1998). We shall focus on the first two programs because these are universal programs, which focused on 'mainstream' schoolchildren. The prevention of eating disorders program 'Everybody's Different' (O'Dea \& Abraham, 2000), is aimed at female adolescents aged 11-14 years old. It was developed in response to the poor efficacy of conventional body-image education in improving body image and eating behavior. 'Everybody"s Different' has adopted an alternative methodology built on an interactive, school-based, self-esteem approach and is designed to prevent the development of eating disorders by improving self-esteem. The program has significantly changed aspects of self-esteem, body satisfaction, social acceptance, and physical appearance. Female students targeted by the intervention rated their physical appearance, as perceived by others, significantly higher than control-group students, and allowed their body weight to increase appropriately by refraining from weight-loss behavior seen in the control group. These findings were still evident after 12 months. This is one of the first controlled educational interventions that had successfully improved body image and produced long-term changes in the attitudes and self-image of young adolescents.

'The 'Positive Action Program' (Flay \& Ordway, 2001) serves as a unique example of some BSA principles in practice. The program addresses the challenge of increasing self-esteem, reducing problem behavior, and improving school performance. The problem behavior types that were reduced were delinquent behavior, misdemeanors, and objection to school rules (Flay \& Ordway, 2001). This program concentrates on self-concept and self-esteem but also includes other risk and protective factors, such as positive actions, self-control, social skills, and social support that could be considered as determinants of self-esteem. Other important determinants of self-esteem, such as coping with internal self-processes, are not addressed. At present, the literature does not provide many examples of BSA studies that produce general preventive effects among adolescents who do not display behavioral problems as yet (Greenberg, Domitrovich, \& Bumbarger, 2000). 


\section{Conclusion}

To conclude, research results show beneficial outcomes of positive self-esteem, which is seen to be associated with mental well-being, happiness, adjustment, success, academic achievements, and satisfaction. It is also associated with better recovery after severe diseases. However, the evolving nature of self-esteem could also result in negative outcomes. For example, low self-esteem can be a causal factor in depression, anxiety, eating disorders, poor social functioning, school dropout, and risk behavior. Interestingly, the cross-sectional characteristic of many studies does not exclude the possibility that low self-esteem can also be considered as an important consequence of such disorders and behavioral problems.

Self-esteem appears to be an important risk and protective factor that is linked to a diversity of health and social outcomes. Therefore, self-esteem enhancement can serve as a relevant component in a broad spectrum approach in prevention and health promotion. The design and implementation of mental health programs with self-esteem as one of the core variables, is an important and at least conceptually promising development in health promotion. 


\section{Chapter 3}

Internalizing and externalizing problems in normal children: Relationships with self-esteem, self-perceived competence and parenting stress

A revised version of this chapter was submitted in January 2003 as: Michal Mann, Cor Meesters, Peter Muris, Clemens MH Hosman, Gerard Van Breukelen \& Nanne $K$ de Vries. Internalizing and externalizing problems in normal children:

Relationships with self-esteem, self-perceived competence and parenting stress. 
$\vdots$
$\cdots$ 


\section{Abstract}

The relationships between self-esteem, self-perceived comperence and parenting stress and internalizing and externalizing problem behaviors were investigated in a sample of 709 elementary schoolchildren. Subjects completed the Self-Perception Profile for Children and the Youth Self Report. The Self-Perception Profile for Children is an index of self-esteem and self-perceived competence, including selfevaluation in domains such as behavioral conduct, and the Youth Self Report is a measure for internalizing and extemalizing problem behaviors. Parents completed the Nijmegen Parenting Stress Index. Results indicate that self-esteem and selfperceived competence, in particular regarding behavioral conduct and social acceptance, are negatively associated with problem behavior. More specifically, self-esteem, scholastic competence, and social acceptance appeared to be negatively related to internalizing problems. Behavioral conduct appeared to be negatively related to externalizing problems. Parenting stress was positively associated with externalizing problem behavior. Gender differences regarding internalizing and externalizing problems were found. Boys had more externalizing problem behavior while girls had more internalizing problem behavior. Scholastic competence interacted with gender, and only served as a predictor for internalizing problems for girls. Further analysis implied that self-esteem could serve as a mediating factor between parenting stress and problem behavior. Furthermore, self-esteem and scholastic competence are apparently mediating factors between gender and internalizing problem behavior.

\section{Introduction}

Self-esteem is one of the most widely studied topics in developmental psychology. The beliefs and evaluations children hold about themselves affect their thoughts, feelings, and behaviors. These powerful inner influences provide an internal guidance mechanism, steering children through life. A high sense of self-esteem is viewed as a protective factor for children's mental health, whereas a low sense of self-esteem is regarded as a non-specific risk factor for the development of 
psychopathology and problem behavior. Thus, positive self-esteem is related to good mental health, whereas poor self-esteem is associated with a broad range of mental disorders (Mann et al, submitted a), including internalizing problems such as anxiety and depression (Harter, 1999; Neighbors; 1995; Stanchfield, 2000; Vargo, 1995; Wolf, Fisman, Ellison, \& Freeman, 1998) and externalizing problems such as aggression and delinquency (Aunola, Stattin, \& Nurmi, 2000; Jessor et al., 1998; Schoen, 1999).

The discrepancy between the value and the perception of competence one assigns to a certain domain is an important factor in the development of self-esteem. Research has demonstrated that once a child's rating of the importance of specific domains (e.g. scholastic competence, athletic competence, social acceptance, behavioral conduct, and physical appearance) exceeds the perception of his or her competence in these domains, the level of self-esteem will be lower (Harter, 1999).

Harter's work has demonstrated that there are also gender differences across self-esteem domains. That is, boys view themselves more favorably with regard to athletic competence, physical appearance, and scholastic competence, whereas girls seem to evaluate themselves higher with respect to behavioral conduct. Girls report more adaptability to social norms, are mostly doing what is expected of them and are not externalizing their problems to the same extent as boys. Therefore, they are more inclined to internalize their problems. Boys score lower on the "behavioral conduct" self-perceived competence scale, and they are at greater risk of externalizing problems (Harter, 1999). Furthermore, gender also plays a significant role in psychopathology. There is an emerging body of literature that has examined gender differences in problem behavior. Girls seem to have more internalizing symptoms than boys and boys apparently have more externalizing symptoms than girls (Benjet \& Hernandez-Guzman, 2001; Block \& Gjerde, 1986; Harter, 1999: Rolf et al., 1990).

Self-esteem, self-perceived competence, and gender are apparently factors that influence mental health. Apart from focusing on personal characteristics, in recent years studies on the determinants of problem behavior have emphasized factors external to the individual, such as family characteristics that may influence mental well-being. Social support, in particular parental support, is assumed to have 
a significant impact on children's mental well-being. Children who experience lack of support and communication problems with their parents, and who view their parents as rejective and overprotective, report higher levels of worry, anxiety, depression, maladaptation, and stress (Graham-Bermann, Coupet, Egler, \& Mattis, 1996; Mulsow, 1999; Muris, Meesters, \& Fijen, in press; Muris, Meesters, Merckelbach, \& Hülsenbeck, 2000).

Levant (1984) noted that the general link between good family functioning and an individual's psychosocial adjustment is well established, both from an empirical and theoretical standpoint. Elevated levels of family dysfunction are related to the development of low psychosocial resilience in children. Furthermore, family dysfunction can be associated with stressful life antecedents such as death, physical or mental illness in the family, marital problems and divorce, and child abuse and neglect. Stress is known to affect overall functioning (Milgram, 1989) and stressful life events can elevate parenting stress. This may result in the parents having negative views of themselwes as parents and negative views of their parenthood and their children. The latter can affect the child him/herself. He/she can be exposed to problematic parental modeling, experience stress and lack of support, and might be influenced by his/her parents' concepts. Recent empirical work confirms that parenting stress is found to be significantly associated with adjustment difficulties in children (Graham-Bermann et al., 1996; Shadmon, 1998). Parenting stress, stressful life events, and lack of social support from family members can significantly affect the mental health of a child and are associated with psychopathology (Kashubeck \& Christensen, 1993; Mesman \& Koot, 2000; Oliver \& Paull, 1995).

Self-esteem and parenting stress are critical determinants of problem behavior. The relations between these two variables could shed light on the development of psychopathology. However, studies focus mainly on the association between parental support and self-esteem rather than on the influence of parenting stress on self-esteem. Regression studies indicate that parents ${ }^{*}$ supportive reactions (e.g. involvement, positive reinforcement, and acceptance) are crucial determinants of children's positive self-esteem (Patterson \& Capaldi, 1992). In contrast to secure harmonious parent-child relationships, poor family relationships are associated with 
children's low self-esteem and depression (Kashubeck \& Christensen, 1993; Oliver \& Paull, 1995).

To summarize, self-esteem and parenting stress could affect children's mentall health. Moreover, the relation between these variables, including the combined effect of the two, together with gender effects, could have an influence on the development of psychopathollogy.

Taken together, there is abundant evidence that self-esteem and adverse family conditions are associated with internalizing and externalizing symptomatology in children. However, to our present knowledge, no study has examined the relative contribution of these two variables to children's levels of psychopathology.

In the present study, an attempt was made to examine this issue. A large sample of elementary schoolchildren aged 10-12 years $\underline{N}=709$ ) completed the Self-Perception Profile for Children (SPPC; Harter, 1985). This is a self-report questionnaire assessing self-perceived competence in five domains: scholastic competence, social acceptance, athletic competence, physical appearance, and behavioral conduct, as well as global self-esteem. The Youth Self Report (YSR; Achenbach, 1991), is a self-report inventory, which covers a broad range of emotional and behavioral problems in children. Parents completed the Nijmegen Parenting Stress Index (NPSI; De Brock, Vermulst, Gerris, \& Abidin, 1992) which assesses the level of parenting stress originating from several child and parent characteristics within the caregiver context.

The current study explores the link between self-esteem/self-perceived competence and problem behavior on the one hand, and parenting stress and problem behavior on the other hand. More specifically, it was tested whether children who classify themselves as low in self-esteem and self-perceived competence were high in problem behavior, and whether children high in parenting stress were high in problem behavior. Finally, the possible role of self-esteem and parenting stress as mediating or moderating risk factors for problem behavior is evaluated. 


\section{Method}

\section{Children and procedure}

Seven hundred and nine children (337 boys and 372 girls) out of 742 children were included in the study after parents and teachers had given informed consent. There were $23(3 \%)$ pupils that were excluded because their parents' approval was not acquired in time. The dropout rate was 10 pupils $(1.5 \%)$, as within the testing period, a few students were absent, left their schools, or moved from the area. Because of the low percentage, the dropout was not investigated any further. Mean age of the children was 10.87 years $(S D=.57$, range $10-12$ years). They attended 32 classes at 16 regular elementary schools in the southern part of The Netherlands. The sample of schools mainly included schools with a middle to high social economic status on average. Questionnaires were administered to the children during regular classes. The teacher and a research assistant were allways present in order to answer questions and to provide clarifications if necessary. Parents received the questionnaire (NOSIK) via their child, completed it at home, and returned it in a sealed envelope to the university.

\section{Instruments}

\section{Self-esteem and self-perceived competence}

The Self-Perception Profile for Children (SPPC) (Harter, 1985) is a 36-item scale for assessing A. self-esteem or global self-worth beliefs and B. competence in five important domains, namely scholastic competence, social acceptance, athletic competence, physical appearance, and behavioral conduct. Items involve structured alternatives (e.g. "Some kids often forget what they learn" but "Other kids remember things easily"). Children and adolescents have to choose the description that best fits them and then indicate whether the description is somewhat true or very true for them. Accordingly, each item is scored on a 4-point scale with a higher score reflecting a higher level of perceived competence. Sub-scale scores can be 
computed by summing relevant items. Extensive research has indicated that it is a reliable and valid measure (Miller, 2000; Muris et all., in press).

\section{Internalizing and externalizing problem behaviors}

The Youth Self Report (YSR) is a widely used, reliable, and valid self-report questionnaire, modeled on the Child Behavior Checklist (CBCL, Achenbach \& Edelbrock, 1983). The questionnaire comprises 112 items tapping a broad range of emotional and behavioral problems of youngsters. Children and adolescents are asked to indicate on 3-point scales the extent to which each item applies to them: 0 $=$ not, $1=$ sometimes and $2=$ often. YSR scores are obtained by summing the relevant items. The YSR addresses two broad domains of children and adolescent problem behavior, i.e. internalizing and externalizing behavioral problems. Each domain is divided into sub-scales. For example, the externalizing domain includes aggression and delinquent behavior and the internalizing domain includes depression, withdrawal, and somatic complaints. The present study focuses on the domain level.

\section{Parenting stress}

The Nijmegen Parenting Stress Index (NPSI) is a Dutch adaptation of the Parenting Stress Index (Abidin, 1997), a 123 item questionnaire measuring child, parent, and situational characteristics associated with the presence of parenting stress and dysfunctional parenting. Parents are requested to answer each question on a 6-point. Likert scale of 1 (I totally disagree with) to 6 (I totally agree with) regarding one particular child. In the present study, a short version of the NPSI called NOSIK comprising 25 items was applied. Previous research on the NPSI and NOSIK has indicated that the indexes are reliable and valid measures (Loyd \& Abidin, 1985). 


\section{Results}

\section{General statistics}

All questionnaires were found to be reliable in terms of internal consistency, as shown in Table 3.1. T-tests revealed significant gender differences for most scales. First, girls reported more internalizing symptoms than boys $[t(656)=3.17, \mathrm{p}<.05]$, whereas boys reported higher levels of externalizing symptoms than girls $[t(635)=-$ $5.00, \mathrm{p}<.001]$. For the NOSIK, parents reported more parenting stress regarding boys than girls $[\mathrm{t}(582)=-2.41, \mathrm{p}<.01]$. Second, in the SPPC sub-scales of selfperceived competence, boys exhibited higher levels of scholastic competence $[\mathrm{t}(699),=-3.06, \mathrm{p}<.005]$, athletic competence $[\mathrm{t}(700)=-4.27, \mathrm{p}<.001]$, physical appearance $[\mathrm{L}(700)=-4.07, \mathrm{p}<.001]$, and global self-worth/self-esteem [t(698) $=$ $2.24, \mathrm{p}<.05]$ than girls did. Girls, however, scored higher on behavioral conduct $[\mathrm{t}(671)=4.71, \mathrm{~g}<.001]$ than boys. No significant gender difference was found for the social acceptance sub-scale.

\section{Table 3.1}

General statistics (mean scores, standard deviations, gender differences, and Cronbach"s alphas) for the various SPPC scales, the internalizing and externalizing YSR scales, and NOSIK

\begin{tabular}{|c|c|c|c|c|}
\hline & $\begin{array}{l}\text { Total group } \\
(\mathrm{N}=709)\end{array}$ & $\begin{array}{c}\text { Boys } \\
(\mathrm{n}=337)\end{array}$ & $\begin{array}{c}\text { Girls } \\
(\mathrm{n}=372)\end{array}$ & \\
\hline & $\mathrm{M}(\mathrm{SD})$ & $M(S D)$ & $M(\mathrm{SD})$ & $\alpha(11)$ \\
\hline \multicolumn{5}{|l|}{$S P P C$} \\
\hline Self-esteem & $19.97(3.67)$ & $20.30(3.50)$ & $19.69(3,79)^{*}$ & $.80(6)$ \\
\hline Scholastic competence & $17.24(3.82)$ & $17.70(3.76)$ & $16.82(3.83)^{\text {味 }}$ & $.78(6)$ \\
\hline Social acceptance & $18.45(4.11)$ & $18.57(3.98)$ & $18.34(4.22)$ & $.79(6)$ \\
\hline Behavioral conduct & $18.33(3.27)$ & $17.73(3.41)$ & $18.88(3.05)^{*}$ & $71(6)$ \\
\hline Athletic competence & $18.47(3.70)$ & $19.09(3.54)$ & $17.91(3.75)^{*}$ & $.76(6)$ \\
\hline Physical appearance & $19.07(4.41)$ & $19.77(3.96)$ & $18.44(4.70)^{*}$ & $.84(6)$ \\
\hline \multicolumn{5}{|l|}{ YSR } \\
\hline Internalizing & $12.06(8.56)$ & $10.97(8.24)$ & $13.08(8.75)^{\text {th }}$ & $.89(29)$ \\
\hline Externallizing & $9.94(7.05)$ & $11.33(7.72)$ & $8.67(6.13)^{4}$ & $.86(30)$ \\
\hline \multicolumn{5}{|l|}{ NOSIK } \\
\hline Parenting stress & $48.03(17.58)$ & $49.85(18.01)$ & $46.38(17.04)^{4}$ & $92(25)$ \\
\hline
\end{tabular}




\section{Self-esteem/self-perceived competence, parenting stress and problem behavior}

Pearson product-moment correlations were computed in order to examine the relation between problem behavior and self-esteem or self perceived competence as can be seen in Table 3.2. For both boys and girls there are relatively strong ( $r>.30$ ) negative correlations between internalizing and externalizing problem behavior and self-esteem. A strong negative correlation was also found between externalizing problem behavior and behavioral conduct. There are mild $(\mathrm{r}<30)$ correlations for other self-perceived competence sub-scales. Significant correlations were found between parenting stress and internalizing and externalizing problem behaviors for girls only. Since $4 \times 7$ correlations were tested, $\underline{\alpha}$ of .01 was chosen in order to prevent type I errors due to multiple testing.

\section{Table 3.2}

Pearson product-moment correlations between SPPC scales, NOSIK (parenting stress) and YSR (internalizing and externalizing problems) for boys $(N=337)$ and girls $(N=372)$ separately.

\begin{tabular}{|c|c|c|c|c|}
\hline & Boys & & Girls & \\
\hline & Internalizing & Externalizing & Intemalizing & Externalizing \\
\hline \multicolumn{5}{|l|}{$S P P C$} \\
\hline Self-esteem & $-.39^{*}$ & $-.37 *$ & $-.47 *$ & $-.36 *$ \\
\hline Scholastic competence & -26 & $-.28 *$ & $-37 *$ & $-.24 *$ \\
\hline Social acceptance & $-3 \|^{\prime *}$ & -.13 & $-.36 *$ & -.16 \\
\hline Behavioral conduct & -.28 & $-.48 *$ & $-.27 *$ & $-.49 *$ \\
\hline Athletic competence & $-.24 *$ & -.17 & $-.20 *$ & -.15 \\
\hline Physical appearance & $-.32^{4}$ & $-.32 *$ & $-.33^{*}$ & $-.30^{*}$ \\
\hline \multicolumn{5}{|l|}{ NOSIK } \\
\hline Parenting stress & 17 & .16 & $.21^{*}$ & $.25 *$ \\
\hline
\end{tabular}




\section{Self-esteem, self-perceived competence, and parenting stress as predictors of problem behavior}

To explore the relationship between self-esteem, self-perceived competence and parenting stress as predictors of internal and external problem behavior, multiple regression was carried out SPPC sub-scales, parenting stress, gender, and age were predictors while internalizing and externalizing problem behavior were the dependent variables. The regression model was then extended with a term for the interaction between gender and SPPC sub-scales and NOSIK, if those were significant (using $\alpha$ of $5 \%$ for each interaction).

As can be seen in Table 3.3, results indicate that for YSR internalizing problem behavior a main effect was found of SPPC self-esteem, scholastic competence, and social acceptance. For YSR externalizing problem behavior a main effect was found of gender, SPPC behavioral conduct, and tentatively also of NOSIK parenting stress.

There was one tentative interaction between the SPPC scholastic competence sub-scale and gender with respect to internalizing problems $(\mathrm{D}<.04)$. All other interactions were not significant $(\mathrm{g}>.10)$. Further regression analysis was performed separating girls and boys using a regression model with all SPPC scales, NOSIK, and age as predictors to test the relation between scholastic competence and internalizing problems within each gender. Scholastic competence was predictive of internalizing problems for girls $(\underline{B}=-.6, \underline{\mathrm{SE}}=.13, \mathrm{~g}<.000$ and $\underline{\beta}=$ .27), but not significant for boys $(\underline{B}=-.16, \underline{S E}=.15, \mathrm{D}=.29$ and $\underline{B}=-.07$ ).

The present data was obtained using a nested design, with 709 pupils. nested within 32 classes nested within 16 schools. If results have to be generalized. to cover not only other pupils, but also other classes and schools, then class and school must be included into the regression analyses as random effects using muliilevel regression. Ignoring school or class effects and in particular ignoring the interaction of school or class with our predictors, may lead to underestimation of standard errors and type I errors (false positives) in significance testing (Moerbeek, Van Breukelen, \& Berger, 2003). The regression models were therefore checked with multi-level regression, using MLwiN version 1, extending the model first with 
a random intercept to accommodate for random main effects of school and class, and then with random slopes to accommodate for interaction of school or class with predictors that were significant according to SPSS. A main effect of school, but not of class within schools, and no interactions of school or class with SPPC scales were found. The regression weights and standard errors obtained with MLwiN were very similar to those obtained with SPSS that are reported in Table 3.3.

\section{Table 3.3}

Main results of regression analyses with SPPC scales, NOSIK scales, age, and gender as predictors of YSR Internalizing and Externalizing problem behavior (the dependent variables)

\begin{tabular}{|c|c|c|c|c|c|}
\hline Dependent & Predictors & $\underline{\mathrm{B}}$ & $\underline{\mathrm{SE}}$ & $\mathrm{p}$ & $\underline{B}$ \\
\hline \multicolumn{6}{|c|}{ YSR intermalizing } \\
\hline & Age & -.25 & .57 & .66 & -.02 \\
\hline & Gender & -.87 & .70 & .21 & .05 \\
\hline & $S P P C$ & & & & \\
\hline & Self-esteen & -.62 & .15 & .000 & -.26 \\
\hline & Scholastic competence & -.40 & .10 & .000 & -.18 \\
\hline & Social acceptance & -.30 & .09 & .001 & -.14 \\
\hline & Behavioral conduct & -.03 & .12 & .82 & -.01 \\
\hline & Athletic competence & -.02 & .10 & .88 & -.01 \\
\hline & Physical appearance & -.04 & .11 & .70 & -.02 \\
\hline & NósIK & & & & \\
\hline & Parenting stress & .03 & .02 & .10 & .07 \\
\hline \multicolumn{6}{|c|}{ YSR externalizing } \\
\hline & Age & .26 & .46 & .57 & .02 \\
\hline & Gender & 2.12 & .56 & .000 & .15 \\
\hline & $S P P C$ & & & & \\
\hline & Selfoesteem & -.19 & .12 & .11 & -.10 \\
\hline & Scholastic competence & -.09 & .08 & .25 & -.05 \\
\hline & Social acceptance & .10 & .08 & .17 & .06 \\
\hline & Behavioral conduct & -.82 & .10 & .000 & -.37 \\
\hline & Athletic competence & -.00 & .08 & .98 & -.00 \\
\hline & Physical appearance & -.13 & .09 & .16 & -.08 \\
\hline & NOSIK & & & & \\
\hline & Parenting stress & .03 & .02 & .03 & .08 \\
\hline
\end{tabular}

Note: $\underline{B}$ * raw, $\underline{B}$-standardized, regression co-efficient. 


\section{Self-esteem and parenting stress interaction or self-esteem as a mediating factor between parenting stress and problem behavior}

To explore the possibility of interaction between self-esteem and parenting stress as predictors of internalizing and externalizing problem behavior, the regression model of Table 3.3 was extended with the interaction between self-esteem and parenting stress as predictor of problem behavior. No interactions were found $(p>10)$ for either outcomes.

Finally we checked the possible role of self-esteem as a mediating factor between parenting stress and problem behavior. Age and gender were co-variates throughout the analysis. Regression showed that parenting stress was predictive of self-esteem $(\underline{B}=-.06, \underline{\mathrm{SE}}=.008, \underline{\mathrm{D}}<.000$ and $\underline{B}=-.28)$. An estimation and test of the 'effect' of parenting stress on problem behavior (internalizing and externalizing) was done, without and then with adjusting for self-esteem. The analysis without adjustment for self-esteem gives a total effect of parenting stress, both direct and indirect via self-esteem (for internalizing, $\underline{B}=.09, \underline{S E}=.02, \underline{D}<.000$ and $\underline{\beta}=.19$, for externalizing, $\underline{B}=.08, \underline{\mathrm{SE}}=.02, \mathrm{p}<.000$ and $\underline{B}=.19$ ). The regression with adjustment for self-esteem gives the direct effect of parenting stress on problem behavior, i.e. excluding the indirect effect via self-esteem (for internalizing, $\underline{B}=.04$, $\underline{\mathrm{SE}}=.02, \underline{\mathrm{p}}<.05$ and $\underline{\beta}=.08$, for externalizing, $\underline{\mathrm{B}}=.04, \underline{\mathrm{SE}}=.02, \underline{\mathrm{p}}<.009$ and $\underline{\underline{\beta}}=$ .10). The direct effect is $50 \%$ smaller than the total effect, but is still significant. This suggests that parenting stress has both a direct and an indirect effect (i.e. mediated by self-esteem) on internalizing and externalizing problem behavior.

\section{Discussion}

The present study was an attempt to examine the link between self-esteem/selfperceived competence and problem behavior. The relations between parenting stress and problem behavior were also examined. Moreover, the possible role of selfesteem and parenting stress as mediating or moderating risk factors for problem behavior was evaluated. 
Results indicate a negative correlation between self-esteem/self-perceived competence and problem behawior on the one hand, and a positive correlation between parenting stress and problem behavior on the other hand. In other words, it was found that children who classified themselves as low in self-esteem and selfperceived competence were high in problem behavior, as was the case for children whose parents scored high on parenting stress.

The current findings, in a data sample of primary schools children, are consistent with previous studies that stress the importance of low self-esteem in the development of internalizing symptoms (Harter, 1999; Neighbors, 1995; Stanchfield, 2000; Vargo, 1995; Wolf et al., 1998) and externalizing symptoms (Aunola et al., 2000; Jessor et al., 1998; Schoen, 1999). Furthermore, the results correspond with other studies on the role of self-perceived competence concerning behavioral conduct in externalizing problem behavior (Hoffman, 1999; RedaNorton, 1995), and the effect of lack of social acceptance and parenting stress in the development of problem behavior (Graham-Bermann et al., 1996; Harter, 1999; Mulsow, 1999; Muris et al., in press; Rolf et al., 1990). Self-esteem, scholastic competence and social acceptance predict internalizing problems, while behavioral conduct and parenting stress predict externalizing problems.

Gender differences regarding externalizing and internalizing problem behavior in this study are consistent with previous studies. Girls had more internalizing symptoms than boys, and boys had more externalizing symptoms than girls (Benjet \& Hernandez-Guzman, 2001; Block \& Gjerde, 1986; Harter, 1999; Rolf et al ${ }^{2}, 1990$ ).

Furthermore, it was found that in particular, girls" low scholastic competence tentatively predicted internalizing problems. Previous studies have also shown that girls are typically lower in self-evaluated scholastic competence than boys, as confirmed in this research and in other studies (Harter, 1999). The development of low scholastic competence in girls could be explained by laboratory studies that reveal that parents give more negative feedback to girls than boys, despite the absence of gender differences in actuall performance (Lewis, Allesandri, \& Sulliwan, 1992). Observations in classrooms show similar results: girls receive more negative and less positive feedback from teachers (Dweck \& Leggett, 1988; 
Eccles \& Blumenfeld, 1985). The negative feedback can result in girls" low selfperceived competence in this domain, which could increase internalizing problems.

Parenting stress was a predictor of externalizing problems. These results were in line with previous findings on the associations between parenting stress and problem behavior (Mesman \& Koot, 2000).

Analyses were done in order to explore interaction (moderation) between parenting stress and self-esteem with respect to problem behavior. It was tested but not found.

We also analyzed the possiblle role of self-esteem as a mediator of the effect of parenting stress on problem behavior. Regression analyses showed that parenting stress is predictive of self-esteem. It is also predictive of internalizing and externalizing problem behavior but partly via self-esteem. This means that selfesteem may serve as a mediating factor between parenting stress and problem behavior.

Combining the results in Tables 3.1 and 3.3 suggests that the gender effect on internalizing problem behavior is mediated by self-esteem and scholastic competence. More specifically, Table 3.1 shows that girls score lower than boys on self-esteem and scholastic competence, but higher on internalizing problem behavior. However, Table 3.3 shows that gender is no longer predictive of internalizing problem behavior after adjusting for all SPPC scales, while self-esteem and scholastic competence are predictive of problem behavior. Our explanation is that the gender effect was mediated through self-esteem and scholastic competence, and that there is more of an indirect influence of gender than a direct one.

To conclude, the current findings shed light on the mediating role of selfesteem between parenting stress and problem behavior. The possible role of selfesteem, self-perceived competence, and gender in problem behavior can contribute to the understanding of the development of problem behavior, and could be used as crucial determinants in the planning of interventions which aim to prevent problem behavior.

It should be acknowledged that the current study suffers from various limitations. Firstly, the sample of schools included a middle to high socio-economic 
status in average, and no schools with a low socio-economic status. This may cause restriction of range or even ceiling or floor effects on scales that are related to this component and those weaken the correlations. For future studies the inclusion of schools with a full range of socio-economic status is recommended. Secondly, the measurement instruments were self-report questionnaires, which are not objective criteria. A better alternative would be to use a more objective report, for example from teachers and parents. The latter would enable a more objective view from which the study could have benefited. Thirdly, the current findings corroborate the importance of self-esteem, self perceived competence, and social acceptance as mental health variables. It is tempting to regard self-esteem and self-perceived competence as antecedents and the levels of problem behavior as consequences. However, it cannot be ruled out that those high levels of problem behavior are the cause of less favorable reports of self-esteem and self-perceived competence. Thus it should be emphasized, that because the current study employed a correlational approach, it could not answer the causality issue.

Notwithstanding these considerations, we believe that the current findings may stimulate researchers to further investigate the combined effect of self-esteem and parenting stress on problem behavior. A challenge for the future is to continue to use prospective studies to explore determinants of children's mental health and to gain more understanding of risk and protective factors in the development of mental disorders and social problems. In order to gain a better understanding of the predictors and the development of problem behavior, the results of the current study should be followed up by additional longitudinal research of children low in selfesteem, high in parenting stress, and high in problem behavior, in order to control for different influences on the development of psychopathology. A better insight into this matter could provide a foundation for the development of intervention programs for children and parents to prevent the development of problem behavior in children, thereby leading to reduced internalizing and externalizing problem behavior in later life. 
Chapter 4

The 'I Am The Key' (IATK) program 
"If I am not for myself who is for me; and being for my own self what am I?" (Hillel, "The Elder' c.60 BC-AD c.9: Pirqe Aboth)

\section{Abstract}

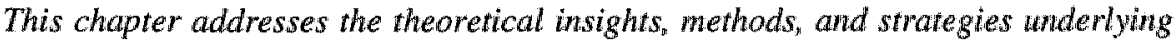
'I Am The Key' (IATK), a program which aims to foster self-esteem in children I012 years old. First, the consequences of poor and positive self-esteem are introduced and self-esteem is addressed as a core element in mental health promotion and in a broad spectrum approach in prevention. Second, this chapter provides the theoretical underpinning of the educational methods of the 'I Am The Key' program. Third, it gives an outline of the curriculum, its main themes, methods, and strategies. Fourth, pilot results are discussed and further educational implications within the school system are introduced.

\section{Introduction}

\section{Self-esteem in a broad spectrum approach to Mental Health}

One of the main findings of the cross-sectional study in the former chapter is that self-esteem is a risk factor in the development of problem behavior. Self-esteem, therefore, is an important focus both in mental health and mental health promotion. An extensive literature research review, which includes prospective studies, has highlighted low self-esteem as a risk factor and positive self-esteem as a protective factor in mental health. An unstable self-concept and poor self-esteem play a critical role in the development of an array of mental disorders and social problems such as depression, anorexia nervosa, bulimia, anxiety, violence, substance abuse, and highrisk behaviors (Mann et all, submitted a; Mann, Hosman, Breukelen, Meesters, \& De Vries, submitted c). Moreover, according to definitions provided by the WHO (1988), positive self-esteem is a basic feature of mental health and a protective factor that enhances health and contributes to positive social behavior. It has been 
found to actively promote healthy functioning, as reflected in achievements, success, satisfaction, and the ability to cope with physical diseases e.g cancer and heart disease (Mann et al., submitted a Mann et al., submitted c).

The risk of the development of a range of mental disorders could be reduced, and individual well-being promoted by targeting non-specific risk and protective factors such as self-esteem. We have termed this type of intervention the broad spectrum approach (BSA) as it aims at multiple outcomes in prevention and promotion. This approach focuses on the generic risk or protective factors of different symptoms and disorders (see Chapter 2). Several common factors could serve as the fundament of the BSA program development, such as self-esteem, social skills, and social support. The potential of a BSA program to reduce or prevent multiple disorders and problems is based on a vast body of studies that confirms that many poor outcomes have overlapping associated risk factors and a significant degree of comorbidity. This was shown in poor outcomes such as

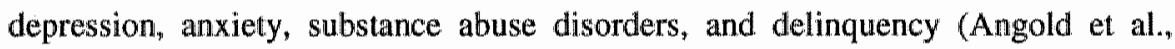
1999; Swendsen \& Merikangas, 2000). BSA programs therefore focus on the prevention of mental disorders and on the promotion of psychollogical wellness.

\section{Wellness programs and The 'I Am The Key' (IATK) program}

Psychological wellness can be referred to in two different ways: it can be seen as a condition and as an action. The condition could refer to the current mental health status of an individual, this/her sense of belonging, purpose, satisfaction, cetera. The action refers to psychological wellness as ones behavior, such as sleeping well, eating well, and working well (Cowen, 1994). A definition that stresses behawioral and dynamic aspects of wellness, is given by Shillingford \& Shillingford-Mackin (1991). According to them, "wellness espouses self-responsibility for a healthy lifestyle, an approach designed to improve the quality of life" (pp. 457). Hoeger (1990) also describes wellness as the constant and deliberate effort to stay healthy and achieve the highest potential for well-being. More specifically, he defines wellness as "the concept that incorporates physical fitness, nutrition, stress management, spirituality, cardiovascular risk reduction, safety, health education, substance abuse controll, sexuality, cancer protection and smoking cessation" (pp.3). 
There is a growing body of literature on programs that promote or enhance wellness worldwide, especially in the USA (Cowen, 1994; Elias et al., 1997). The common denominator of existing wellness programs is the focus on competence enhancement. Elias terms this 'Social Emotional Learning" (SEL): "Social and Emotional Learning is the process through which children develop the skills, attitudes and values necessary to acquire social and emotional competence" (Elias et al., 1997). The research and guidelines committee of the Collaborative for the Advancement of Social and Emotional Learning (Elias et al., 1997, (CASEL)) highlighted implementation practices that effectively promote Social and Emotional Learning. These life-skills programs aim to promote psychological wellness by improving competence, for example through fostering social skills such as promoting alternative thinking, resolving conflict creatively, et cetera.

An increasing number of SEL programs showed their efficacy and were successful in increasing social and emotional competence (Elias, Gara, Schuyler, Branden-Muller, \& Sayette, 1991). However, the lack of structured work on the self is a weakness in SEL programs. Recently, Myers \& Sweeney (2000) stressed the importance of understanding individuals" needs in wellness programs and suggested a systematic and comprehensive approach to work on the self in wellness programs. They proposed using the holistic model of weliness and prevention over ones lifespan, called the Wheel of Wellness. This model described by Sweeney and Witmer (1991) has a multidisciplinary focus and theoretical grounding in theories of human growth and behavior. The wheel of wellness can be used as a basis for developing personal wellness plans and to help clients achieve greater wellness. According to the authors, work with middle schoolchildren on this model is currently underway.

One of the important tasks in Sweeney \& Witmers" model is the work on the self or self-direction. Self-direction is divided into sub-tasks, including sense of worth, sense of control, and emotional awareness (Myers, Sweeney, \& Witmer, 2000). The 'I Am The Key' (IATK) program strives to answer the need to work with middle schoolchildren on self-direction as it focuses on the self. The IATK program recognizes the role of positive self-esteem as a protective factor, which could improve mental health, and could reduce the risk of multiple mental disorders and social problems. Therefore, the IATK program is defined as a BSA prevention 
program and is evaluated as such, while it could at the same time also be considered a wellness program. IATK focuses on wellness humanistic principles as other wellness programs do. However, a lot of wellness programs aim to promote the well-being but do not necessarily aim at preventing the risk of mental disorders, and therefore do not evaluate it. Since these programs focus on risk and protective factors they could have an influence on the prevention of mental and social problems, even though it was not measured.

\section{The I Am The Key (IATK) program}

The IATK program was first developed and implemented in elementary schools in Israel by the author (Mann, 1987). The program was then translated from Hebrew into English (Mann, 1997) and was implemented in the International Primary School of Maastricht, The Netherlands, where additional indications for multicultural compatibility were obtained. Finally, in the context of the current study, the program was tramsilated into Dutch in 1999, at which time it was implemented in a Dutch school as part of a small-scale pilot study. In its original version the program was implemented once a week during a full school year. However, in order to comply with the school's time constraints, the program was reduced to 18 sessions.

\section{The pilot study}

As part of the preparation for the pilot study within the Dutch school system, a prepilot survey was conducted. Prior to the pilot study interviews were undertaken with 45 children, adolescents, parents and teachers in three cities in the Netherlands: Maastricht, Utrecht and Arnhem. This was done in order to assess the emotional and social needs of children, who are in a period of transition before starting high school, and in order to verify that those needs are matched by the program"s design. Moreover, a literature survey on Dutch children and youth lifestyle was conducted. The results of this survey indicated that during the last two years of elementary school, children are very busy with lots of extra-curricular activities. In the last year of primary school they are mostly stressed because of their lifestyle and their Cito test, which partly determines the school they will attend the next year. These 
pressures and stressors are sometimes reflected as aggressive behavior and a low frustration threshold. In the first year of their secondary education, children are even more stressed by the transition to the new school. The social aspect is the most important to them. Older children often bully them, since they are the youngest in school. During this period adolescents like to be part of a peer group, which gives them a feeling of belonging and support, which strengthens them in their identity consolidation. Their need for identity is answered by striving towards a shared identity with others. Janssen \& Prins (1991) classified 11 different styles of groups within the Dutch Youth Culture, which were also distinguished by the adolescents themselves (e.g. Jungle, Hiphop, Skate, Gabber and Superboer). At least some of these groups could have an influence on mental health and might have a negative influence on teenagers (such as the Gabber group, whose members are assumed to be associated with drugs, as was indicated by the adolescents themselves). Under these circumstances, we found that it is most important to provide children with additional tools to cope with their social surrounding, and to do so first by strengthening their self-esteem and social support network.

A pilot study with the Dutch version of the IATK program was carried out in The Netherlands during 1999. The aim of this pilot was to get preliminary evidence concerning the feasibility of the program and to pre-test the content and materials used in the sessions. It was also done to assess the compatibility of the IATK program to the Dutch culture, to explore the program's effects on mental health variables, and to get an insight into individual and group processes that were stimulated by the program (De Haan, 2000; Kuijpers, 2001). The pilot was performed in an elementary school with 31 children aged 10-11. A set of measures was used. Firstly, children completed the SPPC, the Self-Perception Profile for Children (Harter, 1985) and the CBCL, the Child Behavior Checklist (Achenbach \& Edelbrock, 1983). Secondly, special questionnaires for children and teachers were filled out after every session to assess their view on the content, the group process, and the materials. Thirdly, observations were conducted during the sessions by health education Masters students. Three methods of observation were used: first the Bales system for process analysis in a group (Remmerswaal, 1992); second, open observations; and third, body language category observations. Fourthly, 
interviews with the teachers were held after each IATK session in order to analyze the group process and the suitability of the content and materials.

The results of the pilot study were in the favorable direction (De Haan, 2000, Kuijpers, 2001). The SPPC and the CBCL showed a decrease in the aggression sub-scale and a small decrease in the depression and social problems sub-scales. There was a small increase in the physical appearance sub-scale. Furthermore, the program was found to be suitable within the Dutch school context. There were enthusiastic reactions from children and teachers regarding the content and most materials, as reflected by questionnaires and observations. There were recommendations though, for a change in some puppets' design in order to make them more appealing. Moreover, a change in one story was requested. This was later done accordingly.

According to qualitative data, the atmosphere in the group improved and there were more positive interactions in the class. Social skills (e.g. listening skills and social acceptance) improved. The case studies results indicated an improvement in the psychosocial competence of several children that were high in problem behavior prior to the implementation of the program. Furthermore, positive reactions from teachers, children, parents, school management, and staff members were expressed during and after the pilot. Local and national media covered the pilot and the results to a considerable extent (see Appendix). On the basis of the qualitative and quantitative results, combined with enthusiastic feedback, it was concluded that no further crucial adjustments were required in the program for the full-scale implementation.

\section{The theoretical underpinning of the intervention structure and educational methods}

\section{Rationale for the age group}

IATK is a group-work process, which aims at fostering the self-esteem of children aged 10-12 years through addressing and optimizing coping skills and social support. This age is the transition between childhood and the early stage of 
adolescence. According to Harter's empirical work (Harter, 1999), during this phase of late childhood, more abstract thinking develops. Children in this age group progressively describe themselves with more trait labels established through selfevaluation in different domains (e.g. in school and in sport). More specifically, they summarize the evaluations of few experiences (in different domains and across time) in order to draw conclusions on how and who they are as a person. In other words, they start to define their identity and thereby develop their self-concept and self-esteem. According to Selman's research findings (1980), from the age of 10-15, the individual is more ready to see her/himself as if he/she was a third person, an outsider who is watching the needs, feelings, and reactions of him/herself and others. In this phase self-esteem is in the process of 'taking shape'. Harters' research review confirms that at this age children come to appreciate the fact that previously contradictory attributes (e.g. hard worker and lazy), can now simultaneously exist within the self. Their self-concept becomes compound and they become more self-critical. Therefore, coordinating contradicting views and enhancement of a positive and realistic self-esteem in this developmental phase could be very effective for the future mental and emotional well-being of the child. The social environment exercises great influence on the formation of individual identity.

To conclude, at the age of $10-12$, it would be optimal to offer prevention and promotion programs that focus on the self as children are eager to learn about themselves at this pre-pubescent age. They are starting to form and consolidate their own unique identity and this could be an opportunity to influence processes, which could help the participants to grow and develop in a positive way.

\section{Self-esteem in a broad spectrum approach within the IATK program}

Based on a vast research review, Harter (1999) recommends that in order to supply fertile ground for self-growth, it is important to help children from middle childhood upwards, to cope with their developing ability to coordinate contradictory self-views. Hence to gain a more balanced view of the self. As was discussed in chapter 2, the nature of a BSA program designed to foster self-esteem within the school setting should include important determinants of self-esteem, namely: self 
perceived competence and social support. Enhancement of positive though realistic self-esteem in this developmental phase together with the promotion of social support could be very effective for the future mental and emotional well-being of the child. Based on Harter's own work and others' research on the development of the self, she suggests the following principles to prevent the development of negative self-esteem and to enhance self-worth:

- Reduction of the discrepancy between the real self and the ideal self.

- Encouragement of relatively realistic self-perceptions.

- Encouraging the belief that positive self-evaluations can be achieved.

- Appreciation for the individual's views about their self-esteem and individual perceptions on causes and consequences of self-worth.

- Increasing awareness of the origins of negative self-perceptions.

- Providing a more integrated personal construct while improving understanding of self-contradictions.

- Encouraging the individual and his/her significant others to promote the social support they give and receive.

- Fostering internalization of positive opinions of others (Harter, 1999).

These principles are part of the pillars of the Humanistic theory and the Gestalt theory which, the IATK program is based on. The relation between these psychological theories and IATK will be further described below.

\section{Humanistic theory and the Gestalt theory}

Two main psychological theories form the basis of the program: the Humanistic theory and the Gestalt theory. Both theories were formulated in the sixties and were closely related to developments in therapeutic practice. Client-centered therapy was developed by Rogers (1951), and serves as an example of Humanistic therapy. Gestalt therapy was developed by Perls (1969) and was driven by the Gestalt theory. Principles from both therapies and theories are adopted nowadays in therapeutic practice. Their successors, the Humanistic approach (Davies, 1996) and the NeoGestalt approach (Greenberg \& Paivio, 1997) emphasize the importance of individual differences in therapeutic processes and are further influenced by the 
following theories, concepts, and principles: existentialism and its phenomenological principles, self-actualization, self-discrepancies, and unconditional positive regard. All these concepts had an influence on the IATK program, as will be demonstrated below.

\section{Phenomenological principles}

Existentialism stresses the subjective aspect of human existence and the individual's responsibility for ones own view. The phenomenological theories strive to understand the individual's subjective point of view and devote considerable attention to the individuality and uniqueness of each person, and his/her experiences, feelings, and thoughts. Every individual has his/her own subjective perceptual phenomenal field, which is a psychological space. In order to understand the individual we have to understand his/her phenomenological field. Humanistic therapy and Gestalt therapy are therefore strongly focused on the experience of the individual. This approach anticipates that each person goes through an individual process according to his/her profile. The IATK program focuses on phenomenological principles, since individual differences, self-identity, and the uniqueness of each group member, are important themes within the promotion of individual well-being. This principle was applied during the implementation. For example, each group member has a personal folder with his/her photo on top of it. The idea is that in every IATK session he/she is learning about him/herself, and about his/her unique characteristics (containing different reflections such as personal views, dreams, coping patterns, et cetera.). The IATK program also stimulates creativity. Each child is encouraged to express him/herself creatively, which reflects each individual's phenomenological field. The creativity-fostering environment in IATK respects the views of the child and encourages the expression of those views.

\section{Self-actualization}

One of the aims of Humanistic therapy and Gestalt therapy is to enable individuals to develop and to attain self-actualization. Self-actualization is defined as "the 
directional trend, which is evident in all organic and human life, the urge to expand, extend, develop, mature, the tendency to express and activate all the capacities of the organism" (Roger, 1961). In other words, self-actualization is the fulfillment of one's potential. It is in many ways equivalent to the capacity of self-growth of the mentally healthy individual (Ryff, 1995). Perls (1969) emphasized that the goal of every individual is to actualize him/herself as he/she is. It is the process in which an individual learns to be self-supporting.

The self is a key structural element in both Rogers' and Perls' theories. Self-esteem, self-acceptance and acceptance of one's emotional life, are important elements of self-actualization and serve as items in the self-actualization measure (Jones \& Crandall, 1986).

The self is the starting point of the IATK program as well. The program's name is 'I Am The Key', since it works from the idea that every group member is 'the key". Every child can be self-supporting, (supporting him/herself with solutions and coping strategies) and thereby, can 'open new doors in life' and fulfill his/her potential. The idea is that everyone is unique, and therefore there are as many different keys as there are children. The abstract idea of self-actualization is translated into a concrete one and is demonstrated by a puppet of a key. The key is the symbol of improved coping skills, in other words, being self-supporting and actualizing him/herself. The children use the key puppet in role-play when they demonstrate dilemmas and conflicts that are solved by the 'inner key' and not with the help of other group members.

In order to actualize him/herself as he/she is, every indlividual has to gain awareness of different aspects of the self. This is done by the work on the multifaceted self.

\section{Gestalt within the multifaceted self}

Gestalt therapy stresses the importance of working on different parts of the self in an integrated way. Gestalt means a pattern or a configuration, especially a configuration in which the whole is assumed to be greater than the sums of its parts. Perls' (1969) use of the term 'Gestalt' refers to a reorganization or reintegration of 
all the components of an individual (cognition, emotions, actions, ideals, et cetera.), thereby creating a "whole": a healthier and less disjointed person. According to Perls, optimal psychollogical health can only exist when there is a balance between all the components that constitute the self. This balance can influence the way an individual functions. More than a hundred years ago, James (1890-1902), distinguished between ' $\mathrm{I}$ ' and 'Me' as two main components of the self. The ' $\mathrm{I}$ ' is the self as knower, who interprets experience in a subjective manner. The ' $\mathrm{Me}$ ' is the self as known. According to the Gestalt approach, a balance should be obtained between the I and the Me. This means that there should not be a big gap between the self as knower (the D) and the self as known (the Me).

Having a self with multiple components that are integrated with one another is consistent with Rogers' view of the self. The Rogerian therapy concentrates on a balance within the self, mainly between two parts: the real self (the way an individual performs) and the ideal self (the way he/she would like to be). The smaller the discrepancy between the real self and the ideal self, the more a person can be positive about her/himself. Modern self-theorists argue that the self may consist of 'multiple selves', any of which may interact with the others in a dialogical fashion (Hermans \& Kempen, 1993). The self-concept is viewed as a multi-faceted set of schemas. The different schemas can be reflected through any expression including verbal ones such as self-narratives.

The multi-voiced self-narratives develop during an individual's life-span (Hermans, 1996; Hermans \& Kempen, 1993). When these inner dialogues are guided in a structured way, they could help individuals to find the balance within themselves, and that in turn could reduce mental problems and enhance selfknowledge and positive self-esteem. Neo-Gestalt therapy stresses the importance of the 'Dialogic' approach. Gestalt Therapy has, in recent years, been moving strongly in the direction of emphasizing this powerful therapeutic dialogue, as well as emphasizing the importance of providing support for the client during the therapeutic process. When the process is appropriately designed, the child can experience self-understanding and awareness.

Coping with self-discrepancies is a major goal within the IATK program. Different discrepancies within the self are addressed: the real self versus the ideal 
self, the logical self versus the emotionall self, and the external self (public self) versus the internal self (private self). Self-narratives and self-dialogues are encouraged in order to promote balance and develop a holistic view. In the IATK program, self-dialogue is one of the main methods used. A unique focus in the program is that the abstract concept of the multi-faceted self is translated into a tangible one by using puppets, which are personifications of the interior voices. The children inject life into the puppets and 'completely disappear' behind the puppets' personality. They can project and discuss inner conflicts in a safe and secure way behind stage curtains. For example, in one role play there is a puppet that represents the "ideal self" (a good student at math) that has a dialogue with a puppet representing the 'real self' (a bad student at math). Each child that presents a conflict between the two selves is asked to demonstrate the conflict between the two sides in a two-puppet play. The role-play between the two puppets is actually a selfdialogue. This dialogue presents the juxtaposition between different parts of the self, and the child becomes aware of the parts of him/herself that he/she has ignored beforehand. The child as the director of his own role-play is asked to cause a change in the dialogical process and to obtain a balance between the different parts of the self; in other words to find the key. The change in the improvisation may help the child in the organization of his/her self-knowledge while obtaining an inner balance.

\section{Unconditional positive regard}

An important Rogerian idea is that everyone would like to feel valued and has a need for unconditional positive regard. This means that the group leader communicates a deep and genuine caring for each individual as a person. The IATK group leader is trained to express such an attitude towards the group members in a non-threatening way. The group leader encourages each individual towards selfacceptance. While the child presents different aspects of his/herself the group leader accepts those parts. Furthermore, the leaders stress the importance of acceptance and respect between group members. Positive feedback is a fundamental issue in the program. Through the different activities (art, drama, and storytelling) children are 
encouraged to be creative, and their creative expression is always accepted and rewarded by the group leader.

\section{The learning process}

As mentioned above, the IATK program intertwines emotional, social, cognitive, and behavioral aspects. The sessions emphasize acting out and creativity. At the end of every session there is also sharing and discussion. In the sharing part children share their experiences and emotions. Afterwards, the discussion facilitates a better understanding of the process in terms of social, emotional, cognitive, and behavioral aspects. Specifically, it aims to increase the children's emotional and social awareness. Through this process children are expected to get more emotional and social insights by learning about themselves and each other.

To summarize, the program is aimed at children at the beginning of prepubescence and its main principles are adopted from Gestalt and Humanistic therapy. The IATK program focuses on phenomenological principles. It refers to the uniqueness of every individual and sees the self as a whole: the total of emotions, cognition, and behaviors. Unconditional positive regard, acceptance, and mutual respect are essential communication skills that build the IATK supportive group. The positive atmosphere within the group serves as a fertile background to working on the multifaceted self and finding the balance between the different selves.

\section{Methods}

The above-mentioned theories are translated into methods and strategies, although it is not a one-to-one translation. There could be more than one way to translate these theories into preventive programs. The translation of broad and global theories into practice could result in different preventive interventions. The theories that are used, emphasize the importance of creative methods. These methods are not specifically structured as cognitive oriented methods that follow a rigidly constructed model. The IATK program incorporates drama and art as its main tools. Creative work is considered useful in the process of fostering self-esteem and promoting well-being and is used frequently within Gestalt theory and therapy. Firstly, when using drama 
and art, the participants open themselves up to a new experience through which they may gain new insights and self-awareness (Blatner, 1973; Langley \& Langley, 1983; Moreno ${ }^{\circ}$ 1945). They experience the process 'in vivo', not just discussing, talking, and analyzing, but doing and feeling (King, 1975; Ziv, 1986). Secondly, drama and art are tools to facilitate the expression of thoughts (cognition) and feelings (emotions). They enable a person to identify and use thoughts and feelings in personally rewarding, and socially acceptable ways (King, 1975). Thirdly, through drama and art, children are exposed to an 'acting out' process, which could lead to cathartic reactions. This has an important therapeutic effect on emotions, cognition, and behaviors (Moreno, 1945).

\section{Content}

The main goal of the "I Am The Key" program is to promote mental health and reduce the risk of mental disorders and social problems such as symptoms of depression and aggression. Self-esteem and its determinants (competence and social support) are risk and protective factors in the development of mental and social problems (see chapter 2). Therefore, the program strives to meet the main goal by fostering positive and realistic self-esteem, coping skills, and social support. Positive self-esteem together with the awareness of the social supportive network could serve as a key for effective coping with conflicts and challenges.

The Dutch long version of the program was implemented in the pilot study twice a week through a series of 18 sessions. The program is composed of a series of three units. Each unit has its intermediate goals. First, a general description of the unit level goals are drawn. Later on, a more detailed explanation is given as can be seen in Table 4.1.

Unit 1: Group building:

"To build an IATK group with clear working patterns (e.g. to acquaint the children with the programs' behavioral rules).

To make the participants aware of their unique sides and their similarities to others. Unit 2: Inner self-processes:

To learn how to cope with self discrepancies (e.g. the gap between the logical self and the emotional self, the inner self and external self, the real self and ideal self). 


\section{Unit 3: Social support:}

To increase the giving and receiving of social support.

Each unit was developed in a structured way and was based on themes, goals, theory, methods, and strategies, as can be seen in Table 4.1 below.

\section{Table 4.1}

Description of the program, divided into three wnits, structured and based on

themes, goals, theory, methods, and strategies

\begin{tabular}{|c|c|c|c|c|c|}
\hline Unit & Thennes & Goals & Theory & Methods & Strategies \\
\hline \begin{tabular}{|c|} 
Unit d \\
5 \\
sessions \\
\end{tabular} & $\begin{array}{l}\text { Introduction to } \\
\text { the program. } \\
\text { (Group } \\
\text { building) }\end{array}$ & $\begin{array}{l}\text { Building } \\
\text { awareness and } \\
\text { understanding of } \\
\text { the self and } \\
\text { others. } \\
\text { Developing self- } \\
\text { identity } \\
\text { awareness } \\
\text { (uniqueness and } \\
\text { similarities to } \\
\text { others). } \\
\text { Introducing } \\
\text { group } \\
\text { communication } \\
\text { skills. }\end{array}$ & $\begin{array}{l}\text { Rogerian } \\
\text { Hummanistic } \\
\text { theory and } \\
\text { therapy }\end{array}$ & $\begin{array}{l}\text { Art } \\
\text { Drama } \\
\text { Role play } \\
\text { Communication } \\
\text { games } \\
\text { Establishing a } \\
\text { contract } \\
\text { Discussion }\end{array}$ & $\begin{array}{l}\text { The clinildren discuss the } \\
\text { meaning of: 'I Am The Key' } \\
\text { and 'the key to someone's } \\
\text { heart'. } \\
\text { They participate in several } \\
\text { role plays where } \\
\text { comnunication problems are } \\
\text { introduced. By analyzing } \\
\text { problematic behavior, the } \\
\text { children reach decisions } \\
\text { concerning the } \\
\text { comnunication skills that } \\
\text { are essential in the LATK } \\
\text { supportive group. } \\
\text { The children get acquainted } \\
\text { with each other through } \\
\text { different media such as self- } \\
\text { portraits. }\end{array}$ \\
\hline \begin{tabular}{c|} 
Unit 2 \\
8 \\
8 \\
sessions
\end{tabular} & $\begin{array}{l}\text { Coping with } \\
\text { self- } \\
\text { discrepancies } \\
\text { and creating a } \\
\text { balance } \\
\text { between the } \\
\text { different } \\
\text { elements of } \\
\text { the } \\
\text { multifaceted } \\
\text { self: emotional } \\
\text { self: } \\
\text { Logical self, } \\
\text { inner self, } \\
\text { external self; } \\
\text { real self, and } \\
\text { ideal self }\end{array}$ & $\begin{array}{l}\text { The logical self } \\
\text { and the emotional } \\
\text { self: } \\
\text { Distinguishing } \\
\text { between feelings } \\
\text { and thoughts. } \\
\text { Learning to } \\
\text { intertwine } \\
\text { emotions and } \\
\text { cognition and } \\
\text { find the balance } \\
\text { between the two. } \\
\text { The inner self } \\
\text { and the external } \\
\text { self: } \\
\text { Comparing inner } \\
\text { feelings and } \\
\text { thoughts to } \\
\text { external } \\
\text { behavior. }\end{array}$ & $\begin{array}{l}\text { Gestalt theory } \\
\text { and therapy }\end{array}$ & $\begin{array}{l}\text { Personal } \\
\text { narratives } \\
\text { Self-dialogue } \\
\text { Group work } \\
\text { Art } \\
\text { Use of puppets } \\
\text { and drama } \\
\text { Self humor } \\
\text { Storytelling } \\
\text { Discussions } \\
\text { Sharing }\end{array}$ & 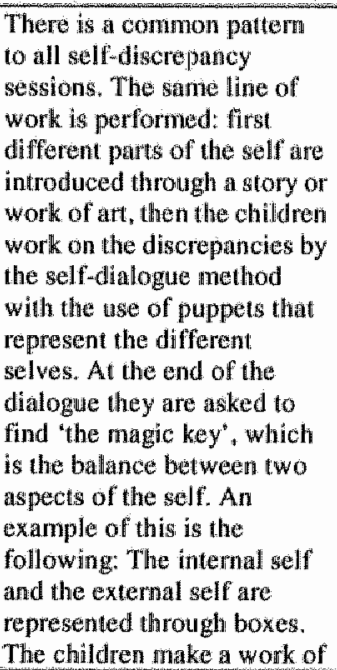 \\
\hline
\end{tabular}




\begin{tabular}{|c|c|c|c|c|c|}
\hline & & $\begin{array}{l}\text { Learning to } \\
\text { develop positive } \\
\text { self-expression. } \\
\text { to control } \\
\text { emotional } \\
\text { outbursts } \\
\text { ultimat to } \\
\text { the discrepancy } \\
\text { between the } \\
\text { internal and } \\
\text { external self. } \\
\text { The real self and } \\
\text { the ideal self: } \\
\text { Promoting and } \\
\text { creating reallistic } \\
\text { expectations and } \\
\text { aspirations of } \\
\text { performance. } \\
\text { This can be } \\
\text { achieved by } \\
\text { either } \\
\text { increasing/decrea } \\
\text { sing expectations } \\
\text { or aspirations. }\end{array}$ & & & $\begin{array}{l}\text { art. They are asked to choose } \\
\text { a box that reflects } \\
\text { themselves (transparent, } \\
\text { solid, flexible. et cetera.). } \\
\text { They choose how to } \\
\text { decorate the outside of the } \\
\text { box and what to put in the } \\
\text { inside. Gradually during the } \\
\text { sessions they can decide } \\
\text { whether to take things out of } \\
\text { their box or to put more } \\
\text { things inside. Ewery child } \\
\text { thinks about a possible } \\
\text { conflict between the } \\
\text { different sides of the self } \\
\text { (e.g, the internal self loves } \\
\text { Barlbie, but the external self } \\
\text { will not tolerate it because it } \\
\text { is not considered desirable } \\
\text { for boys to like Barbie). } \\
\text { Then the child is asked to } \\
\text { perform a self dialogue on } \\
\text { the topic when the child is } \\
\text { the external self and the } \\
\text { puppet in his/her hand is the } \\
\text { internal self. The two have } \\
\text { to find the magic key } \\
\text { together and to reach a } \\
\text { ballance. }\end{array}$ \\
\hline \begin{tabular}{|c|} 
Unit 3 \\
5 \\
sessions
\end{tabular} & $\begin{array}{l}\text { Promoting } \\
\text { social support. }\end{array}$ & $\begin{array}{l}\text { Developing } \\
\text { awwareness of } \\
\text { shatring. } \\
\text { Incrensing the } \\
\text { giving and } \\
\text { receiving of } \\
\text { social support, } \\
\text { particularly of } \\
\text { significant others. } \\
\text { Creating care, } \\
\text { cooperation and } \\
\text { colllaboration } \\
\text { within the social } \\
\text { network. } \\
\text { particularly } \\
\text { within the group } \\
\text { and between the } \\
\text { participants and } \\
\text { their parents. }\end{array}$ & $\begin{array}{l}\text { Humanistic } \\
\text { theory and } \\
\text { Gestalt theory }\end{array}$ & $\begin{array}{l}\text { Art } \\
\text { Personal } \\
\text { narratives } \\
\text { Creative writing } \\
\text { Use of puppetts } \\
\text { and drama } \\
\text { Information to } \\
\text { parents } \\
\text { A workshop for } \\
\text { children and } \\
\text { parents } \\
\text { Feedback } \\
\text { techniques } \\
\text { Discussions } \\
\text { Sharing }\end{array}$ & $\begin{array}{l}\text { Each child designs his/her } \\
\text { own 'supportive train'. } \\
\text { Every child is the driver and } \\
\text { the people in the differemt } \\
\text { wagons are helping him/her } \\
\text { to reach his/her destinations } \\
\text { in life. The child is not just } \\
\text { supported by these } \\
\text { significant people, she/he } \\
\text { supports herself/ himself and } \\
\text { others as well. For example, } \\
\text { in at session in which parents } \\
\text { are involved there is a 'train } \\
\text { exhibition' and a sharing of } \\
\text { positive ideas regarding } \\
\text { social support. Parents and } \\
\text { children experience a "light } \\
\text { point exercise' in which } \\
\text { positive feedback and } \\
\text { compliments from both sides } \\
\text { are shared. The parents } \\
\text { participate in a lecture and } \\
\text { receive a brochure on } \\
\text { parental support and its role } \\
\text { in promoting self-esteem. }\end{array}$ \\
\hline
\end{tabular}




\section{Conclusions}

In this chapter we addressed the importance of self-esteem as a non-specific risk and protective factor in mental health and as one of the core elements in a broad spectrum approach. The theoretical underpinning, methods, and strategies of the IATK program were introduced together with the first insights from the pilot study. The pilot study aimed at testing the attractiveness, comprehensibility, relevance, workability, and efficacy of the program within the school context. The results of the pilot study were promising and shed light into the possibility of further implementation of Gestalt and Humanistic interventions. Such programs, which use drama and art, could play a role within the schools' promotion of healthy behavior curriculum. The current situation worldwide is that counseling programs for schoolchildren need further development and research (Myers et al., 2000). Health educators, educational counselors, teachers, therapists and researchers could profit from a description of the IATK program since it could serve as an example of a broad spectrum systematic implementation of a broad spectrum approach in practice. As the IATK program is focused on non-specific risk factors, which reflect BSA core principles, it could clearly be defined as a BSA program (see Chapter 2).

According to Gardner (1993) 'intra-personal intelligence' is the ability to form an accurate model of oneself and the ability to use it to operate effectively in life. Self-esteem is an important component of this ability (see Chapter 2). The uniqueness of IATK as a BSA program is in focusing on the development of children's intra-personal-intelligence as an important non-specific risk factor.

The research and guidelines committee of the Collaborative for the Advancement of Social and Emotional Learning (CASEL, 1997) highlighted implementation practices that effectively promote Social and Emotional Learning (SEL). Universal primary prevention could provide children with systematic emotional and social learning, which could be adjusted to account for varying developmental needs throughout school life. Schools could be the optimal setting for implementing such broad-spectrum programs since they access the entire population and are responsible for promoting healthy behavior (PHB curriculum). 
A recent review on the effectiveness of prevention programs for schoolchildren concluded that successful programs lasted at least one school year and were implemented on a regular basis (Greenberg et al., 2000). This helped to get the intensity needed to change attitudes and behavior. One of the main problems within the school system is the external restriction resulting from the time limits in implementing such programs. The ability to transfer IATK's principles from the sessions into real life and to maintain it as a core element in the learning process in school life as a whole is essential in order to precipitate a change. This could be implemented by a constant usage of IATK guidelines in daily life situations and applying them as part of a problem-solving process in the class. For example, a program could be considered as part of the school lifestyle when its messages are repeated by management, parents committee and children school council in similarity to the ideas and principles of the Health Promoting School (Marx \& Wooly, 1998; Noerthorp \& Cynthia, 2000). Moreover, children could be asked to try to solve social problems in school according to the coping with selfdiscrepancies' method and in this sense to enlarge the implementation scope from their class to the whole school setting.

More research is needed in order to establish the linkage between Humanistic and Gestalt theory in the practice of broad spectrum interventions. Studies that integrate qualitative and quantitative methods are needed in the field of mental health promotion and prevention in order to have a better insight into the workability and effectiveness of mental health programs. Insights from such studies could improve the quality, development, and implementation of mental health programs. 


\section{Chapter 5}

Searching for the key to the self: An evaluation of the short-term effects of 'I Am The Key', a Generic School Mental Health Promotion Program

A revised version of this chapter was submitted in January 2003 as: Michal Mann, Clemens MH Hosman, Gerard Van Breukelen, Cor Meesters \& Nanne K de Vries. Searching for the key to the self: An evaluation of the short-term effects of 'I Am. The Key", a Generic School Mental Health Promotion Progran 



\section{Abstract}

The main question of the present efficacy study is whether the 'I Am The Key' (IATK) counseling program has an effect on mental health promotion variables (i.e. global self-esteem and self-evaluated competence in behavioral conduct) and the prevention of mental and social problems (delinquency, depression, and aggression) of schoolchildren. The main focus of the intervention was on selfesteem and self-concept, using methods such as self-dialogue, creative expression, and group discussion.

The program was implemented in 16 schools in The Netherlands, in a nested randomized design: within every school there were experimental and control classes. The sample included $7095^{\text {th }}$ grade 10-12 year old students with 372 girls and 337 boys. The study showed that the program had a significant effect in reducing delinquent behavior for participants ranking high in such behavior at the pre-test, reducing self perceived competence in behavioral conduct for subjects scoring high in this domain, and increasing aggressive behavior for those who scored low on this sub-scale at the pre-test. A mild increase in this scale could be considered as increased assertiveness in children previously ranking low in assertive behavior. No impact was found on internalizing problems such as symptoms of depression or on self-esteem. Implications for the field are discussed.

\section{Introduction}

In modern society an array of mental disorders and social problems are highly prevalent. These include disorders with internalizing characteristics such as depression, anxiety, and substance abuse, and problems with externalizing qualities including aggressive behavior, delinquency, high-risk behaviors (such as that predisposing to Aids), and dropping out of education. These problems not only impose a considerable social and economic burden on society, but also result in a high degree of personal suffering and thereby decrease the quality of life. Schools are an ideal setting for preventing such problems, since they have a responsibility in 
this respect, they possess the means, and they cover nearly the total youth population. Mental health promotion curricula and wellness programs, oriented towards emotional and sociall learning, could provide children with universal primary prevention tailored to the varying developmental phases and needs in a systematic way throughout school life. According to the research and guidelines committee of the Collaborative for the Advancement of Social and Emotional Learning (CASEL, 1997) social and emotional learning programs are being used in thousands of schools in the United States. Worldwide, counseling programs for schoolchildren still need further development and research (Myers et al., 2000).

Many mental health programs aim to reduce specific problems, one by one e.g. prevention of eating disorders or anxiety. A current debate is which direction school-based mental health promotion programs should follow: a preventive approach separately for each specific risk behavior or disorder, or a generic preventive approach? (Myers et al., 2000). Generic counseling programs focus on risk and protective factors common to a range of disorders and risk behaviors before the onset of specific problems. Therefore, generic interventions could be suitable for universal prevention of an array of problems, whereas programs targeting specific problems are suitable for indicated prevention, in which its target group consists of persons who already show specific symptomatology, although no diagnosed disease is present yet. Selective prevention interventions addressing the population at risk could have a generic nature as well, when the targeted population has been found at risk for multiple problems and diseases.

In generic programs the development of a range of mental disorders could be prevented and individual well-being promoted by treating non-specific risk and protective factors, before any problems manifest themselves. We have termed this the broad spectrum approach (BSA) (see Chapter 2). Based on the evidence supporting the role of self-esteem as a crucial factor in mental health (Mann et al., submitted a), we developed a global preventive approach built around the self.

The beliefs and evaluations people hold about themselves are powerful inner influences steering the individual through life. The self-concept is the sum of an individual's beliefs and the knowledge he/she holds about his/her personal attributes and qualities (Kihlstrom \& Cantor, 1983). Self-esteem is the evaluative 
and affective dimension of the self-concept. It refers to a person's appraisal of his/her value (Markus \& Nurius, 1986). Self-esteem and self-concept are generally regarded as important indexes of children's well-being and mental health (Tudor, 1996). Positive self-esteem has been linked to satisfaction and happiness in later life. In contrast, low self-esteem and unrealistically high self-esteem are two key characteristics known to contribute to mental disorders, risky behavior, and social problems. Individuals with these characteristics are at higher risk of not achieving their maximum potential. Their lack of trust in themselves, or conversely, their exaggerated and unrealistic self-confidence, can lead to an alarming deterioration in physical and mental well-being (Baumeister, 1999; Coie et al., 1993; Mann et al., submitted a). Therefore, a focus on self-concept and self-esteem seems an appropriate starting point for a broad spectrum approach in mental health promotion.

An important question then becomes whether it is possible to change selfesteem through interventions. Indeed, self-esteem can be improved through interventions, as was shown in Haney and Durlak's (1998) meta-analytical review of 116 intervention studies with children and adolescents. Most studies indicated significant improvement of self-esteem and self-concept and significant changes in behavior, personality, or academic functioning. Interventions that specifically focused on changing self-esteem and self-concept were significantly more effective in fostering self-esteem (mean effect size $=0.57$ ) than programs focusing on another target such as behavior and social skills (mean effect size $=0.10$ ). Unfortunately, the effect of improved self-esteem among schoolchildren on a diversity of mental health and mental illness indicators was neither measured nor reported.

In order to foster self-esteem in an integrated way, insight is needed into the determinants and the working mechanisms that influence it. A recent review of available research indicates that the most important determinants of self-esteem are self-perceived competence in domains of importance and social support (Harter, 1999). On the basis of her extensive research review on the construction of the self, Harter suggests some principles that may prevent the development of negative selfesteem and might enhance positive and realistic self-esteem. She proposes focusing 
on the construction of personal narratives in order to preserve a sense of unified self and to improve self-esteem. The main principles are summarized below:

- Reduction of the discrepancy between the "real self' and the "ideal self" by focusing on domains in which one displays competencies, while accepting those domains in which one is less adequate.

- Encouragement of relatively realistic self-perceptions and encouraging the belief that positive self-evaluations can be achieved.

- Increasing awareness of the origins of negative self-perceptions.

- Providing a more integrated personal construct while improving the understanding of coping with self-contradictions.

- Encouraging the individual and his/her significant others to create a more supportive social environment.

None of the programs investigated so far have followed all these recommendations systematically. The I Am The Key (IATK) program, as described and evaluated in this study, seeks to fill this gap and strives to integrate the above concepts (Mann, 1997).

The present study aims to evaluate the effects of this generic BSA preventive intervention on self-esteem, behavioral conduct, depressive symptoms, aggressiveness, and delinquency.

\section{The 'I Am The Key' (IATK) program}

The IATK program focuses on self-concept and self-esteem while aiming to promote two determinants of self-esteem: self-perceived competence and social support. For every participant, self-understanding, self-acceptance, and coping skills, together with openness to the social support network, serve as a key to effective coping with conflicts and challenges. A unique feature of the program is the focus on the multi-faceted self and self-discrepancies; these abstract concepts are demonstrated in various concrete ways so children are able to understand them. This is done through self-dialogue and creative methods, while during the group 
sessions children are encouraged to find the key to a balanced inner dialogue between the different parts of the self (see Chapter 4).

The program is implemented among 10-12 year old children. This age is the end of childhood and the early stage of adolescence. According to Selman's research findings (1980), from the ages of 10-15 years the individual is more ready to see him/herself as an object or third person, as an outsider who is watching the needs, feelings, and reactions of the self and others. In this phase, self-esteem is in the process of 'taking shape' and participants are eager to learn about themselves. It is the optimal period in life to start a BSA prevention program and to influence processes that could help the participants grow and develop in a positive way.

The IATK program was developed and implemented in Israel by Mann (1987). The program was then translated from Hebrew into English (Mann, 1997) and was implemented in the International Primary School of Maastricht, The Netherlands, where more indications for multicultural compatibility were presented. Finally, in the context of the current study, the program was translated into Dutch. During 1999 a pilot study was conducted in The Netherlands in order to check compatibility of the program with the Dutch population. The program was found to be suitable for Dutch schools and was highly appreciated by the children, parents and schools' teachers. As discussed in Chapter 4, the pilot study indicated a range of positive outcomes, such as a decrease in aggressive behavior and a small decrease in depressive symptoms and social problems. Unfortunately though, the program thad to be shortened, from 18 to 12 sessions, so that the full-scale implementation could fit in with other curriculum demands. More specifically, the unit of social support, which was a very important element in the pilot study, had to be shortened in the full-scale implementation. Attention to this aspect was therefore limited to two sessions and one lecture to the parents on parental support. The sessions on social acceptance within the peer group were also not included in the shorter version. Moreover, some adaptations of the materials were done on the basis of the pilot intervention. In 2000 , the shorter version of the program was implemented in $\mathbb{1 6}$ primary schools in the south of The Netherlands.

The finally implemented program aims to promote mental health and reduce the risk of mental disorders and social problems by fostering children's 
positive and realistic self-esteem, coping skills and social support. This is done through a series of 12 sessions, divided into three units. Each unit has its specific goals and uses special methods, as can be seen in Table 5.1.

Table 5.1

The I Am The Key program (abbreviated version of table 4.1)

\begin{tabular}{|c|c|c|}
\hline Unit Content & Goals & Methods \\
\hline$\frac{\text { Groud }}{\text { buillding }}$ & $\begin{array}{l}\text { Building awareness and understanding of the self and } \\
\text { others. } \\
\text { Developing self-identity awareness (uniqueness and } \\
\text { simillarities to others). } \\
\text { Introducing group communication skills. }\end{array}$ & $\begin{array}{l}\text { Art } \\
\text { Drama } \\
\text { Role play } \\
\text { Communication } \\
\text { games } \\
\text { Establishing a } \\
\text { contract } \\
\text { Discussion } \\
\end{array}$ \\
\hline $\begin{array}{l}\frac{\text { Competence: }}{\text { coping with }} \\
\frac{\text { imner self }}{\text { processes }} \\
(6 \text { sessions })\end{array}$ & $\begin{array}{l}\text { The logiedl self and the emotional self: } \\
\text { Distinguishing between feelings and thoughts. } \\
\text { Learning to intertwine emotions and cognition and to } \\
\text { find the balance between the two. } \\
\text { The inner self and the external self: } \\
\text { Comparing inner feelings and thoughts to external } \\
\text { behavior. } \\
\text { Learning to develop positive self-expression, to control } \\
\text { emotional outbursts and to strive to limit the } \\
\text { discrepancy between the internal and external self. } \\
\text { The real self and the ideal self: } \\
\text { Promoting and creating realistic expectations and } \\
\text { aspirations of performance. This can be achieved by } \\
\text { either increasing/decreasing expectations or aspirations. }\end{array}$ & $\begin{array}{l}\text { Personal narratives } \\
\text { Self-dialogue } \\
\text { Group work } \\
\text { Art } \\
\text { Use of puppets and } \\
\text { drama } \\
\text { Self humor } \\
\text { Storytelling } \\
\text { Discussions } \\
\text { Sharing }\end{array}$ \\
\hline$\frac{\text { Social support }}{(3 \text { sessions) }}$ & $\begin{array}{l}\text { To increase the social support within the social } \\
\text { environment, especially between parents and children }\end{array}$ & $\begin{array}{l}\text { Art } \\
\text { Personal narratiwes } \\
\text { Creative writing } \\
\text { Use of puppers and } \\
\text { drama } \\
\text { Information to } \\
\text { parents } \\
\text { A workshop for } \\
\text { children and parents } \\
\text { Feedback techniques } \\
\text { Discussions } \\
\text { Sharing }\end{array}$ \\
\hline
\end{tabular}

It was expected that the IATK program would foster self-esteem and reduce symptoms of depression and aggression through the intermediate goals described in Table 5.1. The IATK program was assumed to have indirect effects on symptoms of depression and aggression by improving self-esteem. Moreover, a possible direct effect on these problem behaviors was not excluded. 


\section{Method}

\section{Sample and procedure}

This evaluation study consisted of a pre-test and a post-test. The pre- and post-test measures were taken immediately before and after the program was run. The IATK program was implemented in 16 primary schools in the southern part of The Netherlands. Most of the children in these schools belong to medium-high socioeconomic status families.

To be included in the study, schools had to have at least two classes of pupils aged 10-12. Within schools, classes were randomized by the researchers, with one class being assigned to the experimental condition and the remaining class serving as the control.

The schools and classes selected included a total of 742 pupils, of whom 23 (3\%) pupils were excluded since their parents' approval was not acquired in time. The dropout rate during the intervention period was $1.5 \%$ (10 pupils) as some students left their schools or moved from the area. Because of the low percentage the dropout was not investigated any further. Three hundred seventy nine pupils (53\%) participated in the experimental group, while 330 pupils (47\%) were in the control group. Three hundred seventy two of the pupils (52\%) were girls, and 337 $(48 \%)$ were boys. For every session the class was divided into two smaller groups in whicls the program was implemented, and each group was led by two group leaders.

\section{Instruments}

The Self-Perception Profile for Children (Harter, 1985) is a 36-item scale for assessing beliefs about self-competence. In the present study two sub-scales were selected: self-esteem and behavioral conduct. Behavioral conduct is the subjective competence to behave in accordance with expected social norms and to be satisfied with this. The estimate of internal consistency across the six items of each sub-scale (post-test) was found adequate ( $\alpha=0.75$ and $\alpha=0.81$ respectively). Items involve structured alternatives (e.g., in the behavioral conduct sub-scale, an item read: "Some kids often do what is expected of them" versus "Other kids are not often 
doing what is expected of them"). Children had to choose the description that best fits their views about themselves and then indicate whether the description is somewhat true or wery true for them. Accordingly, each item was scored on a 4point scale with a higher score reflecting a higher level of perceived competence. Extensive research has indicated that this is a reliable and valid measure (Miller, 2000; Muris et al, in press).

The Child Behavior Checklist ( $\mathrm{CBCL}$ ) was administered to measure emotional and behavioral problems in children (Achenbach \& Edelbrock, 1983). It has well-established psychometric properties. In this study the YSR-version of the CBCL was used. It is a self-report questionnaire for children and adolescents that includes 112 items which describe children's feelings, thoughts and behavior. On each item, children respond on a 3-point scale marking 'not true', "somewhat true' or 'very true', in regards to whether the behavior, feeling et cetera has occurred over the past six months.

From this questionnaire the scales for delinquency, depression, and aggression were used. The estimate of internal consistency of each sub-scale (11, 14 , and 19 items respectively) was found adequate $(\alpha=0.61, \alpha=0.86$ and $\alpha=$ $0.85)$.

\section{Training of the group leaders and implementation fidelity}

Fourth-year Bachelor students in social pedagogic work, participated in a twosemester training program about IATK which included theory and practice, while doing a their internship. In the first semester the students formed an IATK counseling group themselves. In the second semester supervision and consultation was given while they were implementing the program in schools. During that period the students also had to submit a thesis about theoretical aspects of the program.

Two trained students ('group leaders') were responsible for the implementation of the program in each group. Two educational counselors randomly attended the sessions, monitored the process and were responsible for supervision and consultation with the group leaders. 


\section{Cooperation with schools}

The group leaders implemented the program in cooperation with the class teachers and management. School staff participated in a two-day seminar on the program, one before and one during the implementation. There were meetings in schools with IATK supervision team members in order to improve cooperation and to tackle problems. The teachers participated in the groups of their pupils and were asked to integrate core elements of the sessions in other lessons when needed.

\section{Data analysis}

In our study design, pupils were nested within classes within schools. There are two classes per school, of which one is randomly assigned to the treatment and the other to the control condition. All pupils within the same class received the same treatment. If treatment effects have to be generalized beyond the present classes and schools, class and school have to be included in the data analysis as random effects. Ignoring such effects, if they are present, will in general lead to underestimation of the standard error of the treatment effect and thereby to type I errors in significance testing and too narrow confidence intervals for treatment effects (Moerbeek et al., 2003). However, with only one class per treatment per school, class effects are indistinguishable from school by treatment interaction. Furthermore, given class rather than school randomization, treatment by school interaction rather than a main effect of school affects the standard error of the treatment effect. The following analysis procedure was therefore chosen for all variables.

First, we tested the presence of school by treatment interaction with multilevel (mixed effect) regression using MLwiN version 1.02 (Goldstein, Rasbash, \& Yang, 1998), with school as random effect, treatment as fixed effect, and age, gender, and the pre-test score of the outcome variable at hand as covariate with fixed effects. More specifically, the presence of random between-school variation of the treatment effect was tested with a likelihood ratio test (see (Verbeke \& Molenberghs, 2000), pp. 66, 70 for details).

If no school by treatment interaction was found, and the treatment effect size and its standard error according to MLwiN were almost the same as those 
according to SPSS regression ignoring school effects, then subsequent analyses were run with SPSS regression analysis. These latter analyses tested the presence of treatment by gender interaction, and treatment by pre-test interaction. If interaction of treatment by pre-test was found (either linear or curvilinear), then the sample was split into a low, medium, and high sub-group based upon tertiles of the pre-test score of the variable at hand. Then, regression of the post-test on treatment, gender, age and pre-test was run within each sub-group. If treatment by school interaction was found, then any significant treatment or interaction (with gender or pre-test) effect as obtained with SPSS regression was always checked with MLwiN to prevent type I errors. Furthermore, to prevent type I errors due to multiple testing (5 outcome variables, 4 interaction tests, one main treatment effect test), we used the following rules for significance testing:

$\underline{\alpha}=0.05$ for interaction tests, with the understanding that only interactions significant at the 0.01 level were considered meaningful, and those with a p-value between 0.01 and 0.05 tentative.

$\underline{a}=0.01$ for testing a treatment main effect on the primary outcome variables (behavioral conduct, self-esteem, depression, aggression, delinquency), that is, we applied a Bonferroni correction for multiple testing.

All significance tests were performed as two-tailed tests in order to: be able to detect any aversive effect, if present, and be consistent with (two-sided) confidence intervals.

\section{Missing values treatment}

The analysis was done on $16^{*} 2$ classes with a total of 709 pupils. Missing values at the pupil level were treated in the following way. A missing item value was replaced by the mean score of that pupil on the specific sub-scale. This was done only if she/he had at most $10 \%$ of the items missing in a sub-scale. In the case that this condition was not met and there were more items missing in a sub-scale, the whole sub-scale was considered as missing for that pupil.

As a result, on every sub-scale, between 0 and $4 \%$ of all pupils had a missing value, and there was no substantial difference between treatment conditions 
with respect to missing values (see Table 5.2). Similar missing values rates were also found at pre-test for both treatment conditions.

\section{Table 5.2}

Missing values, means and standard deviations for each of the five outcome variables by experimental and control at post-test

\begin{tabular}{lcccc|cccc}
\hline \multicolumn{4}{c|}{} & \multicolumn{4}{c}{ Control } \\
\hline Sub-scale & $\underline{N}$ N Valid Missing Mean & SD & N Valid & Missing & Mean & SD \\
\hline Delinquency & 370 & $2 \%$ & 2.71 & 2.08 & 318 & $4 \%$ & 2.99 & 2.55 \\
Aggression & 379 & $0 \%$ & 6.22 & 4.88 & 330 & $0 \%$ & 5.73 & 4.91 \\
Behavioral & & & & & & & & \\
conduct & 372 & $2 \%$ & 18.93 & 3.13 & 318 & $4 \%$ & 19.52 & 3.39 \\
Depression & 374 & $1 \%$ & 4.74 & 4.49 & 319 & $3 \%$ & 4.14 & 4.15 \\
Self-esteem & 372 & $2 \%$ & 20.25 & 3.64 & 322 & $2 \%$ & 20.58 & 3.57 \\
\hline
\end{tabular}

Regression analysis of each of the five sub-scales was done excluding pupils with a missing value on the pre-test and/or post-test of the sub-scale at hand.

\section{Results}

Treatment by school interaction was found only for depression $(0.01<\mathrm{D}<0.05)$. Regression analysis with SPSS, ignoring school effects, and using treatiment, gender, age, and the pre-test score of the variable at hand as predictors, showed no treatment effect on any outcome variable (all ps $>0.30$ ), except for a possibly 'aversive' effect on behavioral conduct and depression (both $\mathrm{ps}<0.05$ ). See Table 5.3 for details. Since we used an alpha of 0.01 instead of 0.05 to correct for multiple testing, these two effects are not convincing. Moreover, the presence of a significant school by treatment interaction with respect to depression, called for testing the (average across schools) treatment effect on depression with MlwiN rather than SPSS, and MlwiN gave a $\mathrm{p}>0.10$ for depression.

Regression analysis with SPSS, again ignoring school effects, and now extending the model with treatment by gender interaction and treatment by pre-test 
interaction (linear and curvilinear), showed no treatment by gender or treatment by pre-test interaction (all $\mathrm{ps}>0.20$ ), except the following: treatment by pre-test interaction with respect to delinquency $(\mathrm{p}=0.001)$ and behavioral conduct $(\mathrm{p}=$ $0.031)$ and treatment by squared pre-test interaction with respect to aggression $(\mathrm{p}=$ $0.045)$.

\section{Table 5.3}

Mean difference $(\underline{B})$ between experimental and control condition with respect to the post-test per sub-scale, adjusted for pre-test, age and gender

\begin{tabular}{lcccc}
\hline Sub-scale & Range & $\underline{B}$ (treatment effect) & $\underline{\text { SE }}$ & $\underline{\mathbf{P}}$ \\
\hline Delinquency & $0-19$ & -0.22 & 0.14 & 0.123 \\
Aggression & $0-30$ & 0.20 & 0.27 & 0.466 \\
Behavioral conduct & $7-24$ & -0.43 & 0.21 & 0.041 \\
Depression & $0-24$ & 0.50 & 0.25 & 0.045 \\
Depression (MlwiN) & $0-24$ & 0.44 & 0.33 & 0.184 \\
Self-esteem & $6-24$ & -0.09 & 0.22 & 0.696 \\
\hline
\end{tabular}

Splitting the sample into low, medium, and high sub-groups based upon tertiles of the pre-test interacting with treatment showed the following treatment effects (see Table 5.4 for details):

a. Only in the group with high pre-test delinquency there was a treatment effect on post-test delinquency (experimental $<$ control).

b. Only in the group with low pre-test aggression there was a treatment effect on post-test aggression (experimental > control).

c. Only in the group with high pre-test behavioral conduct there was a treatment effect on post-test behavioral conduct (experimental $<$ control). 


\section{Table 5.4}

Treatment effects (mean difference between experimental and control group at posttest) within sub-groups based upon the pre-test score of the sub-scale ar hand

\begin{tabular}{lccccccccccccc}
\hline & Low & \multicolumn{1}{c}{ Middle } & \multicolumn{1}{c}{ High } \\
\hline Sub-scale & Range & $\underline{B}$ & $\underline{\text { SE }}$ & D & Range & $\underline{B}$ & $\underline{\text { SE }}$ & D & Range & $\underline{B}$ & $\underline{S E}$ & $\underline{P}$ \\
\hline Delinquency & $0-2$ & 0.11 & 0.19 & 0.539 & $2-4$ & -0.04 & 0.26 & 0.877 & $4-19$ & -0.67 & 0.29 & 0.021 \\
Aggression & $0-3.5$ & 0.98 & 0.31 & 0.002 & $3.5-18$ & -0.60 & 0.48 & 0.207 & $18-30$ & 0.18 & 0.55 & 0.748 \\
Behavioral & $0-17$ & -0.06 & 0.37 & 0.871 & $17-20$ & 0.01 & 0.43 & 0.984 & $20-24$ & -1.10 & 0.31 & 0.000 \\
conduct & & & & & & & & & &
\end{tabular}

$B^{\prime}=$ Mean difference between experimental and control condition on post-test, adjusted for age, gender, and pre-test score

The treatment effects within the high-behavioral conduct, low-aggression, and high-delinquency sub-groups raise the question to what extent these effects occur within the same participants. The high-behavioral conduct and low-aggression sub-groups each contain about 240 pupils, of whom about $60 \%$ are members of both sub-groups. In contrast, both sub-groups show only small overlap with the highdelinquency sub-group.

\section{Discussion}

The IATK program was found to have significant effects in certain segments of the targeted population in primary schools, albeit not on the population as a whole as was assumed. Effects were found on externalizing behavior such as delinquency, aggression, and behavioral conduct while the program had no effect on self-esteem and internalizing factors (e.g. depression).

The changes in externalizing but not in internalizing problem behavior correspond with results of the recent review on the effectiveness of the prevention of mental disorders programs for schoolchildren (Greenberg et al., 2000). Their report refers to 34 effective prevention programs out of 130 programs among which are universal prevention programs that aim to prevent externalizing and internalizing problem behavior. According to Greenberg et al (2000), there has been 
greater attention to prevention programs that have focused on externalizing problem behavior whilst little is known regarding effective prevention models for internalizing problem behavior. Several universal programs in this report were successful in reducing externalizing problem behavior such as violence. However, there was only one universal prevention program that has specially targeted childhood depression and it failed to find significant effects (Clarke, Hawkins, Murphy, \& Sheeber, 1993). There are relatively few universal programs addressing generic risk and protective factors such as social skills and competence (STEP, PATH, Stress Inoculation Training) that showed a reduction of depression symptoms among other outcomes.

The IATK program is based on self-theory but it seems that the intervention does not significantly improve participants' self-esteem at posttest. Apparently such effects on self-esteem are not necessary for positive results in externalizing behavioral domains, to occur. By participating in the process, pupils seem to improve, not in terms of their global perception of themselves, but in these specific problem behaviors.

Nowadays, as the rates of delinquent behavior in schools worldwide are increasing, it is a social necessity to develop effective counseling interventions that reduce delinquency. Perhaps the most important result therefore is the effect of IATK on participants high in delinquent behavior. Subjects high in delinquent behavior at pre-test also had significantly lower levels of delinquency at post-test compared to control subjects. These findings are in accordance with data from interviews with schoolteachers who indicated that classes were calmer and children with problem behavior had less disruptive and aggressive behavior after participating in the program. These findings are especially important in relation with the recent review on the effectiveness of the prevention of mental disorders programs for schoolchildren (Greenberg et al., 2000). The authors' conclusion is that one significant drawback in many selective and indicative child-focused programs, that aim to prevent externalizing behaviors, is that they have a small sample size and have focused exclusively on boys. Our IATK trail has a large sample size and covers both genders. It is a universal prevention program but since its effectiveness was apparent in the subgroup high in delinquent behavior at pretest, 
the intervention can also be labeled as indicated prevention within a universal preventive approach.

Experimental participants with high self-perceived competence on behavioral conduct (i.e. behaving in accordance with social norms) at the pre-test had a lower score at post-test compared to control subjects, while participants who had a medium or low score on this scale did not change. Thus, the program led to desirable changes without having negative side-effects for this variable. For aggression no changes were found for the high and mid tertiles, whille a significant increase was observed for the lower sub-group. Both effects may be related to an increase (desirable) in assertiveness for vulnerable sub-groups. The behavioral conduct and aggression sub-scales include questions that seem to refer to assertiveness. For instance, in the behavioral conduct scale, one question reads: "Some children often do what they should do" versus "Other children are not often doing what they should do"; and in the aggression scale there are questions like "I am trying to get attention". Those questions could be considered as assertiveness indicators because one is assertive when one's behavior is in accordance with one's inner self and not necessarily a result of social norms (the 'shoulds'). The fact that $60 \%$ of the high behavioral conduct and low aggression tertiles overlap supports this interpretation. In the program, participants were encouraged to express their 'inner self', to be aware of their feelings and thoughts and the fact that they can be unique. Only the group of children that was Jow in aggression or high in behavioral conduct had changed significantly. This fact could be considered as a sign of standing up for their own rights and being aware of their own unique opinions and not just being responsive to other people's point of view or expectations.

Another interesting finding is that the effect on delinquent behavior was specific to one sub-group and did not occur in other groups as shown in Table 5.4. The program significantly reduced delinquent behavior among children with high pre-intervention scores, but there were no changes in the middle sub-group and only a non-significant increase in the lower sub-group.

The sub-group differences could be explained by the assumption of the self-process that might mediate problem behavior. These findings could be compatible with the ideas behind the phenomenological approach (see Chapter 4). 
According to Spruijt (1996) phenomenological aspects should be included in health education planning. Health education processes become more relevant to participants once their own phenomenologicall field is introduced within the program. This field includes cognitive aspects such as knowledge, values, beliefs, together with emotional aspects such as feelings and emotional state. During the IATK program, the group leader stresses the importance of individuals' subjective point of view and devotes considerable attention to the individuality and uniqueness of each participant. Therefore, children with different characteristics and different problem profiles could go through different individual processes of inner selfreflections. They might set different targets and different goals depending on their own unique profile, their real self, ideal self, external and internal self et cetera (see Chapter 4). More research will be needed to draw firmer conclusions on the effectiveness of the implementation of phenomenological principles in generic counseling programs.

Despite the encouraging results, found on externalizing factors within subgroups of the target population, we have to conclude that no effects were found for the two core outcome indicators: self-esteem and depression. The absence of these hypothesized results might be attributed to different types of causes such as program and study design, measures and program implementation.

- Design and programs' implementation: The ideal research design to study the efficacy of mental health promotion programs is a longitudinal study that measures long-term effects (WHO, 2002). The research discussed in this chapter only gives an indication of short-term effects (for long-term effects see Chapter 6). The intervention itself may also have covered too short a time span to affect different concepts and processes within the multifaceted self (see Chapter 4). Such concepts may require a more comprehensive as well as longer intervention. Interviews with teachers and group leaders at the post-test confirmed that the program was too short in order to internalize and assimilate the programs' messages and processes and the children needed more time to do so. An emotional and social process focusing on the self should ideally be supported by a long-term program which is important as part of the school curriculum. Moreover, when the program is an integral part of school 
philosophy and lifestyle, the children have more support, encouragement and opportunities in the school setting. This support could assist them to internalize ideas and concepts that they have learned during the implementation in their class as was introduced in the policy of the Health Promoting School (Marx \& Wooly, 1998; Noerthorp \& Cynthia, 2000). Unfortunately, in contrast to the successful pilot study, the intervention in the final study was not carried out by school personnel. Due to restrictions in resources for the research project, students implemented the program under supervision of external educational counselors and the relation between the implementation team and the schools was much less intense in comparison to the situation in the pilot setting. The disadvantage of having trained, but inexperienced students as group leaders compared to experienced teachers is clear. Moreover, their knowledge of group building and creative processes could entance the quality of the implementation. Internal educational counselors, when available in schools, could have an important role in guiding and supervising teachers on a daily basis. The collaboration of teachers and internal counselors during the implementation of emotional and social curriculum, whilst reinforcing these processes throughout the school day could turn this learning process into an integral part of school lifestyle. School lifestyle can be observed by its customs, habits, codes of behavior, atmosphere and level of involvement. The pilot, qualitative observations indicated changes in school lifestyle, while in the fullscale implementation no changes as such were expected, as external counselors and students were in charge of the implementation.

- The measurement instruments: The questionnaires chosen may not reflect the process that was generated in the intervention well enough. First, the SPPC measures global self-esteem and self-perceived competence. However, the IATK program was designed to work on self-discrepancies as well. "The assumption was that coping with discrepancies within the self would promote self-esteem. This assumption was not tested as the only available instrument was for an adult population but not for a population of children (Hermans \& Kempen, 1993). Secondly, the CBCL is developed for a diagnostic process of populations with mental disorders (Achenbach \& McConaughy, 1997) whereas 
this research studied effects of IATK in a normal population. As the CBCL aims to detect mental disorders in children, it might be less sensitive to detecting changes within the normal range. Since the research focused on normal school settings, it would have been an adwantage if measurements that evaluate schoolchildren's mental health condition were available. Thirdly, both SPPC and CBCL, were self-report questionnaires, which do not reflect objective criteria. The reduction in aggressive and delinquent classroom behavior reported in interviews with the teachers, confirmed the findings from the selfreport measures. However, combining self-report questionnaires with quantitative measures taken from parents and teachers could have provided an even better perspective and a more objective one. In addition, questionnaires in which children are asked how they would cope with imaginary daily situations connected to the "self' and 'significant others" could broaden our understanding of their coping skills and self-perceptions in different situations. Such measurement instruments would be useful to the field as well. School counselors could use them to conduct needs-assessments for mental health promotion. In addition, future studies addressing common risk or protective factors within a broad spectrum approach, should use a broader range of outcome indicators, targeting a larger variety of problems.

- The sample: The nature of the research dictated a nested design comprising of at least three levels: the individual level, the class level, where the intervention was carried out, and the school level. The ideal setup would be to have several experimental and control classes per school, so "within school effects" could be detected. However, there were no availlable schools with more than two classes per age group. Furthermore, having two classes in the same school could have a contaminating effect of the results since the children and teachers from the control group could have been exposed to some information of the IATK program activities and goals. Moreover, due to time and budget constraints, the smallest number of schools that could ensure enough statistical power was taken. This limited the number of possible analyses, including, an abundance of interesting analyses, such as risk factor prediction. The ideal sample would have been one that included both schools with a low socio-economic status and 
schools with a high socio-economic status, to allow a comparison of the program effects between children of different socio-economic backgrounds. However, the socio-economic background of all the schools was middle to high (which might result in flooring distortion). This is because in the region that was chosen, schools with a low socio-economic status had only one class of the desired age group, which was not sufficient for inclusion in the research project.

Notwithstanding these limitations, we believe that the IATK program as evaluated in the current study shows the fruitful potential of BSA programs. As demonstrated, the IATK program focuses on the self and not, for example, directly on violent behavior and delinquency. In spite of that, self-reported delinquent behavior was reduced for subjects ranking high in this sub-scale. Although there were no significant changes in self-esteem, there were improvements in different subgroups in externalizing problem behavior, therefore there might be another explanation to the mediating process. This might mean that the program addresses other non-specific risk and protective factors such as coping with self-discrepancies, dialogical self-skills, social norms and group atmosphere. By treating these factors, externalizing symptoms can be modified, even though they are not directly treated. This study has shown that a universal program has differential effects on specific subgroups, which stresses the potential of combining universal and indicated prevention in one approach. 


\section{Chapter 6}

\section{A follow-up study of the effectiveness of 'I Am The Key', a generic school counseling program}

A revised version of this chapter will be submitted in 2003 as: Michal Mann, Clemens MH Hosman, Gerard Van Breukelen, Cor Meesters, Rianne Kasander \& Nanne $K$ de Vries. A follow-up study of the effectiveness of 'I Am The Key', a generic school counseling program 


\begin{abstract}
This paper presents a follow-up study on the impact of the 'I Am The Key' (IATK) counseling program; it was conducted following a booster session eight months after the intervention. The IATK program aims to foster selfesteem in elementary schoolchildren. The main research question was what would be the long-tern effects of IATK on some mental health promotion variables (e.g. global self-esteem and self-evaluated competence in behovioral conduct) and the prevention of mental and social problems (e.g. depression and aggression). The program and the booster were implemented in 16 elementary schools in the south of The Netherlands, in a nested randomized design, with experimental and control classes in every school. The sample included $6806^{\text {th }}$ grade students, 10-12 years old with 351 girls and 329 boys.

Comparisons between the experimental and control group at the follow-up test showed that the program had a significant effect in mitigating excessive levels of self evaluated competence in adjusting to social norms ('behavioral conduct') for subjects ranking themselves high in: such competence at pre-test, increasing aggressive behavior for subjects scoring low on this sub-scale at pre-test. A mild increase in this scale could be considered as increased assertiveness in children previously ranking low in assertive behavior. Moreover, a trend toward decreased aggressive behavior was found for subjects ranking high on this scale at pre-test. Implications for the field are discussed.
\end{abstract}




\section{Introduction}

Society today suffers from widespread mental and social problems including disorders such as depression and anxiety (disorders with internalizing characteristics), and problems such as aggressive behavior and delinquency (problems with externalizing qualities). More than one in four people are expected to develop one or more mental or behavioral problems during their lifetime (WHO, 2001). These problems impose a considerable social and economic burden on society. Furthermore, they also result in personal suffering and thereby decrease ones quality of life.

These mental disorders and social problems are highly prevalent in all ages. One fifth of adolescents under the age of 18 has emotional or behavioral problems (Costello, 1989). The ideal environment for preventing such problems with teenagers is in school, since schools have a responsibility in this respect, they have the means, and they cover virtually the whole child and adolescent population. Throughout school life and the varying developmental phases, mental health promotion curricula could provide universal primary prevention tailored to student needs in a systematic way. These programs should be focused on both emotional and social learning. Although social and emotional programs are being implemented in thousands of schools across the United States (CASEL, 1997), the current situation worldwide is that counseling programs for schoolchildren need further development and research (Myers et al., 2000).

By using programs that treat generic, non-specific risk and protective factors such as self-esteen, coping skills, and social support, we could prevent the development of a variety of mental disorders and social problems, and at the same time, strengthen positive mental health and promote individuals' mental well-being. We have termed this approach a broad spectrum approach (BSA). The BSA focuses on the source, the generic risk or protective factors of different symptoms, and not on the symptoms or specific disorders. Generic Broad Spectrum programs could be suitably used for universal prevention of an array of problems. Universal prevention is actually "those interventions that are targeted to the general public or to the whole 
population group that has not been identified on the basis of increased risk" (Mrazek \& Haggerty, 1994, pp.24) .

The role of self-esteem as a crucial non-specific risk and protective factor in mental health and in universal prevention is strongly supported by evidence (Mann et al., submitted a). The beliefs and evaluations people hold about themselves are powerful inner influences steering the individual through life. The self-concept is the sum total of an individual's beliefs and the knowledge he/she holds about his/her personal attributes and qualities (Kihlstrom \& Cantor, 1983). Self-esteem is the evaluative and affective dimension of the self-concept. It refers to a person's appraisal of his/her value (Markus \& Nurius, 1986). Self-esteem is generally regarded as an important index of children's well-being and mental health.

Based on these ideas about the broad spectrum function of self-esteem and its antecedents, the 'I Am The Key' (IATK) program was developed in order to enhance self-esteem and self-perceived behavioral conduct, and to reduce depressive symptoms and aggressive behavior.

The IATK program was developed and implemented in Israel by Mann (1987).

During 1999 a pilot study was conducted in The Netherlands in order to assess the compatibility of the program with the Dutch population. The program was found to be suitable for Dutch schools, but had to be shortened in order to fit in with schools' time constraints. Moreover, some adaptations of the materials were done on the basis of the pilot intervention. During 1999-2001 the shorter version of the program was implemented in 16 primary schools in the south of The Netherlands.

The program is targeted at 10-12 year old children. This age is the end of childhood and the early stage of adolescence. According to Selman's research findings (1980), from the age of 10-15 the individual is more ready to see her/himself as an object or third person, an outsider who is watching the needs, feelings, and reactions of him/herself and others. In this phase self-esteem is in the process of 'taking shape' and participants are eager to learn about themselves. It would be the optimal period in life to start a BSA prevention program, to influence processes that could help the participants grow and develop in a positive way.

In an earlier study the short-term efficacy of the program was studied among $5^{\text {th }}$ grade students aged 11. It showed no overall efficacy in the target 
population, only within specific sub-groups of that population (Mann et al., submitted c). The short term study showed that the program had a significant effect in reducing child delinquency behavior for participants ranking high in such behavior at the pre-test, reducing self perceived competence in behavioral conduct for subjects scoring high in this domain, and increasing aggressive behavior for those who scored low on this sub-scale at the pre-test. A mild increase in the aggressive behavior scale could be considered as increased assertiveness in low assertive children. No impact was found on internalizing problems such as symptoms of depression or an self-esteem.

The current study discusses the follow-up test results of IATK as measured after a booster session had been held. The booster session is aimed at sustaining and reinforcing the messages and changes brought about by the program. There is some evidence on the effectiveness of follow-up booster sessions in prevention programs and in therapeutic interventions. A review of the literature carried out by Whisman (1990), identified 30 clinical trials of booster maintenance sessions spanning different problem behavior targets. He concluded that booster maintenance sessions have been moderately successful in maintaining treatment behavior including depression and assertiveness. Moreover, a recent study on booster sessions in an indicative prevention program for depressed adolescents showed a positive effect. The booster sessions appeared to accelerate recovery for patients that were still depressed at the end of their acute phase (Clarke, 1999). An important role of a booster session is to reinforce the usage of skills acquired during the intervention and to cope with problematic situations (Clarke, 1999). The IATK booster session was designed accordingly.

This follow-up study aims to evaluate the effects of IATK on self-esteem, self-perceived competence in behavioral conduct, and symptoms of depression and aggression, eight months after the intervention.

The IATK program was assumed to have an indirect effect on symptoms of depression and aggression by improving self-esteem. In this sense, self-esteem was assumed to have a mediating role on problem behavior and therefore, an improvement in self-esteem could result in a decrease in problem behavior. 
Moreover, a possible direct effect on these problem behaviors on the basis of the short-term results can not be excluded. This effect would than be without the mediating role of self-esteem. The short-term outcome study did find a significant effect on aggressive and delinquent behavior of indicated groups at risk, but no effects on self-esteem and depression in the population, nor in groups at risk. It was expected that the short-term results might show maintenance at follow up or even an improvement due to a sleeper effect.

\section{Method}

\section{Sample and procedure}

The IATK program was implemented in 16 elementary schools in the south of The Netherlands. All schools had medium-high social economic status. Each school had a control and an experimental group. Three hundred sixty three pupils (53\%) were in the experimental group and 317 pupils (47\%) were in the control group. Three hundred fifty one pupils $(52 \%)$ were girls while 329 pupils (48\%) were boys.

This efficacy study consisted of a pre-test, post-test and a follow-up test. The program was implemented for 12 weeks. The pre- and post-test measures were taken immediately before and after the implementation of the program in schools. The follow-up test took place eight months after the intervention. To be included in the study, schools had to have at least two classes of pupils aged 10-12. Within schools, classes were randomized by the researchers, with one class assigned to the experimental condition and the remaining class serving as the control. No school dropped out.

The schools and classes selected included a total of 742 pupils, of whom 23 (3\%) pupils were excluded since parental approval was not acquired in time. The dropout rate at follow-up was 39 pupils (5\%), as within the year between the pretest and the follow-up few students left their schools, moved away from the area or were absent on that specific date. Because of the low percentage the dropout was not investigated any further. 
I Am The Key consists of an intervention spanning three months and a booster session after an interval of eight months. The program focuses on selfconcept and self-esteem, while aiming to promote two determinants of self-esteem: self-perceived competence and social support. For every participant, selfunderstanding, self-acceptance, and coping skills together with an openness to the social support network serve as the key to effective coping with conflicts and challenges.

The program aims to foster children's self-esteem and its determinants through a series of 12 sessions, divided into three units: group-building, competence development in coping with inner-self processes, and increasing social support. Unfortunately, this latter unit of social support, which was a very important element in the pillot study (see Chapter 4), had to be shortened because of other curriculum demands. Attention to this aspect was limited in the current version to two sessions and one lecture to the parents on parental support. The sessions on sacial acceptance within peers were also not included in this shorter version.

Each unit has its specific goals and special methods (see Table 5.1 in Chapter 5). A unique feature of the program is the focus on the multifaceted self. This abstract concept is demonstrated in various concrete ways so children are able to understand the idea of differentiation between logic and emotion, the inner and external self, and the real and ideal self. This is implemented through self-dialogue and creative methods, while during the group sessions children are encouraged to find the key to a balanced inner dialogue between the different parts of the self.

Eight months after the implementation, a booster session was carried out in order to help the children recall the program and reinforce the program"s messages. The booster session was implemented during one lesson (45 minutes) and consisted of the following elements. First, a short introduction about the new session was given. Second, free associations by the children followed of what they remembered about the project. Third, a storytelling session was held. There were two stories about children who had participated in the project and how they had used the messages of the program in order to cope with problems. Fourth, the children were asked to write or draw about their personal experience with the program regarding their newly acquired skills. 


\section{The group leaders}

The 12 sessions program was implemented by fourth-year Bachelor students in social pedagogic work. They participated in a two-semester training program about IATK which included theory and practice, while doing their internship. Two trained students ('group leaders') were responsible for the implementation of the program in each group. Two educational counselors randomly attended the sessions, monitored the process and were responsible for supervision and consultation to the group leaders.

The booster session was implemented by two graduate Masters students in Psychology and Health Education from the Maastricht University, The Netherlands. They were research assistants in the IATK program and they were familiar with the program's messages and strategies. Before the booster implementation they participated in a workshop and a training session. During the implementation they received supervision from an educational counselor.

\section{Instruments}

The Self Perception Profile for Children (SPPC) (Harter, 1985) is a 36 item scale for assessing beliefs about self-competence. In the present study two sub-scales were selected: self-esteem and perceived competence in behavioral conduct. The latter refers to the subjective competence to behave in accordance with expected social norms and being satisfied with that. The estimate of internal consistency across the six items of each sub-scale was found adequate ( $\alpha=0.75$ and $\alpha=0.81$ respectively).

Items involve structured alternatives (e.g., in the behavioral conduct subscale, an item read: "Some kids often do what is expected of thern" versus "Other kids are not often doing what is expected of them"). Children have to choose the description that best fits their views and then indicate whether the description is somewhat true or very true for them. Accordingly, each item is scored on a 4-point scale with a higher score reflecting a higher level of perceived competence. A total score can be computed by summing scores across all items. 
The Child Behavior Checklist (CBCL) (Achenbach \& Edelbrock, 1983) has well-established psychometric properties. In this study the YSR-version of the CBCL was used. It is a self-report questionnaire that was designed for children and adolescents. It includes 112 items which describe children's feelings, thoughts and behavior. On each item, children respond on a 3-point scale marking "not true", 'somewhat true" or "very true' regarding whether the behavior, feeling, et cetera has occurred over the last six months.

From this questionnaire the scales for depression and aggression are used. The estimate of internal consistency across the items (14 and 19 respectively) of each sub-scale was found adequate $(\alpha=0.86$ and $\alpha=0.85)$. The delinquency scale, used at the post-test, was not used at follow-up, as part of a strategy to reduce the time to fill in the questionnaire, as the session time was restricted by the schools.

\section{Data Analysis}

In our study design, pupils were nested within classes within schools, and there were two classes per school, of which one was randomized to the treatment and the other to the control condition. All pupils within the same class received the same treatment. If treatment effects have to be generalized beyond the present classes and schools, class and school have to be included in the data analysis as random effects. Ignoring such effects, if they are present, will in general lead to underestimation of the standard error of the treatment elfect and thereby to type I errors in significance testing and too narrow confidence intervals for treatment effects (Moerbeek et al., 2003). However, with only one class per treatment per school, class effects are indistinguishable from school by treatment interaction. Furthermore, given class rather than school randomization, treatment by school interaction, rather than a main effect of school, affects the standard error of the treatment effect. The following analysis procedure was therefore followed for all variables:

First, we tested the presence of school by treatment interaction with multilevel (mixed effect) regression using MLwiN version 1.02 (Goldstein et al., 1998), with school as random effect, treatment as fixed effect, and age gender, and the pre-test score of the outcome at hand as covariates with fixed effects. More 
specifically, the presence of random between-school variation of the treatment effect was tested with a likelihood ratio test (see (Verbeke \& Molenberghs, 2000), pp. 66,70 for details). If no school by treatment interaction was found and the treatment effect size and its standard error according to MLwiN were almost the same as according to SPSS regression ignoring school effects, then subsequent analyses were run with SPSS regression analysis. These latter analyses tested the presence of treatment by gender interaction, and treatment by pre-test interaction. If interaction of treatment by pre-test was found (either linear or curvilinear), then the sample was split into a low, medium and high sub-group based upon tertiles of the pre-test score of the variable at hand, and regression of the post-test on treatment, gender, age, and pre-test was run within each sub-group.

If treatment by school interaction was found, then any significant treatment or interaction (with gender or pre-test) effect as obtained with SPSS regression was always checked with MLwiN to prevent type I errors.

Furthermore, to prevent type I errors due to multiple testing (4 outcome variables, 4 interaction tests, one main treatment effect test per outcome), we used the following rules for significance testing:

$\underline{\alpha}=0.05$ for interaction tests, with the understanding that only interactions significant at the 0.01 level were considered real, and those with a $\mathrm{p}$-value between 0.01 and 0.05 tentative.

$\underline{\alpha}=0.01$ for testing a treatment main effect on the primary variables (behavioral conduct, self-esteem, depression, aggression), that is, we applied a Bonferroni correction for multiple testing. All significance tests were performed as two-lailed tests in order to be able to detect any aversive effect, if present, and to be consistent with (two-sided) confidence intervals.

\section{Missing values treatment}

The analysis was done on $16^{*} 2$ classes with a total of 680 pupils. Missing values at the pupil level were treated in the following way. A missing item value was replaced by the mean score of that pupil on the specific sub-scale. This was done only if the following condition was fulfilled: Either the pupil had only one missing 
item value for that sub-scale or she/he had at the most $10 \%$ of the items missing in a sub-scale. In the case that this condition was not met and there were more items missing in a sub-scale the whole sub-scale was considered as missing for that pupil.

As a result, on every sub-scale, between 0 and $6 \%$ of all pupills had a missing value, and there was no substantial difference between treatment conditions with respect to missing values.

Regression analysis of each of the four sub-scales was done excluding pupils with a missing value on the pre-test and/or follow-up measurement of the sub-scale at hand.

\section{Results}

Treatment by school interaction was found only for depression $(0.01<\mathrm{p}<0.05)$. Regression analysis with SPSS, ignoring school effects, and using treatment, gender, age and the pre-test score of the variable at hand as predictors, showed virtually no treatment effect on any variable (all $\mathrm{ps}>0.25$ ), except for a possibly 'aversive' effect on depression ( $\mathrm{p}<0.05)$. Since we used an alpha of 0.01 instead of 0.05 to correct for multiple testing, the latter effect is considered only tentative. Moreover, the presence of significant school by treatment interaction with respect to depression called for testing the (average across schools) treatment effect on depression with MlwiN rather than SPSS, and MlwiN gave a $\underline{p}>0.10$ for

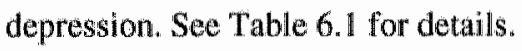

Regression analysis with SPSS, again ignoring school effects, and now extending the model with treatment by gender interaction and treatment by pre-test interaction (linear and curvilinear), only showed treatment by pre-test interaction with respect to aggression $(\mathrm{p}=.000)$ and behavioral conduct $(\mathrm{g}=.002)$; all other treatment by gender or treatment by pre-test interactions were non significant ( $\mathrm{ps}>$ 0.20 ). 


\section{Table 6.1}

Mean difference $(B)$ between experimental and control condition with respect to the follow-up per sub-scale, adjusted for pre-test, age and gender

\begin{tabular}{lcccc}
\hline Sub-scale & Range & B (treatment effect) & SE & P \\
\hline Aggression & $0-30$ & 0.21 & 0.28 & 0.45 \\
Behavioral conduct & $7-24$ & -0.08 & 0.20 & 0.69 \\
Depression & $0-24$ & 0.58 & 0.28 & 0.04 \\
Depression (MlwiN) & $0-24$ & 0.55 & 0.35 & 0.12 \\
Self-esteem & $6-24$ & -0.26 & 0.22 & 0.25 \\
\hline
\end{tabular}

A longitudinal analysis, comparing post-test and follow-up measures, showed no significant interaction of time by treatment with respect to the changes between post-test and follow-up.

Splitting the sample into low, medium and high sub-groups based upon tertiles of the pre-test interacting with treatment showed the following treatment effects (see Table 6.2):

There was a treatment effect (experimental $>$ control) on the aggressive behavior sub-scale, only in the sub-group with low pre-test aggression; after the booster session the treated low aggression subjects had significantly higher aggression than the untreated subjects. In the sub-group with high pre-test aggression there was a trend towards an opposite effect (experimental < control); after the booster session the treated subjects had 'an insignificantly lower level of aggression' than the untreated subjects.

In addition, a treatment effect was found in the sub-group with high pre-test behavioral conduct (experimental < control); after the booster session the treated subjects had significantly lower behavioral conduct than the untreated subjects. In the sub-group with low pre-test behavioral conduct there was a trend towards an opposite effect (experimental > control); after the booster session the treated subjects had 'an insignificantly higher level of behavioral conduct' than the untreated subjects. 
The treatment effects within the high-behavioral conduct and lowaggression sub-groups raise the question to what extent these effects occur within the same subjects. The high-behavioral conduct and low-aggression sub-groups each contain about 240 pupils, of whom about $60 \%$ are member of both sub-groups, which confirms that the two aforementioned treatment effects occurred indeed by and large within the same subjects.

\section{Table 6.2}

Treatment effects (mean difference between experimental and control group) at follow-up within sub-groups based upon the pre-test score of the sub-scale at hand

\begin{tabular}{cccccccccccccccc}
\hline & \multicolumn{4}{c}{ Low } & \multicolumn{1}{c}{ Medium } & \multicolumn{4}{c}{ High } \\
\hline Sub-scale & Range & $\underline{B}$ & SE & D & Range & $\underline{B}$ & SE & P & Range & B & SE & D \\
Aggression & $0-3.5$ & 1.41 & 0.36 & 0.000 & $3.5-18$ & 0.31 & 0.48 & 0.52 & $18-30$ & -1.00 & 0.57 & 0.08 \\
Behavioral & $0-17$ & 0.44 & 0.33 & 0.19 & $17-20$ & 0.52 & 0.41 & 0.21 & $20-24$ & -1.01 & 0.33 & 0.002 \\
conduct & & & & & & & & & & & & \\
\hline
\end{tabular}

$B=$ Mean difference between experimental and control condition on follow up -test, adjusted for age, gender and pre-test score.

\section{Discussion}

The follow-up test, similarly to the short-term study, showed significant effects on externalizing behavior such as aggression and behavioral conduct in certain segments of the study population. However, no effect was found on the population as a whole as was assumed. On internalizing factors (e.g. self-esteem and depression) the intervention had no short-term nor long-term effect. More specifically, for aggression and behavioral conduct the treated subjects showed less variation around the mean than the untreated subjects.

It was anticipated that the IATK program would have an effect on selfesteem and on symptoms of depression and aggression. The short-term outcome study did find a significant effect on aggressive and delinquent behavior of indicated groups at risk (low \& high in those sub-scales), but no effects on self- 
esteem and depression in the population, nor in groups at risk. It was expected that the short-term results would show maintenance at follow up (see Chapter 5). Posttest results indicated that the IATK program had significant effects on delinquency, aggression, and behavioral conduct in certain sub-groups of the child population while for self-esteem and depression no effect was found. The follow-up test revealed maintenance of these post-test results excluding delinquency that was not measured at follow-up.

Self-esteem is defined as a non-specific risk and protective factor in the development of mental disorders and social problems (see Chapter 2). Therefore, increased self-esteem was assumed to have a mediating role in the decrease of problem behavior. Unexpectedly, the self-esteem of the participants did not show improvement. According to research results, it is possible to improve self-esteem through mental health promotion interventions, as was shown in Haney and Durlak's (1998) meta-analytical review of 116 intervention studies with children and adolescents. Most studies indicated significant improvement of self-esteem and self-concept and significant changes in behavior or personality. There is a discrepancy between Haney and Durlak's findings and our posi-test and follow-up results on self-esteem. Three issues might explain this: the visibility of externalizing behavior, the duration of the IATK program and the work on the multifaceted self:

1. Externalizing behavior is more visible than inner concepts such as self-esteem and internalizing behavior. Therefore, it is easier to control, for example through an agreement with the group regarding social norms of desirable conduct.

2. The IATK program stimulates active participation and creative self-expression during the sessions. This often becomes "an acting-out process' in which children reflect their conflicts and problems in a creative way (i.e. role-play or art). In a creative expression process there is sublimation of aggression, which enables individuals to express their aggression in a socially acceptable way. This process has more influence on externalizing problem behavior than on internalizing problem behavior. After the active phase in each session there is a closing part, which includes sharing and discussion. This part, which focuses on insights, and is expected to influence self-esteem and internalizing problem 
behavior, was lacking in the recently implemented IATK intervention mainly due to time restrictions. There was less time per topic than originally planned, and therefore, less time was left for the insights and feedback part.

3. While most programs focus on a single or few sides of the self, the IATK program deals with the multifaceted self. The work on self-acceptance of different parts of the self is a more complex method than the work on the self as one component. It requires more time to assimilate and internalize the process while working on the multifaceted self.

The above-mentioned results of externalizing problem behavior were analyzed in sub-groups. The experimental sub-group of children with low pre-test aggression, had a higher level of aggression than did the untreated subjects in the follow-up test. In the sub-group with high pre-test aggression, the treated subjects had non-significantly lower aggression than did the untreated subjects in the followup test. The latter result was not found in the short-term study. This might be due to a sleeper effect that could become significant over time. According to Priester, Wegner, Petty, and Fabrigar (2000), "The sleeper effect describes a persuasive influence that increases, rather than decays, over time" (pp. 27). Severall mental health promotion programs showed stronger effects on follow-up than they did at post-test (Greenberg et al., 2000).

It was found that the high pre-test behavioral conduct subjects had significantly lower behavioral conduct than did untreated subjects after the followup test. Low pre-test behavioral conduct treated subjects had non-significantly higher behavioral conduct than did the untreated subjects in the follow-up test. To visualize the findings and trends in the sub-groups we have summarized them in Table 6.3. 


\section{Table 6.3}

Effects and trends (Experimental group (Exp) us. Control group (Con)) at follow-up within sub-groups based on pre-test levels

\begin{tabular}{|l|l|l|l|}
\hline $\begin{array}{l}\text { Pre-test sub-group } \\
\text { level }\end{array}$ & Low & Medium & High \\
\hline Aggression & Exp $>$ Con & Exp $>=$ Con & Exp $<$ Con $^{* *}$ \\
\hline Behavioral Conduct & Exp $>=$ Con & Exp $>=$ Con & Exp $<$ Con $^{* *}$ \\
\hline
\end{tabular}

* $\alpha=.05$ significant with one-tailed test, ** significant

Interesting findings were that the effect gained differed from one sub-group to another as shown in Tables 6.2 and 6.3 . This could be demonstrated by the different results for each of the three tertiles. Subjects high on behavioral conduct in the pre-test had a lower score in the post-test, while within the subjects medium and low in this scale there were no significant findings. With aggression subscale, an increase at the lower sub-group was found, no changes at the mid tertile, while in high tertile subjects a trend to reduce aggression was found, although non-significant. This might be related to the fact that very low levels of aggression are actually assertiveness indicators: Both behavioral conduct and aggression scales contained questions that refer to assertiveness. The subjective competence scale on behavioral conduct included questions such as: "Some children often do what they should do" but "Other children don't often do what they should do" and in the aggression scale there were questions like "I am trying to get attention". These questions could be considered as assertiveness indicators because one is assertive when his/her behavior is in accordance with her/his inner self and not necessarily a result of social norms (the 'shoulds'). The fact that $60 \%$ of the high behavioral conduct and low aggression tertiles overlap supports this interpretation. The participants were encouraged to express their "inner self", to be aware of their feelings and thoughts, and of the fact that they are unique. Therefore, the fact that only the group of children that were low in aggression or high in behavioral conduct have changed significantly, could be seen as a sign of standing up for their rights and being aware of their own unique opinions and not just other people's points of view or 
expectations. In summary, the findings could apparently be explained by the phenomenological principles (see Chapter 4). These findings are largely compatible with the ideas behind the phenomenological approach (see Chapter 4 and Chapter 5). Children with different problem profiles could each go through an individual process of change. This might trigger the self-reflection of their unique profile and their subjective self. More research will be needed to draw firmer conclusions on the effectiveness of the implementation of phenomenological principles in BSA generic counseling programs.

Although non-significant, an aversive trend was found in the depression sub-scale at the follow-up test. After the follow-up there was a small increase in depression within the treated subjects. As it might be a sampling error, it is recommended that these results should be replicated by another study. The IATK program aims to foster self-esteem but at the same time, encourages realistic selfperceptions and not an inflated sense of esteem. It might well be that the awareness that was developed within the subjects during the program implementation and the booster session triggered questions and doubts that might be observed through internalizing factors such as depression.

Despite the promising results, found on the post-test and follow up test on externalizing factors within a subgroup of the target population, we have to conclude that on both time measures no effects were found for two core outcome indicators: self-esteem and depression. These results might be attributed to different types of causes such as program and study design, measures and program implementation.

- Design and program's implementation: The current study only gives an indication of short- and mid-term effects, eight months after the implementation was finished. A recent review on the effectiveness of the prevention of mental disorders programs for schoolchildren (Greenberg et al., 2000) has been carried out. The report refers to 34 effective prevention programs out of 130 programs, among which are universal prevention programs that aim to prevent externalizing and internalizing problem behavior. The report found that few studies meet the criteria for fully validated program models. As an example, an ideal investigation could serve the six years longitudinal social awareness 
program, but this long investigation seems to be an exception (Elias et al., 1991). Of most concern, according to Greenberg et al. (2000), is the lack of long-term follow-up studies which examine the stability of program effects. It might well be that the lack of findings on self-esteem and depression could be due to the sleeper effect phenomenon as was described earlier. Several mental health promotion programs showed stronger effects on follow-up depression than they did at post-test (Gillham et al., 1995). It might well be that the effects of universal programs for children on symptoms of depression have a sleeper nature and therefore might increase over time.

Moreover, another design limitation was that the net effect of the booster session could not be measured, due to the design of the study. The booster session included the entire experimental group. There were no subjects from the experimental group left to serve as a control group. Therefore, the booster effect and any time effect such as decay of an initial treatment effect could not be distinguished, although the results measured during the follow-up test (after the booster), were similar to the changes found at the post-test, right after the intervention.

- Measurement instruments: In the current study the measurements were selfreport questionnaires, which are not objective criteria (see Chapter 5). Another disadvantage is the fact that the CBCL is a questionnaire that serves in the diagnostic process of populations with mental disorders. Since the research took place in normal schools, it would have been an advantage if measurements that evaluate schoolchildren's mental well-being were available (see Chapter 5). Moreover, due to time constraints the total time of the booster session had to be reduced to one session of 45 minutes. That unfortunately meant that some of the questionnaires had to be shortened and some of the sub-scales had to be dropped, such as the delinquent behavior scale, which was eventually found to have significant changes after the intervention. This is a disadvantage because it is not a recommended approach, to not measure the same variables over time.

To conclude, the ideal research of the effectiveness of mental health promotion programs should be a longitudinal study that measures long-term effects. 
The current research only gives an indication of short- and mid-term effects. The intervention itself and the booster were too short in order to work thoroughly on internalizing concepts. It is difficult to achieve more results in such a short time while having trained, but inexperienced students implementing the program. An emotional and social process focusing on the self should ideally be a long-term program and an important part of the curriculum; it needs to be an integral part of school philosophy and school lifestyle. Ideally the teachers should implement it with collaboration within the school system. School counselors, school principles, teachers, students, and parents should all take an active role in such an approach. In order to succeed in a Broad Spectrum process, collaboration and involvement, time and resources investment from all parties is required. 
Chapter 7

General Discussion 


\section{General Discussion}

There is a growing concem in our society about the prevalence of an increasing number of mental disorders and social problems, including disorders with internalizing characteristics such as depression, and problems with externalizing qualities such as aggressive behavior and delinquency. These conditions impose a considerable burden on the individuals affected and their families as they result in a high degree of personal suffering and a decreased quality of life. Society, too, pays a high price for these problems, since the consequences can result in a high level of social and economic burden. Notwithstanding the obvious human suffering that can affect every individual's life.

As there is an increasing risk of depression and aggression in children and adolescents, evidence is needed on the causes and determinants of these problem behaviors in order to know how to prevent them. A broad range of mental disorders and social problems are found to be associated with poor self-esteem, including. symptoms of both depression and aggression (see Chapter 2). Moreover, positive self-esteem can lead to good mental health and social behavior. Self-esteem is a potential risk and protective factor in mental and physical health (Hosman, 1997). By changing common risk and protective factors such as self-esteem, and adopting a generic prevention approach, the dewelopment of a range of mental disorders and problem behaviors can be influenced, and individual well-being promoted, before the onset of any specific problem has presented itself. Focusing on self-esteem is considered an important element of mental health promotion and of a broad spectrum approach (BSA) in the prevention of mental disorders and social problems (see Chapter 2).

This thesis represents a study on the implementation and efficacy of the "I Am The Key" (IATK), a Broad-Spectrum mental health promotion program, that focuses on self-esteem. Firstly, it gives an extensive literature review and a crosssectional study emphasizing the importance of self-esteem as a protective factor and a non-specific risk factor in mental health (as described in Chapters 2 and 3). Then the IATK program's main themes and methods are presented (Chapter 4). Finally, 
the short- and mid-term effects of the IATK program are discussed (Chapters 5 and 6).

In the second chapter, evidence is presented illustrating that self-esteem can lead to good mental health and positive social behavior and that a broad range of mental disorders and social problems are associated with poor self-esteem. Such mental disorders and social problems include both internalizing problems (e.g. depression, suicidal tendencies, eating disorders and anxiety) and externalizing problems (e.g. violence and substance abuse). This chapter concentrates on selfesteem from a developmental and educational point of view, as a potential risk and protective factor in mental and physical health. Focusing on self-esteem is considered to be an important element of mental health promotion and of a Broad Spectrum Approach (BSA) in prevention. Since self-esteem is presented in this chapter as a buffer against stress, it was assumed in Chapter 3 that self-esteem could serve as a moderating or mediating factor in the relation between parenting stress and problem behavior in children. Parenting stress was measured as an example of one of the most common environmental stressors for children.

The third chapter describes the results of a cross-sectional study on internalizing and externalizing problems in normal children. The relationship between self-esteem, self perceived competence, and parenting stress, on the one hand, and internalizing and externalizing problem behaviors on the other, was investigated in a sample of 709 elementary schoolchildren. Results indicate that self-esteem and self-perceived competence, in particular behavioral conduct and social acceptance, are negatively associated with problem behavior. More specifically, self-esteem, scholastic competence, and social acceptance appeared to be negatively related to internalizing problems. Self-perceived behavioral conduct appeared to be negatively related to externalizing problems. Parenting stress was positively associated with externalizing problem behavior. Gender differences regarding internalizing and externalizing problems were found. Boys had more externalizing problem behavior while girls had more internalizing problem behavior. Scholastic competence interacted with gender, and only served as a predictor for internalizing problems for girls. Further analysis implied that selfesteem could serve as a mediating factor and not as a moderating factor between 
parenting stress and problem behavior. Furthermore, self-esteem and scholastic competence seemed to be mediating factors between gender and internalizing problem behavior.

\section{The 'I Am The Key' program}

Chapters 2 and 4 provide the theoretical basis of the methods of the "I Am 'The Key" (LATK) program (Mann, 1987,1997). 'I Am The Key' focuses on self-concept, selfesteem, coping skills, and social support. The idea behind it is that selfunderstanding, together with an awareness of the social supportive network, could serve as a key for effective coping with conflicts and challenges. Coping with selfdiscrepancies is the major goal within the program. Different discrepancies within the self are addressed in LATK: (e,g. the real self versus the ideal self). The Dutch version of the program is implemented once a week through a series of 12 sessions divided into three units: group building, inner self-processes, and social support. Chapter 4 describes an outline of the curriculum's main themes, methods, strategies and the outcomes of a pilot study. This study evaluated a longer Dutch version, which contained 18 sessions. A non-controlled pre-post design was carried out among 35 children aged 11 in a school in Arnhem, The Netherlands. Results were in a favorable direction (De Haan, 2000; Kuijpers, 2001) and indicated a decrease on the aggression sub-scale and a small decrease on the depression and the social problems sub-scale. There was a small increase in the physical appearance subscale. Furthermore, the program was found to be suitable within the Dutch school context. There were enthusiastic reactions from children and teachers regarding the content and most materials, as reflected by questionnaires and observations. According to the qualitative data, the atmosphere in the group improved and there were more positive interactions in the class. Social skills, e.g. listening skills and social acceptance, improved. Case studies results indicated an improvement in the psychosocial competence of children that were high in problem behavior prior to the implementation of the program (De Haan, 2000; Kuijpers, 2001). The program was found to be suitable for Dutch schools, but had to be shortened in order to fit in with schools' time constraints. Moreover, some adaptations of the materials were done 
on the basis of the pilot intervention. The IATK program was therefore subsequently adapted and implemented in 16 schools in the south of The Netherlands, in a nested randomized design with an experimental and control class in every school.

\section{Main findings of the efficacy study}

\section{The post-test and the follow-up test}

Chapters 5 and 6 present short-term and long-term efficacy studies on the program. The program's effects on mental health promotion variables (self-esteem and subjective competence indicators) and the prevention of mental and social problems (delinquency, aggression, and depression) were measured. It was anticipated that the post-test and the follow-up test would show increased self-esteem and reduced symptoms of depression and aggression. However, there were no significant effects of the IATK program on these variables on both time measures. The program only had an effect on externalizing problem behavior regarding specific segments of the population.

The short-term study indicates that the program had a significant effect in reducing delinquency for participating children ranking high in delinquent behavior at pre-test. It also had a significant effect in mitigating excessive levels of self evaluated competence in adjusting to social norms ('behavioral conduct') for subjects ranking themselves high in such competence at pre-test, and increasing aggressive behavior for children who scored low on this sub-scale at pre-test. The latter was interpreted as an assertiveness indicator. A mild increase in this scale could be considered as increased assertiveness in children previously ranking low in assertive behavior (see Chapters 5 and 6 ).

The long-term study included a follow-up test carried out eight months after the intervention and directly after a booster session. Comparisons between treated and untreated participants at the follow-up test showed that the program had three significant effects: first, it reduced behavioral conduct for subjects ranking high in behavioral conduct at pre-test; second, it increased aggressive behavior for subjects 
scoring low on this sub-scale at pre-test; and lastly, it demonstrated a trend towards decreasing aggressiveness for subjects ranking high on this scale at pre-test.

To conclude, the follow-up test, similar to the short-term study, showed significant effects on externalizing behavior such as aggression and behavioral conduct in certain segments of the study population, whilst on internalizing factors (e.g. self-esteem and depression) the intervention had no short-term nor long-term effects. More specifically, IATK had a short-term effect on children high in delinquency. Subjects high in delinquent behavior at the pre-test had significantly lower levels of delinquency at post-test in comparison to similar subjects in the control group. Unfortunately, this sub-scale was not measured during the follow-up test (see Chapter 6). Participants high in self-perceived behavioral conduct at the pre-test had a lower score at the post and follow-up test, while participants who had a medium or low score on this scale did not change. On the follow-up test the treated subjects showed less variation around the mean than the untreated subjects for aggression and behavioral conduct. Changes were found for the high tertile (only on the follow-up test) and a significant increase was observed for the lower sub-group both in the post and follow-up test. "The follow-up test indeed revealed maintenance of the post-test results (excluding delinquency, which was not measured). The post-test and follow-up test results on self-esteem and externalizing versus internalizing problem behaviors relate to other research results, which are discussed below.

\section{Theoretical implications}

The results are discussed with respect to the program's effects on self-esteem and on externalizing problem behaviors versus internalizing problem behaviors. The results are explained with regard to theory and research. Other explanations, including methodological limitations concerning implementation processes and measurements, are discussed in the methodological issues section. 


\section{Fostering self-esteem}

The IATK program did not show an effect on self-esteem. However, self-esteem can be improved through mental health promotion interventions, as was shown in Haney and Durlak's (1998) meta-analytical review of 116 intervention studies with children and adolescents. Most studies indicated a significant improvement in selfesteem and self-concept (see Chapter 5). Other programs showed that they were able to improve self-esteem, whilst IATK did not. It is essential to try to understand this finding. Several explanations could shed light on this result: self-theory, realistic versus inflated self-esteem, one self versus multifaceted self and cognitive and affective skills programs versus behavioral oriented programs.

- The findings with regard to self theory: The finding does not contradict the theoretical underpinning of the role of self-esteem as a risk and protective factor in the development of mental disorders and social problems. This theory is based on vast research works (see Chapter 2). The cross-sectional study in chapter 3 confirms that as well. Moreover, since increased self-esteem is assumed to have a mediating role in the prevention of problem behavior, and there was no evidence for such improvements in the current study, it is reasonable that there was no effect on depression and no effect on the general population in externalizing problems. There was however, an effect of the implementation on specific sub-groups in externalizing problem behavior. This was not shown to be related to increased self-esteem. The explanation might be that other non-specific risk and protective factors that were not measured could have served a mediating role in the change of externalizing problem behaviors in different subgroups. These are:

- Self-variables such as self-concept, coping with self-discrepancies, dialogical-self skills.

- Group characteristics such as social norms and group's atmosphere.

- Realistic versus inflated self-esteem: Many programs improve self-esteem, but in reality they are actially creating an inflated sense of self-esteem because the participants are developing an unrealistic self-concept (Damon, 1995). The IATK was designed and aimed both at lostering self-esteem and at maintaining 
realistic self-perceptions. These two goals might be contradictory. Realistic self-perception would not always be positive and this could be in contrast with the attempt to enhance self-esteem. The mentally healthy individual appears to have the capacity to distort reality in a direction that enhances self-esteem (see Chapter 2). Self-esteem could thus be said to serve as a defense mechanism that promotes well-being by protecting internal balance. This defense however, has its limitations. The beneficial effect becomes invalid in cases of inflated selfesteem and significant distortions of ones self-concept. Seligman (1995) claimed that optimism should not be based on unrealistic or heavily biased perceptions.

The LATK program puts great emphasis on presenting possible discrepancies within the self and developing mechanisms to cope with them. The awareness of contradictions within the self could decrease self-esteem. A program with a more thorough work on realistic self-perceptions and coping mechanisms could help in creating a feeling of mastery and positive self-esteem.

- One self versus the multifaceted self: Harter (1999) proposes focusing on the construction of personal narratives in order to preserve a sense of unified self and to improve self-esteem. The IATK program follows these recommendations (see Chapters $2 \& 4$ ). While most programs focus on a single or on a few sides of the self, the IATK program deals with the multifaceted self. The work process on self-acceptance with its different parts of the self (see Chapter 4) is a more complex model than the work process on the global self as one component. It requires more time to assimilate and internalize the process when working on the multifaceted self. When dealing with such complex concepts, it seems difficult to achieve more results in such a short period of time. Emotional and social processes focusing on the self should ideally be a long-term program and an important part of the curriculum. When the program is positioned as part of a school"s philosophy and lifestyle, the children would have more time to learn, practice and adopt the internal messages of the program into their lives.

- Behavioral versus cognitive and affective programs: According to Haney and Durlak's meta-analytic study (1998), interventions that specifically focused on 
affective (e.g. self-esteem) and cognitive self variables (e.g. self-concept) were significantly more effective in fostering self-esteem ${ }_{*}$ than programs focusing on other variables such as behavior and social skills (see Chapter 5). According to another meta-analytic study on 89 self-esteem programs, Hattie (1992) found that cognitively oriented self concept programs are more effective than affective oriented programs, because cognitive oriented programs are significantly more consistent than affectively based programs. It was evident that cognitive based programs were more likely to be evaluated than affective based programs. Hattie estimates that this might be because the latter programs are harder to evaluate than the cognitively based programs whose goals are clearly set and measured. It might be that cognitive programs are aiming for smaller, more definable goals than affective programs. Since IATK aims to intertwine emotional, cognitive and behavioral aspects and its goals are broad and non specific, it might well be that the process is more complex to measure, and therefore it is harder to show an improvement in self-esteem, in comparison with cognitive programs.

\section{Treating externalizing factors versus internalizing factors}

The results on changes in externalizing but not in internalizing problem behavior, correspond with the recent review on the effectiveness of prevention of mental disorders programs for schoolchildren (Greenberg et al., 2000). The report discusses 34 evidence-based mental health programs among which are universal prevention programs that aim to prevent externalizing and internalizing problem behavior. There are longitudinal data that describe universal programs, successful in reducing externalizing problem behavior such as aggression (Elias et al., 1991). However, there was only one universal prevention program in Greenbergs' report that has targeted childhood depression and it failled to find significant effects (Clarke et al., 1993). Little is known on the prevention of internalizing problems in comparison to the prevention of externalizing problems in children and adolescents. In Europe there have been new initiatives in the field, such as a recent ongoing attempt by the Mental Health Europe (MHE) committee, starting from July 2002, to compile an 
inventory of best practices in the prevention of depression and anxiety within the European Union. The knowledge we have in the field of effective programs on the prevention of depression in schoolchildren is mostly from selective and indicative programs (e.g. the study of Gillham et al., 1995).

There seems to be a difficulty in demonstrating change in internalizing problem behavior (e.g. depression) in universal programs for schoolchildren. There could be several explanations for this: hidden depression, negative thinking and the sleeper effect.

- Hidden depression: There is a phenomenon of 'hidden depression" which means that other problem behavior (e.g. aggression) could be a reflection of underlying depression (Weiner, 1975). Children could use this mechanism in order to hide depression and yet they seek attention by asking for help and treatment by displaying another symptom or problem behavior. This phenomenon is reported as difficult to measure since there is no exact criterion for this concept (Ruiter, 1997). However; it might well be that the significant relation between externalizing problem behavior (e.g. aggression and delinquency) and depression in the current cross-sectional study might support this interpretation. In this sense, if this phenomenon occurs, it could be that there was an effect on depression and the externalizing problem behavior that were treated in the different sub-groups, and this also affected hidden depression.

- Positive thinking versus negative thinking. Perthaps the work in trials with 'at risk" populations was more focused on the specific needs of children with depressed moods which were not met in short universal interventions, including the current one. For example, most of these meaningful interventions include challenging negative thinking and enhancing positive thinking, which relates specifically to depression. The current intervention strives to enhance selfesteem, however at the same time to encourage realistic self-perceptions. Realistic view of the self could sometimes be opposed to positive thinking and therefore, an aversive effect could have been created.

- Sleeper effect: The lack of findings could be due to a sleeper effect. According to Priester, et al, (2000) "The sleeper effect describes a persuasive influence 
that increases, rather than decays, over time" (pp. 27). Several mental health promotion programs showed stronger effects on follow-up than they did at post-test (Gillham et al, 1995; Greenberg et al,; 2000). Hence, it might well be that the effects of universal programs on children with symptoms of depression have a sleeper mature and therefore will increase over time and become only visible after eight months of follow-up in our study. The effects might increase due to developmental phase and/or to life experience. The learning effects might become more relevant in the adolescence period, where identity issues and self-awareness increases. Depressive symptoms do occur in childhood. However, the prevalence of depressive symptoms increase over the years and it is higher in the adolescence period than in chilldhood (Verhulst, Ende, \& Koot, 1997). Moreover, it was demonstrated that symptom levels increase sharply in early adolescence (Petersen et al., 1993). Therefore, the outcome of this variable will take more time to become significant. Moreover, the program could have improved protective factors that might have an impact on depression later on in life. Children that have an increased level of protective factors might not develop depression. And conversely, children that have less protective factors develop more depressive reactions over time. Introducing changes in internalizing problem behavior and self-esteem might take longer than changes in externalizing problem behavior. This might also be due to the fact that changes in externalizing problem behaviors are more visible and therefore, one can become more aware of changes in his/her behavior and to get a feedback about it from ones social environment. While changes in internal concept and internalizing behaviors are less visuble it could take a longer time to become aware of them and to introduce them on a self-report measure. More insight is needed in order to determine what are the best mechanisms in the prevention of depression in universal preventive interventions. 


\section{Methodological issues}

Several limitations should be considered when interpreting the findings of the studies presented in this thesis. Some limitations are due to the methodology used and the process of data collection and analysis. First, time and resource restrictions forced a shortening of the program. The lack of these, affected the quality of implementation, the collaboration with teachers and parents, and the choice of the measurement instruments. Second, research design in terms of number of subjects; socio-economic status, and the nested structure posed constraints. The nested design, and the fact that the program effects were measured at the class level was limiting, since there were only 16 classes in each condition (experimental \& control). Third, the follow-up design was not optimal and prohibited distinguishing the net booster effect from delayed effects.

\section{Restrictions in time and resources}

\section{Program's duration}

The original program's duration was one school year while the Dutch version's duration was only three months. This was due to the fact that the program had to be adjusted to fit in with the schools' timetable. Shorter programs might achieve different effects than longer ones. Moreover, the conclusions in a recent review on the effectiveness of the prevention of mental disorders programs for schoolchildren, is that one of the important characteristics of universal programs identified as effective, is the length. The report refers to effective mental health programs, and one of its main conclusions is that successful programs lasted at least one school year and were implemented on a regular basis to get the intensity needed to change attitudes and behavior (Greenberg et al., 2000). This was confirmed by a recent meta-analytical study on 124 programs (Jane-Llopis, 2002) where it was found that longer mental health programs for children were more effective than shorter ones, while for the elderly the shorter programs have shown to be more effective. In the current intervention there was less time per topic due to shorter duration. 
Furthermore, some topics were minimized or excluded from the Dutch version (e.g. social support and self-perceived scholastic competence). Interviews with teachers and group leaders at the post-test, confirmed that the program was too short, in order to internalize and assimilate the program's messages and processes and the children needed more time to do so. The time limit inhibited the opportunities to work on each discrepancy in a sufficient way, as was described in the paragraph on fostering self-esteem. Also the unit dealing with social support, which was a very important element in the pilot study, had to be shortened. Attention to this aspect was limited in the current version to two sessions and one lecture to the parents on parental support. This was not enough to cover the topic, as, for example, peer support was not covered. Self-perceived scholastic competence is an example of a topic, which was not covered during the implementation. Self-perceived scholastic competence was found to be a mediating factor between gender and internalizing problem behavior (see Chapter 3). Moreover, research results confirm that it is an important determinant of self-esteem. According to Gordon and Grant's survey (1997), about one third of adolescents cited 'doing well at school' as the thing that made them 'feel good about myself'. Increased yet realistic self-perceived competence could have had a positive effect on self-esteem (see Chapter 2). Therefore, narrowing the program's scope apparently reduced the efficacy of the intervention.

\section{Pilot versus full-scale implementation}

The pilot intervention was based on a longer version of the program that included 18 sessions, in comparison with the shorter 12-session version that was used in the full-scale implementation. The intensity of the pilot version was higher than the full-scale one. The pilot was carried out twice a week together with the teachers, a social worker serving as group leader, and educational counselor supervision. There were weekly meetings with the teachers and the school headmaster. This setting was difficult to achieve in the full-scale implementation due to budget, time and human resources constraints. In the full-scale implementation the group leaders' positions had to be staffed by students instead of trained teachers, educational counselors, and social workers. The students participated in the 'I Am The Key theory and practice' 
course. During that course they had to acquire basic skills, not all of which were related to the intervention itself (e.g. how to face a class). The relatively low level of expertise and experience of the group leaders could play a major role in the quality of the implementation. In her meta-analysis Llopis (2002) indeed found that the efficacy of programs increased when implemented by mental health professionals in comparison to non-professionals. The school that participated in the pilot had experienced staff and the time and means to be able to work on the pilot with a high level of cooperation. This resulted in the relatively high quality of implementation, which could not be achieved in the full-scale implementation. Unfortunately, the quality of the full-scale implementation was lower than in the pilot study.

\section{Teachers and parents' collaboration}

The collaboration between the schools' staff, parents, and the programs' coordinators (in this case the research team) is critical to the success of the implementation. According to the review on the effectiveness of the prevention of mental disorders programs for schools, effective universal programs created changes in school and family ecology (Greenberg et al., 2000). This collaboration was lacking in the full-scale implementation of IATK. Firstly, although teachers and school headmasters were involved and helped during the implementation, teachers could have been more actively involved and could have served as group leaders. Human resource problems, time and budget constraints within the schools made it impossible to utilize this opportunity. Moreover, when the program is an integral part of school philosophy and lifestyle, the children have more support, encouragement and opportunities in the school setting. This allows then to internalize ideas and concepts that they have learned during the implementation in their class as was introduced in the policy of the Health Promoting School (Marx \& Wooly, 1998; Noerthorp \& Cynthia, 2000). An active involvement of the teachers could turn the program from a curriculum item into a "lifestyle". For example, a program could be considered as part of school lifestyle when its messages are repeated by the management, the parents' committee and the children's school council. Moreover, children could be asked to try to solve social problems in school according to the 'coping with self-discrepancies' method and in this sense to enlarge 
the implementation scope from their class towards the whole school setting (see Chapter 4). Secondly, the involvement of the parents in the implementation of the program was limited as well. Parents were invited to a lecture and attended one session together with the children. The education of parents is essential in order to support the children's process; however, this was too short in this program due to restrictions in resources.

\section{Measurement instruments}

One other explanation for the moderate outcomes of this trial might be that the measures chosen do not reflect the process that was generated in the intervention well enough. For example, the CBCL is an internationally well-known measure. This questionnaire serves in the diagnostic process of populations with mental disorders, while in the current study, effects of IATK in a normal population were evaluated. As the CBCL aims to detect mental disorders (Achenbach \& McConaughy, 1997), it might be less sensitive to detecting changes within the normal range. Since the research focused on normal school settings, it would have been an advantage to have a measurement that evaluates schoolchildren's mental well-being. The second measurement instrument, the SPPC, measures global selfesteem and self-perceived competence. However, in the IATK program we worked on self-discrepancies as well. Our assumption was that coping with discrepancies within the self would promote self-esteem. This assumption was not measured since such an instrument to measure self-discrepancies ( $\mathrm{KKM}$ ) was available only for an adult population but not for children (Hermans \& Hermans-Jensen, 1995). A children"s version of the ZKM is currently in preparation (Guikers, 2002). In addition, the ZKM is not available as a self-report questionnaire and requires individual interviewing. In the current research the possibility of developing new tools for this purpose was examined, but new instruments with established validity and reliability could not be developed within the given time table and with the available manpower.

Another aspect in regards to the measuring tools is whether to use selfreport questionnaires, which are not objective criteria, or combined measuring tools 
(from parents, teachers and children) that could together give a better perspective and a more objective one. Both SPPC and CBCL are self-report questionnaires. The reduction in aggressive and delinquent classroom behavior reported in interviews with the teachers, confirmed the findings from the self-report measures. However, combining self-report questionnaires with other quantitative measures taken from parents and teachers could have provided an even better perspective and a more objective one. Using combined questionnaires would have been a better solution but was not included in the scope of this research.

\section{Research design}

The nature of the research dictated a nested design comprising at least three levels: the individual level, the class level, where the intervention was carried out, and the school level. The ideal setup would be to have several experimental and control classes per school, so 'within school effects' could be detected. However, there were no available schools with more than two classes per age group. In other words, variables between schools could be controlled for, but variables between classes could not. Furthermore, due to time and budget constraints, the minimal amount of schools that could ensure enough statistical power, was taken. This limited the number of possible analyses, including, an abundance of interesting analyses, such as risk factor prediction.

The ideal sample would have been one that included both schools with a low socioeconomic status and schools with a high socio-economic status, to allow a comparison of the program effects between children of different socio-economic backgrounds. However, the socio-economic background of all the schools was middle to high (which might result in flooring distortion). This is because in the region that was chosen, schools with a low socio-economic status had only one class of the desired age group, which was not sufficient for inclusion in the research project. 


\section{Booster and follow-up design}

To test the additional effects of the booster session, part of the experimental group should have been treated as a control for the booster. In that way, the effect of the intervention, eight months after the program's implementation could have been measured and compared with and without a booster session. This design could have provided us with more insight into the process and improved the understanding of the booster contribution. However, the practical utility of the program was to implement the booster in all classes in order to refresh the program's goals and processes and by that to attempt to broaden the program's effects. Unfortunately, due to this design, there was no possibility to research the unique contribution of the booster since all groups participated in a booster session in the current follow-up study.

\section{Implications for research and practice}

Notwithstanding the above-mentioned methodological limitations, we believe that the results of this study are encouraging, as significant positive changes were found in sub-groups of externalizing problem behaviors: delinquent behavior, aggressiveness and self perceived competence in behavioral conduct. These changes which are one of the main challenges facing modern education systems, can stimulate further research and practice. These findings were reinforced by interviews with teachers, which confirmed the achievements of the intervention.

\section{New developments and future research}

Multi-layered interventions for children that are implemented in collaboration with teachers and parents, and thus integrated with longitudinal research programs are most recommended. A longitudinal research can increase the understanding of developmental processes, as was achieved in the six-year evaluation study conducted by Bruene-Butler, Hampson, Elias, Clabby, \& Schuyler (1997). Moreover, according to Greenberg et al. (2000), a new generation of multi-context programs can provide the promise of greater impact. It is recommended to have both a longer and a simultaneous implementation in several contexts (e.g. groups of 
teachers, parents, and children), combined with a longitudinal investigation. In a recent meta-analitic study, Jane-Llopis (2002) confirmed that the multi-method approach could bring about larger effect size in preventive programs. These findings are also consistent with previous researches (Mullen, Mains, \& Velez, 1992). This multi-layered approach conld be compatible with the BSA approach. The current research is an evaluative study of a BSA program that focuses on the self. It focused on self-esteem, self-concept and coping with discrepancies. However, more components could be tracked in a multi-layered process, such as self-efficacy, selfregulation of behavior, self-help, social-skills, social-support, school atmosphere, resilience and more. It could shed light on mental health promotion, and on the prevention of mental disorders in children. In this way, developmental processes could be tracked and a broad range of risk and protective factors could be introduced. Research on more profound processes could expand the knowledge in the field of mental health promotion and the prevention of mental disorders and social problems, challenging today's society.

Further research could evaluate other programs that focus on different BSA characteristics. An interesting study would be comparisons between generic BSA programs and programs that focus on one problem behavior. An example would be, the prevention of violence and aggression through a problem oriented program in comparison to a BSA self-esteem program such as IATK. This could increase our understanding about the efficacy of generic versus specific prevention programs.

Another considerable issue is the development of questionnaires and tailored tools. One of the main topics in the IATK program is 'coping with selfdiscrepancies' through self-dialogue. The hypothesis is that a developed emotional and social competence could improve the self-esteem of the participants, and therefore, promote their mental health. However, this relation was not studied in this study. There is a need to develop questionnaires that can evaluate 'coping with selfdiscrepancies" in schoolchildren. These measures could shed light on the process within the multifaceted self. This inner process could be evaluated after participating in the IATK program, and provide us with insights about the multifaceted self in healthy and unhealthy individuals. 


\section{Recommendations for the school system}

We conducted a study in Dutch primary schools to assess the value of a mental health promotion and prevention program supplementing the regular curriculum. What implications do our study and field experiences have for health educators, school headmasters, school counselors, and teachers?

Nowadays, as the rates of delinquent behavior and symptoms of aggression in schools worldwide are increasing, it is a social necessity to develop effective counseling interventions that reduce delinquency. Treating aggressiveness and delinquency could be done from a preventive perspective by supplying preventive indicative programs for aggressive and delinquent children at a young age. The short-term results of this study show that children that were high in delinquency at the start demonstrated a significant decrease in delinquency compared with children from the control group. In this sense, the results may suggest that by participating in universal programs, indicated groups could also be treated. This was confirmed in a recent research review (Greenberg et al., 2000). The universal prevention programs target the general public. The indicated prevention programs target high-risk persons who have minimal but detectable signs or symptoms foreshadowing a mental disorder or social problem, but do not meet the diagnostic criteria for disorder at that time (Mrazek \& Haggerty, 1994). It is preferable to prevent problems in indicated groups within a universal program rather than create prevention groups that are exclusively addressing indicated target groups with minimal risk. Directing interventions at indicated groups could by itself create stigmatization processes together with a mutual negative influence within the group. This might deteriorate the group members' condition.

The LATK program does not necessarily focus on the prevention of aggression and delinquency, but aggression and delinquent behavior are dealt with indirectly as children participate in a mental health promotion process focussed on the self. These results should raise the awareness of policy makers and teachers, especially those who choose to prevent violence through problem oriented interventions by dealing with incidents, and imposing regulations. In the IATK program children experienced a self-dialogue between their external public self and 
internal private self. Through self-dialogue between different parts of the self, each child could experience an individual process and had to decide by him/herself how to reach a balance between his/her external and internal self. This is a self-oriented coping approach, which is a different approach than imposing social norms on children. The promotion of mentally healthy individuals has an important role in the prevention of mental and social problems. Furthermore, the implementation of BSA programs in the school system should not consist of a haphazard bunch of sessions, but rather be adopted as part of the school lifestyle. A long-term multi-year policy could help in promoting mental health and in changing the atmosphere in schools. It would also help in applying the program's principles in everyday life.

\section{Collaboration between organizations}

According to a recent WHO report (2002), "prevention and promotion require the collective efforts of all organizations and sectors with responsibility for mental health" (pp.29). School counselors, school principles, teachers, students, and parents should all take an active role in the implementation of a mental health program. In order to succeed in a Broad-Spectrum process, collaboration and involvement, and time and resource investment from all parties is required.

The resources issue raises a well-known dilemma of whether to implement a low-cost program (with minimal time investment and resources) or a high quality program with a long duration and considerable time and resource investment. Normally higher investment can conflict with other school interests such as other curriculum demands or an inspection policy. When comparing the pilot study and the fiull-scale implementation, the current efficacy study poses this dilemma.

In the IATK implementation the university research team supplied almost all the resources. This team was in charge of the implementation, and coordination between the group leaders and the schools. It provided the educational materials, trained the group leaders, and supervised them. Unfortunately, the local health organizations were only marginally involved whille they gave priority to interventions at secondary schools. A deeper involvement of such organizations could increase the quality of the implementation, as it would involve more resources, more expertise, and closer collaboration between the health and 
educational systems. For example, this could help in the early detection of problems in participating children and supply them with additional help from the health services.

Even without the means of the extra support suggested above, the IATK program as evaluated in the current study shows the fruitful potential of a universal program having differential effects on specific subgroups, which stresses the need for combining universal and indicated prevention in a combined approach. Moreover, as demonstrated in Chapters 5 and 6, the current results support the approach that by treating non-specific risk and protective factors there could be a change in externalizing problem behaviors in different subgroups. Externalizing problem behaviors in this study were modified, though they were not directly treated. The nature of this process stayed vague. Possible explanations are given earlier in this chapter. Unfortunately, in this study we could not pin point the exact factors in the intervention that could mediate the BSA change on externalizing problem behavior. Therefore, further development and research in the BSA field is needed.

As fostering self-esteem can affect an individual's well-being, watering the roots of the tree can affect the well-being of the tree. Paradoxically, we can water the roots but are unable to see the changes in the roots themselves; we can only observe the visible changes in the tree. More fieldwork, observations, and research are needed in order to explore changes in self-esteem and their affect on mental health in universal preventive interventions. 


\section{References}

Abel, E. (1998). Sexual risk behaviors among ship and shore based Navy women. Military Medicine, $163(4), 250-256$.

Abidin, R. R. (1997). Parenting Stress index: A measure of the parent-child system. In C. P. Alaquett (Ed.), Evaluating stress: $A$ book of resources (pp. 277291). Lanham, MD, US: Scarecrow Press.

Abramson, L. Y., Metalsky, G. I., \& Alloy, L. B. (1989). Hopelessiness depression: A theory based subtype of depression. Psychological Rewiew, 96, 358-372.

Achenbach, T. M. (1991). Integrative guide to the 1991 CBCL/4-18, YSR, and TRF profiles. Burlington, Vt.: University of Vermont, Department of Psychiarry.

Achenbach, T. M., \& Edelbrock, C. S. (1983). Manual for the child behavior checklist and revised child behavior profile. Burlington: University of Vermont.

Achenbach, T. M., \& McConaughy, S. H. (1997). Empinically based assessment of child and adolescent psychopathology: Practical applications (2nd ed.). Thousand Oaks, CA: Sage Publications, Inc.

Adams, M. J. (1996). Youth in Crisis: An examination of adverse risk factors effecting children"s cognitive and behavioral-emotional development, children ages 10-16. Dissertation Abstract International Section A: Humanities and Social Sciences, $56(8-A)$, 3313.

Ajzen, I. (1991). The theory of planned behavior. Organizational and human decision processes, 50, 179-211.

Albee, G. W. (1985). The argument for primary prevention. Jownal of primary prevention, 5, 213-219.

Alice, E. (1993). Mediating At Risk Factors among Seventh and Eighth Grade Students with Specific Learning Disabilities Using a Holistically Based Model Dissertation. South Carolina: Nove University.

Almeida-Filho, N., Mari, J. C. E., Franca, J. F., Fernandes, J., \& Andreoli, S. B. (1997). Brazilianmulticentric study of psychiatric morbidity. Methodological features and prevalence estimates. British Journal of Psychiatry, 171, 524-529.

Andrews, E. J. (1999). The effects of a self-improvement program on the selfesteem of single college mothers. Dissertation Abstracts Intemational Section A: Humanities and Social Sciences, 60(2-A), 0345.

Angold, A., Costello, E. J., \& Erkanli, A. (1999). Comorbidity. Joumal of Child Psychology and Psychiatry, 40(1), 57-87.

Aunola, K., Stattin, H., \& Nurmi, J. E. (2000). Adolescents' achievement strategies, school adjustment, and externalizing and internalizing problem behaviors. Journal of Youth and Adolescence, 29(3), 289-306.

Bandura, A. (1977). Social learning theory. New Jersey: Prentice - Hall.

Bandura, A. (1986). Social foundations of thought and action: A social cognitive theory. Englewood Cliffs, NJ: Prentice Hall.

Baumeister, R. F. (1990). Suicide as escape from Self. Psychological Review, 97, 90-113. 
Baumeister, R. E. (1999). Self-concept, self-esteem, and identity. In Derlega \& J. Valerian \& B. A. Winstead (Eds.), Personality: Contemporary theory and research (pp. 339-375), Chicago, LL, US: Nelson-Hall Publishers.

Baumeister, R. F., Bushman, B. J., \& Campbell, W. K. (2000). Self-esteem, narcissism, and aggression: Does wiolence result from low self-esteem or from threatened egotism? Current Directions in Psychological Science, 9(1), 26-29.

Beck, A., Steer, R. A., Epstein, N., \& Brown, G. (1990). Beck Self concept test. Psychological Assessment, 2, 191-197.

Beck, A. T., Brown, G. K., Steer, R. A., Kuyken, W., \& Grisham, J. (2001). Psychometric properties of the Beck Self-Esteem Scales. Behaviour Research and Therapy, 39(1), 115-124.

Bee, H. L. (2000). The developing child (9th ed.). Boston: Allyn and Bacon.

Benjet, C., \& Hernandez-Guzman, L. (2001). Gender differences in psychological well-being of mexican early adolescents. Adolescence, 36(141), 47-65.

Bijl, R., Van Zessen, G., \& Ravelli, A. (1997). Psychiatrische morbiditeit onder volwassenen in Nederland: Het NEMESIS-onderzoek. II. Prewalentie van psychiatrische stoornissen. Nederlands Tijdschrift woor de Geneeskunde.

Blatner, H. A. (1973). Acting in practical Application of Psychodrama Methods. Springer Pub Com.

Block, J., \& Gjerde, P. F. (1986). Distinguishing between antisocial behavior and undercontrol. In D. Olweus \& J. Block \& M. Radke-Yarrow (Eds.). Development of antisocial and prosocial behavior: Research, theories, and issues (pp. 17-206). New York: Academic Press.

Bongers, C. (1994). Tackling Violence in Schools: A Report from the Netherlands. Retrieved, from the World Wide Web: http://www.gold.ac.uk/connect/reportnetherlands.html

Bowlby, J. (1980). Attachment and Loss, III: Loss Sadness and Depression. London: Hogarth Press.

Broers, S., Hengeveld, M. W., Kaptein, A. A., Le-Cessie, S., van de Loo, F., \& de Vries, T. (1998). Are pretransplant psychological variables related to survival after bone marrow transplantation? A prospective study of 123 consecutive patients. Journal of Psychosomatic Research, 45(4), 341-351.

Brown, G. W., Bifluco, A., \& Andrews, B. (1990) "Self esteem and depression, 3. Aetiological issues. Social Psychiatry and Psychiatry Epidemiology, $25(235-243)$.

Brown, J. D. (1998). The self. New York: Mc Graw-Hill companies.

Bruene-Butler, L. Hampson, J., Elias, M., Clabby, J., \& Schuyler, T. (1997). The Improving Social Awareness-Social Problem Solwing Project. In G. W. Albee \& T. P. Gullotta (Eds.), Primary Prevention Works. Thousand Oaks, C.A: Sage.

Burns, R. (1982). Self concept-Developing and Education. Dorchester, Dorset: Dorset Press.

Campbell, J. D., Chew, B., \& Scrathley, L. (1991). Cognitive and Emotional reactions to Daily Events: the Effects of Self Esteem and Self Complexity. Jounal of personality and social psychology, 59(3).

Caplan, N. (1974). Who's to blame? Psychology Today, 8(6), 99-104. 
Carvajal, S. C., Clair, S. D., Nash, S. G., Evans, R. I. (1998). Relating optimism, hope, and self-esteem to social influences in deterring substance use in adolescents. Joumal of social and clinical psychology, 17(4), 443-465.

Cervi, D. D. (1998). Gender and personality in the stress process. DissertationAbstracts-Intemational-Section-A:-Humanities-and-Social-Sciences, 59(4A), 1338 .

Chang, A. M., \& Mackenzie, A. E. (1998). State self-esteem following stroke. Stroke, 29(11), 2325-2328.

Clarke, G. N. (1999). Cognitive-behavioral treatment of adolescent depression: Efficacy of acute group treatment and booster sessions. Journal of the American Academy of Child and Adolescent Psychiatry, 38, 272-279.

Clarke, G. N., Hawkins, W., Murphy, M., \& Sheeber, L. (1993). Schools based primary prevention of depressive symptomatology in adolescents: Findings from two studies. Joumal of Adolescence Reseanch, 8(2), 183-204.

Coie, J. D., Watt, N. F., West, S. G., Hawkins, J. D., Asarnow, J. R., Markman, H. J., Ramey, S. L., Sure, M. B., \& Long, B. (1993). The science of prevention: A conceptual framework and some directions for a national research program. American-Psychologist, 48(10), 1013-1022.

Commers, M. J. (2002). Determinants of health; Theory, understanding, portrayal, policy. Dordrecht: Kluwer Academic Publishers.

Connect. (2001). Retrieved, 2002, from the World Wide Web: http://www.gold.ac.uk/connect/aimsbackground.html

Coopersmith, S. (1967). The Antecedents of Self Esteem. San Francisco: Freeman.

Costello, E. J. (1989). Development in child psychiatric empidemiology. Journal of the American Academy of Child and Adolescent Psychiatry, 28, 815-841.

Cowen, E. L. (1994). The Enhancement of Psychological Wellness: Challenges and Opportunties. American Journal of Community Psychology, 22(2), 149. 179.

Crump, R., Lillie- Blanton, M., \& Anthony, J. (1997). The influence of self esteem on smoking among African American school children. Joumal of Drug Education, 27(3), 277-291.

Davies, J. T. R. (1996). Adaptation to change: A comparison of the predictive and humanistic theories of adaptation. Dissertation Abstracts International Section B: The science and engineering, 56(8-B), 4577.

De Brock, A. J. J. L., Vermulst, A. A., Gerris, J. R. M., \& Abidin, R. R. (1992). Nijmeegse Ouderlijke Stress Index: Handleiding Experimentele versie [Nijmegen Parenting Stress Index: Manual.

De Haan, S. C. (2000). Het preventieprogramma "ik heb het". Master's Thesis, Mastricht University.

De Vries, H., Dijkstra, M., \& Kuhlman, P. (1988). Self-efficacyu The third factor besides atitude and subjective norm as predictor of behavioral intentions. Health Education Journal, 3, 273-282.

De Vries, H., \& Mudde, A. N. (1998). Predicting stage transitions for smoking cessation applying the Attitude-Social influence-Efficacy Model.

Psychology and Health, 13, 369-385.

De Vries, H., Mudde, A. N., Dijkstra, A., \& Willemsen, M. C. (1998). Differential beliefs, perceived social influences, and self-efficacy expectations among smokers in various motivational phases. Preventive Medicine, 27, 681-689. 
Devlin, S. D. (1995). Drug use in Rural America: What you can do about it. Conference Proceeding of the American Council of Rural Special Education. Las Vegas, Nevada: ACRES.

Dori, G. A., \& Overholser, J. C. (1999). Depression, hopellessness, and self-esteem: Accounting for suicidality in adolescent psychiatric inpatients. Suicide and Life Threatening Behavior, 29(4), 309-318.

DSM. (1984). Diagnostic and statistical Manual of mental disorders (DSM). Washington: APA.

Dweck, C. S., \& Leggett, E. L. (1988). A social-cognitive approach to motivation and personality. Psychological Review, 95, 256-273.

Eccles, J. S., \& Blumenfeld, P. (1985). Classroom experience and student gender: Are there differences and do they matter? In L. C. Wilkinson \& C. B. Marret (Eds.), Gender influences in classroom interaction (pp. 79-114). Orlando FL: Academic Press.

Elias, M. J., Gara, M. A., Schuyler, T. F., Branden-Muller, L. R., \& Sayette, M. A. (1991). The promotion of social competenec: Longitudinal study of a preventive school-based program. American Journal of Orthopsychiatry, $61,409-417$.

Elias, M. J., Zins, J. E., Weissberg, R. P., Frey, K. S., Greenberg, M. T., Haynes, N. M., Kessler, R., Schwab-Stone, M. E., \& Shiriver, T. P. (1997). Promoting Social and Emotional Learning: Guidelines for Educators. Alexandria, Verginia: ASCD.

Erikson, E. H. (1965). Childhood and Society. New York: W.W. Nortan \& Company, Inc.

Erikson, E. H. (1968). Youth, identity and crisis. New York: Norton.

Evans, D. R. (1997). Health promotion, wellness programs, quality of life and the marketing of psychology. Canadian Psychology, 38(1), 1-12.

Fickova, E. (1999). Personality dimensions and self esteem indicators relationship. Studia Psychologica, 4l(4), 323-328.

Filozof, E., Albertin, H., Jones, C., Sterne, S., Myers, L., \& McDermott, R. (1998). Relationship of adolescent self esteem to selected academic variables. Journal of School Health, 68(2), 68-72.

Fisher, M., Pastore, P., Schneider, M., Pegler, C., \& Napolitano, B. (1994). Eating attitudes in urban and suburban adolescents. International journal of eating disorders, $16(1), 67-74$.

Flay, B. R., \& Ordway, N. (2001). Effects of the positive action program on achievement and discipline: two matched-control comparisons. Prevention Science, 2(2), 71-89.

Flay, B. R., \& Petraitis, J. (1994). The theory of triadic influence: A new theory of health behavior with implications for preventive interventions. Advances in Medical Sociology, 4, 19-44.

Fleming, J., Mullen, P. E., Sibthorpe, B., \& Bammer, G. (1999). The long-term impact of childhood sexual abuse in Australian women. Child Abuse and Neglect, 23(2), 145-159.

Furnham, A., \& Cheng, H. (2000). Lay theories of happiness. Joumal of happiness studies, $I(2), 227-246$.

Garber, J., \& Flynn, c. (2001). Predictors of depressive cognitions in young adolescents. Cognitive Theory and Research, 25(4), 353-376. 
Gardner, H. (1993). Frames of Mind: The Theory of Multiple Intelligences. Gllasgow: Fontana.

Garmezy, N. (1984). The study of stress and competence in children: A building block for developmental psychopathology. Child development, 55, 97-111.

Gilbert, S. E. (1995). Violence in Schools: Why and what can we do about it ? Journal of Health Care, 6(2), 205-208.

Gillham, J. E., Reivich, K., Jaycox, L.u, \& Seligman, M. E. (1995). Prevention of depressive symptoms on schoolchildren: Two-year follow-up.

Psychological Sciences, 6, 343-351.

Ginsburg, G. S., La Greca, A. M., \& Silverman, W. K. (1998). Social anxiety in children with anxiety disorders: Relation with social and emotional functioning. Journal of Abnomal Child Psychology, 26(3), 175-185.

Glick, M., \& Zigler, E. (1992). Risk and Protective Factors in Development of psychopathology: In J. Rolf \& A. S. Masten \& D. Cicchetti \& K. H. Nuechterlein \& S. Weintraub (Eds.), Permorbid competence and outcomes. N.Y.: Cambridge University Press.

Godin, G., \& Kok, G. (1996). The Theory of Planned Behavior: A Review of Its Applications to Health-related Behaviors. American Joumal of Health Promotion, vol 11, No 2, 87-98.

Goldberg, D. P., \& Lecrubier, Y. (1995). Form and frequency of mental disorders across centres. In T. B. Ustun \& N. Sartorius (Eds.), Mental illness in general health care: an international study. Chichester: John Wiley \& Sons on behalf of the World Health Organisation.

Goldstein, H., Rasbash, J., \& Yang, M. (1998). MLwiN version 1.02. Multilevel Models Project, Institute of Education, University of London.

Gordon, J., \& Grant; G. (1997). How we feel. London: Jessica Kingsley.

Graham-Bermann, S. A., Coupet, S., Egler, L., \& Mattis, J. (1996). Interpersonal relationships and adjustment of children in homeless and economically distressed families. Journal of Clinical and Child Psychology, 25(3), 250261.

Green, L. M., \& Kreuter, M. W. (1991). Health promotion planing. An educational and environmental approach. CA: Mountain view, Mayfield.

Greenberg, L. S., \& Paivio, S. C. (1997). Integrating "being' and "doing" in working with shame. Gestalt Review, I(3), 271-274.

Greenberg, M. T., Domitrovich, C., \& Bumbarger, B. (2000). Preventing Mental Disorders in School-age Children: A Review of the Effectiveness of Prevention Programs: Pennsylvenia State University.

Guikers, d. B. (2002). The Self Dialog. Nijmegen University, Nijmegen.

Hage, S. M., \& Nosanow, M. (2000). Becoming stronger at broken places: A model for group work with young adults from divorced families. Journat for" Specialist in Group Work, 25(1), 50-66.

Hammen, C., \& Goodman-Brown, T. (1990). Self Schemes and vulnerability in specific life stress in children at risk for depression. Cognitive Theory and Research, 14, 215-227.

Haney, P., \& Durlak, J. A. (1998). Changing Self Esteem in children and adolescents, A meta analytic review. Joumal of clinical child psychology, $27(4), 423-433$. 
Harrington, R., Rutter, M. \& Fombonne, E. (1996). Developmental pathways in depression: Multiple meanings, antecedents, and points. Development and Psychopathology, 8, 601-616.

Harter, S. (1985). The self-perception profile for children. Denver, CO: University of Denver.

Harter, S. (1986). Processes underlying the construction, maintenance, and enhancement of the self-concept in children. In J. Suls \& A. G. Greenwald (Eds.), Psychological perspectives on the self (Vol. 3). Hillsdale, NJ: Lawrence Erlbaum.

Harter, S. (1990). Causes, correlates and functional role of global self worth: A life span perseptive. In J. Kollgian \& R. Sternberg (Eds.), Perceptions of competence and incompetence across life span (pp. 67-98). New Haven, CT: Yale University Press.

Harter, S. (1999). The construction of the self. A developmental perspective. New York: The Guilford Press.

Hattie, J. (1992). Self-concept. Hillsdale, NJ: Erlbaum.

Hay, I., Ashman, A. F., \& wan Kraayenoord, C. E. (1998). Educational characteristics of students with high or low self concept. Psychology in the Schools, 35(4), 391-400.

Herbert, M. (1987). Living with teenagers. United Kingdom: Basil Blackwell.

Hermans, H. J. M. (1996). Voicing the self: from information processing to dialogical interchange. Psychological Bulletin, 119, 31-50.

Hermans, H. J. M., \& Hermans-Jensen, E. (1995). Self-narratives: The construction of the meaning in psychotherapy. NY: Guilford Press.

Hermans, H. J. M., \& Kempen, H. J. G. (1993). The dialogical self: meaning as movement. San Diego, CA: Academic Press.

Higgins, E. "T. (1987). Self discrepancy; Theory relation self and affect. Psychological Review, 94, 319-340.

Higgins, E. T. (1989). Self discrepancy theory: What patters of self belliefs cause people suffer? In L. Berkowitz (Ed.), Advances in experimental social psychology (Vol. 22). New York: Academic Press.

Hobfool, S. E., \& Walfisch, S. (1984). Coping with a threat to Life: A longitudinal Study of Self Concept, Social Support and Psychological Distress. American Joumal of Community Psychology, 12(1), 87-100.

Hoeger, W. W. R. (1990). Fitmess and wellness. Englewood, CO: Morton.

Hoffman, M. L. (1999). Examining sex differences in adolescent adjustment: The effect of competence on gender role in differences in psychopathology.

Dissertation absiracts intemational: Section B: The science and engineering, 59(9-B), 5086 .

Horowitz, L. A. (1999). The relationship of childhood sexual abuse to revictimisation: Mediating variables and developmental processes. Dissertation Abstracts International: Section B: The Sciences and Engineering, 60(4-B), 1855 .

Hosman, C. M. H. (1997). The concept of mental health promotion. A view of European Mental Health Promotion network. In E. Lorang (Ed.), Impact of family, school and media on the well-being of children and adolescents. Luxembourg: Pro Sano Vita. 
Hosman, C. M. H. (Ed.). (2000). Naar een geestelijke gezonde samenleving: inleiding in de preventieve geestelijke gezondheidszorg. (Towards a mentally healthy community: Introduction in prevention in mental health). Diegem: Kluwer.

Jahoda, M. (1958). Current concepts of positive mental health. New York: Basil Books:

Jane-Llopis, E. (2002). What makes the ounce of prevention effective: A metaanalysis of mental health promotion and mental disorder prevention ptogrammes. Nijmegen, Nijmegen.

Janssen, J., \& Prins, M. (1991). Jeugdsubculturen binnenste buiten. Een onderzoek naar homologie in jeugdsubculturen. Jeogd en samenleving, 21(2/3), 194213.

Jessor, R., Turbin, M. S., \& Costa, F. M. (1998). Risk and protection in successful outcomes among disadvantaged adolescents. Applied Developmental Science, 2(4), 194-208.

Jones, A., \& Crandall, R. (1986). Validation of the short index of self actualization. Personality and Social Psychology Bulletin, 12, 63-73.

Jones, S., \& Heaven, P. (1998). Psychosocial correlates of adolescent drug-taking behaviour. Journal of Adolescence, 21(2), 127-134.

Judge, T. A., Bono, J. E., \& Locke, E. A. (2000). Personality and job satisfaction: The mediating role of job characteristics. Journal of Applied Psychology, 85(2), 237-249.

Kaplan, H. B. (1975). Self-attitudes and deviant behaviour. Pacific Palisades, CA: Goodyear.

Kashubeck, \& Christensen. (1993). Parental alcohol use, family relationship quality, self-esteem end depression in college. Journal of College Student Development, 36(5), 431-343.

Kihlstrom, J. F., \& Cantor, N. (1983). Mental representations of the self. In L. Berkowitz (Ed.), Advances in experimental social psychology (Vol. 17, pp. 1-47). San Diego, CA: Academic Press.

King, N. (1975). Giving from feeling. New York: Drama Books Specialists.

Komen, M. (1997). Gevaarlijke kinderen. Veranderen in de aard van jeugdcriminaliteit, 1960-1995. Amsterdam Sociologisch Tijdschrift, 3.

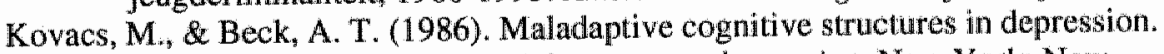
In J. C. Coyne (Ed), Essential papers on depression. New York: New York University Press.

Kressly, J. C. (1994). Middle Level Advisory: Targeting Potential Violence before Tragedy Strikes. Schools in the Middle, 3(3), 27-30.

Kuijpers, Y. A. G. J. (2001). 'Ik heb het". A prevention program to foster self-esteem of children. Master's Thesis, Macistricht University.

Langley, D., \& Langley, G. E. (1983). Dramatherapy and Psychiatry. New York: Croom Helm.

Lazarus, R. S. (1984). Stress, appraisal and coping. New York: Springer.

Levant, R. (1984), From person to system: Two perspectives. In R. Levant \& J. M. Shlien (Eds.), Client-centered therapy and the person-centered approach: New directions in theory, research and practice. Boston, MA: Boston $\mathrm{U}$. 
Lewis, M., Allesandri, S. M., \& Sullivan, M. W. (1992). Differences in shame and pride as a function of children's gender and task difficulty. Child development, 63, 630-638.

Loveland-Cherry, C., Leech, S., Laetz, V., \& Dielman, T. (1996). Correlates of alcohol use and misuse in fourth grade children: psychosocial, peer, parental and family factors. Health Education Quarterly, 23(4), 497-511.

Loyd, B. H., Abidin, R. R. (1985). Revision of the parenting stress index. Journal of the Pediatric Psychology, 10(2), 169-177.

Macdonald, G. (1994). Self esteem and the promotion of mental health. In D. Trent \& C. Reed (Eds.), Promotion of Mental Health (Vol. 3). Aldershot: Avebury.

Mann, M. (1987). 'I am the key', A group work process to foster self esteem, Hebrew Version. Not Published.

Mann, M. (1997). 'I am the key', A group-work process to foster self esteem, English Version. Not published.

Mann, M., Hosman, C. H. M., Schaalma, H. P.y \& De Vries, N. K. (submitted a). Self-esteem in a broad spectrum approach for mental health promotion in schools. Health Education Research.

Mann, M., Hosman, C. M., Breukelen, G. V., Meesters, C., \& De Vries, N. K. (submitted c). Searching for the key to the self: An evaluation of the shortterm effects of 'I Am The Key', a Generic School Mentall Health Promotion Program. Journal of Counseling and Development.

Mann, M., Hosman, C. M., Breukelen, G. V., Meesters, C., Kasander, R., \& De Vries, N. K. (submitted d). A follow-up study of the effectiveness of "I Am The Key", a generic school counseling program. Jownal of School Health.

Mann, M., Meesters, C., Muris, P., Hosman, C. M. H., Breukelen, G., \& De Vries, N. K. (submitted b). Internalizing and externalizing problems in normal children: Relationships with self-esteem, self-perceived competence and parenting stress. Personality and Individual Differences.

Marcia, J. E., Waterman, A. S., Matteson, D. R., Archer, S. L., \& Orlofsky, J. L. (1993). Ego identity, A handbook for psycho-social research. USA: Springer Verlag.

Markus, H. (1977). Self schemata and processing information about the self. Joumal of personality and social psychology, 35, 63-78.

Markus, H., \& Nurius, P. (1986). Possible selves. American Psychologüt, 41, 954969.

Marsh. H. W., \& Yeung, A. S. (1997). Causal effects of academic self-concept on academic achievement: Structural equation models of longitudinal data. Joumal of Educational Psychology, 89(1), 41-54.

Marx, E., \& Wooly, S. F. (1998). Health is Acadentic, a guide to coordinated school health progroms. NY: Teachers College Columbia University.

McLendon, J. A. (2000). The Satir system: Brief therapy strategies. In J. Carlson \& L. Sperry (Eds.), Brief therapy with individuals and couples. Governors State U, University Park, IL.

Mesman, J, \& Koot, H. M. (2000). Common and specific correlates of preadolescent internalizing and externalizing psychopathology. Journal of Abnormal Psychology, $109(3), 428-437$. 
Milgram, N. A. (1989). Children under stress. In T. H. Ollendick \& M. Hensen (Eds.), Handbook of child Psychopathology (2nd ed.). Tel Aviv: Ramat Aviv.

Miller, H. (2000). Cross-cultural validity of a model of self-worth: Application to Finnish children. Social Behavior and Personality, 28, 105-118.

Miller, P. M., Kreitman, N. B., Ingham, J. G., \& Sashidharan, S. P. (1989). Self esteem, life stress and psychiatric disorder. Joumal of Affective Disorders, $17,65-75$.

Moerbeek, M., Van Breukelen, G. J. P., \& Berger, M. P. F. (2003). A comparison between traditional methods and multilevel regression for the analysis of multicenter intervention studies. Journal of Clinical Epidemiology, accepted.

Moreno, J. L. (1945). Mental Catharsis and Psychodrama (Vol. 6). New York: Bacon House.

Mrazek, P. J., \& Haggerty, R. J. E. (1994). Reducing risks for mental disorders: Frontiers for preventive intervention research: Washington: National Academic Press.

Muha, D. G. (1991). Dropout prevention and group counseling. High school journal, 74(2), 76-80.

Mullen, P. D., Mains, D. A., \& Velez, R. (1992). A Meta-analysis of controlled trails of cardiac patient education. Patient Education and Counseling, 19, 143-162.

Mulsow, M. H. (1999). Parenting processes and child self-esteem: An examination of family stress, maternal psychological characteristics and family processes. Dissertation abstracts international: Section A: Humanities and Social Sciences, 60(2-A), 0559.

Muris, P., Meesters, C., \& Fijen, P. (in press). The self-perception profile for children: Further evidence for its factor structure, reliability, and validity. Educational and Psychological Measurement.

Muris, P., Meesters, C., Merckelbach, H., \& Huilsenbeck, P. (2000). Worry in children is related to perceived parental rearing and attachment. Behaviour Research and Therapy, 38, 487-497.

Myers, J. E., Sweeney, T. J., \& Witmer, J. M. (2000). The wheel of wellness counseling for wellness: A holistic model for treatment planning. Journal of Counseling and Development, 78, 251-266.

NCES. (1997a). School Disciplinary Survey on School Violence: National Center for Education Statistics.

NCES. (1997b). Violence and Discipline Problems in U.S. Public Schools: 1996-97. National Center for Education Statistics USA (1997). Retrieved, 1998, from the World Wide Web: http://nces.ed.gow/pubs98/violencel

Neighbors, B. D. (1995). The impact of family of origin stressors on young adult psychological functioning: Issues of longitudinal and concurrent prediction and mediation. Dissertation abstracts international: Section B: The science and engineering, 55(9-B), 41.27.

Noerthorp, D., \& Cynthia, L. (2000). Local Action. Creating Health Promoting Schools. Genewa: WHO. 
Nyamathi, A. (1991). Relationships of resources to emotional distress, somatic complaints and high risk behaviors in drug recovery and homeless minority women. Research in Nursing and Health, 14, 269-277.

O'Dea, J. A. \& Abraham, \$. (2000). Improving the body image, eating attitudes, and behaviors of young malle and female adolescents: A new educational approach that focuses on self-esteem. Invernational Joumal of Eating Disorders, $28(1), 43-57$.

Oliver, J. M., \& Paull, J. C. (1995). Self-esteem and self-efficacy; perceived parenting and family climate; and depression in university students. Journal of Clinical Psychology, 51(4), 467+481.

Overholser, J. C., Adams, D. M., Lehnert, K. L., \& Brinkman, D. C. (1995). Self Esteem deficits and suicidal tendencies among adolescents. Journal of American Academy child and adolescent Psychiatry, 34(7), 919-928.

Papps, B. P., \& O'-Carroll, R. E. (1998). Extremes of self-esteem and narcissism and the experience and expression of anger and aggression. Aggressive Behavior, 24(6), 421-438.

Patterson, G. R., \& Capaldi, D. M. (1992). Mediational model for boys depressed mood. In J. Rolf \& A. S. Masten \& D. Cicchetti \& K. H. Nuechterlein \& S. Weintraub (Eds.), Risk and Protective Factors in Development of psychopathology. Cambridge: Cambridge University Press.

Patton, W. (1991). Relationship between Self Image and Depression in adolescents. Psychological Reports, 68(687-688).

Paul, J. P., Stall, R., \& Davis, D. F. (1993), Sexual risk for HIV transmission among gay/bisexual men in substance-abuse treatment. AIDS-Edacation-andPrevertion, 5(1), 11-24.

Penninx, B. W., van Tilburg, T., J, B. A., Deeg, D. J., Kriegsman, D. M., \& van Eijk, J. T. (1998). Effects of social support and personal coping resources on depressive symptoms: different for various chronic diseases? Health Psychology, 17(6), 551-558.

Perls, F. S. (1969). Gestalt therapy verbatin (in Hebrew). Tel Aviv: Real People Press.

Petersen, A. C., Compas, B. E., Brooks-Gunn, J., Stemmler, M., Ey, S., \& Grant, K. E. (1993). Depression in adolescence. American Psychologist, 48, 155-168.

Poikolainen, K., Tuulio-Henrikkson, A., Aalto-Setaelae, T., Marttunen, M., \& Loennqvist, J. (2001). Predictors of alcohol intake and heavy drinking in early adulthood: A 5-year follow-up of 15-19-year-old Finnish adolescents. Alcohol and Alcoholism, 36(1), 85-88.

Pritester, J., Wegener, D., Petty, R., \& Fabriger, L. (1999). Examining the psychological process of underlying the sleeper effect: The elaboration likelihood model explanation. Media Psychology, I(1), 27-48.

Rappaport, J. (1984). Studies in empowerment: Introduction to the issue. Prevention in hwman services, $3(2-3), 1-7$.

Reda-Norton, L. J. (1995). Elementary school predictors of adolescent adjustment problems. Dissertation abstracts international: Section $B$. The science and engineering, $56(5-\mathrm{B}), 2904$.

Regier, D. A., Boyd, J. H., Burke, J. D., Rae, D. S., Myers, J. K., \& Kramer, M. (1988). One-month prevalence of mental disorders in the United States. 
Based on five epidemiologic Catchment Area sites. Archives of General Psychiatry, 45, 977-986.

Reinherz, H. Z., Giaconia, R. M., Pakiz, B., Silverman, A. B., Farst, A. K., \& Lefkowitz, E. S. (1993). Psychosocial risk for major depression in late adolescence. Journal of Ame rican Academy for child and adolescent Psychiatry, 32(6), 1155-1163.

Remmerswaal, J. (1992). Begeleiden van groepen: groepdynamica in de praktijk. Houten/Zaventem: Bohn Stafleu Van Loghum.

Renouf, A. G. (1990). Low Self worth and anger as components of the depressing experience in young adolescents. Development and Psychopathology, 2 , 293-310.

Reston, V. (1991). HIV Prevention Education for Exceptional Youth: Why HIV Prevention Education Is Important, Office of Educational Research and Improvement. Washington, $\mathrm{DC}$.

Rice, K. G., Ashby, J. S., \& Slaney, R. B. (1998). Sellf-esteem as a mediator between perfectionism and depression: A structural equations analysis. Journal of Counseling Psychology, 45(3), 304-314.

Rodney, H. E., Mupier, R, \& Crafter, B. (1996). Predictors of alcohol drinking among African American adolescents: Implications for violence prevention. Journal of Negro Education, 65(4), 434-444.

Roger, C. R. (1961). On becoming a person. Boston: Houghton Mifflin.

Rogers, C. R. (1951). Client-centered therapy. Boston: Houghton Mifflin.

Rogers, T. B. (1981). A model of the self as an aspect of the human information processing system. In N. Canton \& J. F. Kihlstrom (Eds.), Personality, cognition and social interaction (pp. 193-214). Hillsdale, NJ: Erlboum.

Rolf, J., \& Johnson, J. (1992). The challenges of Aids. In J. Rolf \& A. S. Masten \& D. Cicchetti \& K. H. Nuechterlein \& S. Weintraub (Eds.), Risk and Protective Factors in Development of psychopathology. Cambridge: Cambridge University Press.

Rolf, J., Masten, A. S., Cicchetti, D., Nuechterlein, K. H., \& Weintraub, S. (1990). Risk and protective factors in the development of psychopathology. Cambridge: Cambridge University Press.

Romney, D. M. (1994). Cross-validating a causal model relating attributional style, self-esteem ${ }_{n}$ and depression: An heuristic study. Psychological Reports, $74(1), 203-207$.

Rouse, K. A. (1998). Longitudinal health endangering behavior among resilient and nonresilient early adolescents. Journal of adolescent health, 23(5), 297302.

Ruiter, M. (1997). Preventie van depressie bij jongeren. Katholieke Universiteit Nijmegen, Nijmegen.

Rutter, M. (1992). Psychosocial resilience and protective mechanisms. In J. Rolf \& A. S. Masten \& D. Cicchetti \& K. H. Nuechterlien \& S. Weintraub (Eds.), Risk and Protective Factors in the Development of Psychopathology. USA: Cambridge University Press.

Ryff, C. D. (1995). Psychologocal well-being in adult life. Current Directions in Psychological Science, 4, 99-104.

SAMHSA. (July 142000 ), press release - suicide prevalence in the USA:

Substance Abuse and Mental Health Services Administration. 
Sartorius, N. (1988). Health Promotion strategies: Keynote Address. Canadian Journal of Public Health, 79(suppl. 2), $33-55$.

Scarano, G. M. Gina, M., Kaodner, M., \& Cynthia, R. (1994). A Description of the contimuum of eating Disorders: Implications for Intervention and Research. Journal of Counseling and Development, 72(4), 356-361.

Schoen (1999). The etiology of violence and the voice of the perpetrator. Dissertation abstracts international: Section $B$ : The science and engineering, $60(2-\mathrm{B}), 0875$.

Seligman, M. E. P. (1975). Helplessness. San Francisco, CA: W.H. Freeman.

Seligman, M. E. P. (1995). What you can change and what you can't. New York: Alfred A. Knopf:

Seligman, M. E. P., \& Csikszentmihalyi, M. (2000). Positive psychology: An introduction. American Psychologist, 55(1), 5-14.

Seligman, M. E. P., Reivich, K., Jaycox, L., \& Gillham, J. (1995). The optimistic child. Boston, MA, US: Houghton Mifflin Co.

Selman, R. (1980). The growth of interpersonal understanding: Developmental and clinical analyses. New York: Academic Press.

Shadmon, O. (1998). Family and non-family supports as contributors to adjustment in school-aged chilliren with employed mothers. Dissertation abstracts international: Section B. The science and engineering, 59(2-B), 0898 .

Shillingford, J. P., \& Shillingford-Mackin, A. (1991). Enhancing Self-Esteem through Wellness Programs. The Elementary School Jounal, 9I(5), 457466.

Shin, K. R. (1993). Factors predicting depression among Korean - American women in New York. International journal of Nursing studies, 30(5), 415-423.

Shisslak, C. M. , Crago, M., Gray , N., Estes, L. S., McKnight, K., Parnaby, O. G., Sharpe, T., Bryson, S., Killlen, J., \& Barr-Taylor, C. (1998). The prevention of eating disorders. Studies in eating disorders. In W. Vandereycken \& G. Noordenbos (Eds.), The McKnight Foundation prospective study of risk factors for the development of eating disorders. An international series (Vol. xii, pp. 56-74). New York, NY, US: New York University Press.

Short J. L. (1998). Evaluation of a Substance Abuse Prevention and Mental Health Promotion Program for Children of Divorce. Journal of Divorce and Remarriage, 28(3/4), 139-155.

Smolak, L., Levine, M. P., \& Schermer, F. (1996). Lessons from lessons: An evaluation of an elementary school prevention program.

Solomon, S., Greenberg, J., \& Pysczynski, T. (2000). Current directions in psychological science $9(6), 200-204$.

Somali, A., Kelley, J., Heckman, T., Hackl, K., Runge, L., \& Wright, C. (2001). Life optimism, substance use, and AIDS-specific attitudes associated with HIV $\sim$ risk behavior among disadvantaged innercity women. Joumal of Women's Health and Gender-based Medicine, 9(10), 1101-1110.

Spruijt-Metz, D. (1996). On everyday health-related behavior in adolescence., Vrij Universitiet Amsterdam, Amsterdam.

St Jeor, S. T. (1993). The role of weight management in the thealth of women. Joumal of American Diet Association; 93(9), 1007-1012. 
Stanchfield, L. L. (2000). Internalizing problems in children: Relations to peer acceptance and behavioral style. Dissertation Abstracts International:" Section B: The Science and Engineering, 61(1-B), 566.

Strecher, V. J., DeVillis, B. M., Becker, M. H., \& Rosenstock, I. M. (1986). The role of self-efficacy in achieving health behavior change. Health Education Quarterly, 3I(1), 73-92.

Sweeney, T. J., \& Witmer, J. M. (1991). Beyond social interest: Striving towards optimal health and wellness. Individual Psychology, 47, 527-540.

Swendsen, J. D., \& Merikangas, K. M. (2000). The Comobidity of Depression and Substance Use Disorders. Clinical psychology review, 20(2), 173-189.

Taylor, S., \& Brown, J. (1988). Illusions and well-being: a social psychological perspective on mental health. Psychological Bulletin, 103, 193-210.

Teri, L. (1982). Depression in Adolescence: Its relationship to assertion and various aspects of self image. Joumal of clinical child psychology, $M, 101-106$.

Tudor, K. (1996). Mental Health Promotion - Paradigm \& Practice. London: Routledge.

van der Ham, T., van der Strien, D. C., \& van Engelan, H. (1998). Personality characteristics predict outcomes of eating disorders in adolescents: a 4-year prospective study. European Child and Adolescent Psychiatry, 7(2), 79-84.

Vargo, B. (1995). Are withdrawn children at risk? Canadian Journal of School Psychology, 11(2), 166-177.

Verbeke, G., \& Molenberghs, G. (2000). Linear mixed models for Longitudinal data. New York: Springer.

Verhulst, F. C., Ende, J. v., \& Koot, H. M. (1997). Handeling Voor de Youth SelfRepont (YSR). Rotterdam: Erasmus Universiriet.

Vickers, M. J. (1993). Understanding obesity in woman. Journal of obisity and gynecology, 22(1), 17-23.

Vohs, K. D., Voelz, Z. R., Pettit, J. W., Bardone, A. M., Katz, J., \& Abramson, L. Y. (2001). Perfectionism, body dissatisfaction, and self-esteem: An interactive model of bulimic symptom development. Journal of Social and Clinical Psychology, 20(4), 476-497.

Weare, K. (2000), Promoting Mental, Emotional + Social Health: A Whole School Approach. London: Routledge.

Weiner, I. B. (1975). Depression in adolescence. In F. F. Flach \& S. C. Draghi (Eds.), The nature and treatment of depression. (pp. 99-117). NY: John Wiley \& Sons.

Wells, J. E., Bushnell, J. A., Hornblow, A. R., R, J. P., \& Oakley-Brown, M. A. (1989). Christchurch Psychiatric Epidemiology Study, part 1: methodology and life-time prevalence for specific psychiatric disorders. Australian and New Zealand Joumal of Psychiatry, 23, 315-326.

Whisman, M. A. (1990). The efficacy of booster maintenance sessions in behavior therapy: review and methodological critique. Clinical psychology review, $10,155-170$.

WHO. (1986a). Discussion document on the concept and principles of health promotion. Health Promotion, I, 73-76.

WHO. (1986b). The Ottawa Charter for Health Promotion. Geneva: World Health Organization. 
WHO. (2001). The World Health Repon. Mental health: New understanding, new hope. Geneva: World Health Organisation.

Wiatrek, D. E. (1998). The impact of adolescent self perceptions on decisions to engage in substance use: A social development approach. Dissertation Abstracts International: Section B: The Sciences and Engineering, 59(6B), 3127 .

Wilhelm, K., Parker, G, Dewhurst-Savellis, J., \& Asghari, A. (1999). Psychological predictors of single and recurrent major depressive episodes. Journal of Affective Disorders, 54(1-2), 139-147.

Wolf, L., Fisman, S., Ellison, D., \& Freeman, T. (1998). Effect of sibling perception of differential parental treatment in sibling dyads with one established child. Journal of the American Academy of Child and Adolescent Psychiatry, 37(12), 1317-1325.

Zimmerman, S. L. (2000). Self-esteem, personal control, optimism, extraversion, and the subjective well-being of midwestern university faculty. Dissertation Abstracts International: Section B: The Sciences and Engineering, $60(7-\mathrm{B}), 3608$.

Ziv, A. (1986). Humor and personality (in Hebrew). Tel Aviv: Papyrus. 


\section{Summary}

This thesis describes a study on the implementation and effects of the "I Am The Key' (IATK) Broad Spectrum program to mental health promotion. First, both an extensive literature review and a cross-sectional study stresses the importance of 'self-esteem' as a protective factor and a non-specific risk factor in mental health (chapters 2 and 3 ). Then the main themes and methods of the IATK program are presented (chapter 4). Subsequently, both short-term and long-term evaluation studies on the program's effects on symptoms of depression and aggression are presented (chapters 5 and 6). Finally, implications of the work reported in this thesis for theory and prevention practice, are discussed (chapter 7).

In the second chapter evidence is presented illustrating that positive selfesteem can lead to good mental health and positive social behavior, and that a broad range of mental disorders and social problems are associated with poor self-esteem. Such mental disorders and social problems include both internalizing problems (e.g. depression, suicidal tendencies, eating disorders and anxiety) and externalizing problems (e.g. viollence, substance abuse). This chapter concentrates on self-esteem from a developmental and educational point of view as a potentiall risk and protective factor in mental and physical health. Focusing on self-esteem is considered an important element of mental health promotion and of a Broad Spectrum Approach (BSA) in prevention. BSA is an approach that targets risk or protective factors that are common to a number of problems in preventive interventions and that results in positive outcomes on multiple mental health indicators.

The third chapter describes the results of a cross-sectional study on internalizing and externalizing problems in normal children. The relationships between self-esteem, self-perceived competence and parenting stress and internalizing and externalizing problem behaviors were investigated in a sample of 709 elementary schoolchildren. Results indicate that self-esteem and self-perceived competence, in particular concerning behavioral conduct and social acceptance, are negatively associated with problem behavior. More specifically, self-esteem, scholastic competence, and social acceptance appeared to be negatively related to 
internalizing problems. Whereas, self-perceived competence in behavioral conduct appeared to be negatively related to externalizing problems. Parenting stress was positively associated with externalizing problem behavior. Giender differences regarding internalizing and externalizing problems were found. Boys had more extemalizing problem belvavior while gïls had more internalizing problem behavior. Scholastic competence interacted with gender, and only served as a predictor for internalizing problems for girls. Further analysis implied that selfesteem could serve as a mediating factor between parenting stress and problem behavior. Furthermore, self-esteem and scholastic competence are apparently mediating factors between gender and internalizing problem behavior. No interaction effects between parenting stress and self-esteem were found in the prediction of problem behavior.

The fourth chapter provides a theoretical underpinning to the 'I am the key' program, a program which aims to foster se]f-esteem. It addresses the theoretical insights, methods, and strategies underlying 'I Am The key' (IATK). The main theories are Humanistic theory and Gestalt theory. Both of these stress the importance of phenomenological principles and self-actualization. The main focus of the intervention therefore, was on self-esteem and self-concept, using methods such as self-dialogue, creative expression, and group discussion. First, the consequences of poor and positive self-esteem are introduced and self-esteem is addressed as a core element in mental health promotion and in a Broad Spectrum Approach in prevention. Second, this chapter discusses the theories and educational methods of the "I Am 'The Key' program. Third, it gives an outline of the curriculum, its main themes, methods, and strategies. Fourth, results of a pilot study are discussed. The pilot results were favorable: the program resulted in a decrease in aggression, depression and social problems; there was also an increase in self-rated physical appearance. Furthermore, the program was found to be suitable within the Dutch school context. There were enthusiastic reactions by the children and the teachers regarding the content and most materials as reflected by questionnaires and observations. According to qualitative data, the atmosphere in the group improved and there were more positive interactions in the class. Moreover social skills (e.g. listening skills and social acceptance) had improved. Case studies indicated an 
improvement in psychosocial functioning of children who scored high in problem behavior prior to the program's implementation.

The IATK program was further implemented in 16 schools in the south of the Netherlands, in a nested randomized design: Within every school there were experimental and control classes. The sample included 709 children, $10-12$ years old with 372 girls and 337 boys. The fifth and sixth chapters present short-term effect and long-term effect studies of the program. The main question of the shortterm efficacy study is whether the IATK counseling program has an effect on mental health (promotion) variables (i.e. global self-esteem and self-evaluated competence in behavioral conduct) and thereby contributes to the prevention of mental and social problems (i.e. delinquency, depression, and aggression) of schoolchildren.

Results of the short-term study show that the program had signifficant effects in reducing delinquent behavior for participants ranking high in such behavior at pre-test. Moreover, it also showed reduced behavioral conduct for subjects scoring high in this domain at pre-test, and increasing aggressive behavior for those who scored low on this sub-scale at pre-test. The latter was interpreted as an assertiveness indicator. No impact was found on self-esteem or on internalizing problems such as symptoms of depression.

Chapter 6 presents a follow-up study on the impact of the IATK counseling program; it was conducted following a booster session eight months after the intervention. The booster was implemented in the same 16 elementary schools in the south of the Netherlands, in a nested randomized design, with experimental and control classes in every school. The sample included 680 students, 10-12 years old with 351 girls and 329 boys.

Comparisons between the experimental and control group at the follow-up test showed that the program had a significant effect in reducing behavioral conduct for subjects ranking high in behavioral conduct at pre-test. It also showed increasing aggressive behavior for subjects scoring low on this subscale at pre-test. This last, was interpreted as an assertiveness indicator. It also showed a trend toward decreased aggressiveness for subjects ranking high on this scalle at pre-test. 
Finally, Chapter 7 integrates the findings of the reported studies and discusses the results and the theoretical implications. Furthermore, the limitations and the practical implications are presented. Future recommendations for BSA preventive interventions are discussed. In particular, attention is paid to self-esteem enhancement and to the prevention of both externalizing and internalizing problem behaviors within the school system. 


\section{Acknowledgements}

Many people were key figures in this "search for the key to the self". Most important of all were the schoolchildren who participated in this study. Without their cooperation, feedback and enthusiasm, this project would not have been possible. They were truly 'magic keys'.

My heartfelt thanks also goes to my two supervisors Clemens Hosman and Nanne de Vries.

Clemens Hosman's knowledge in the field of mental health was an inspiring influence. Equally important however was his faith in me and in the program. His assistance in gaining a grant for the project from the Dutch Health Research and Development Council (Zorg Onderzoek Nederland) and his help and guidance in writing this thesis are deeply appreciated.

Nanne de Vries, my second supervisor, contributed his special expertise in the field of social psychology and provided support in facilitating the continuity of the project. I am particularly grateful for his motivating optimism during the writing of this thesis and his enduring confidence in me.

As in most projects of this scale, I benefited tremendously from the help and support of people I encountered during the course of the program. I would like to take this opportunity to thank:

The members of the Beoordelingscommissie Bart van den Borne, Susan Bögels, Nathan Deen, Ingrid Josephs and Gerjo Kok for contributing their time and efforts to evaluate this manuscript;

Gerard Van Breukelen for his warm and constant support during the analysis of the data and the writing of the results. His commitment to this research project is highly appreciated;

Cor Meesters for his help on several chapters of this thesis. His patient guidance, encouragement and optimism during the writing process were most valuable to me;

Herman Schaalma for his continuous help during the pilot and implementation phases" his advice in the writing of the theoretical chapter; and his 
support in the grant application to "Kinder postzegels" for the materials used in the project;

Peter Muris for his important input to chapter 3; I learnt a lot from his comments:

Guy Parcel, Elisabeth Baumler from Houston Texas University, U.S.A, Moshe Israelshvili from Tel-Aviv University, Israel, and Jo Hermanns from The University of Amsterdam for their inspiring conversations;

Matt Commers, Cees Hoefnagels and Ilse Mesters for their useful comments on different drafts of my chapters;

The representatives from different organizations in the Netherlands who took an active role in meetings and helped in promoting the program in schools: Judith Aerdts (GGD Westelijke Mijnstreek), Marc Bosma (RIAGG Westelijke Mijnstreek), Martijn Dingemans (RPC Maastricht), Christianne Hardy (GGD Zuidelijk Zuid Limburg), Marijke Ruiter (RIAGG Maastricht), Paul Stevens (Hogeschool Limburg);

The group leaders (Hogeschool students), the teachers and the school headmasters who made the execution of the project feasible;

The staff from the Jeroen Bosch school in Arnhem: the school headmaster Hela Hogenboom and the teachers Ton Borgers and Gert-Jan Boog and Marilene Lardinois from the Elkerlyk school in Maastricht whose enthusiasm and initiative helped spread the word of 'I Am The Key' to school staff and parents in a variety of schools;

My research assistant Rianne Kasander for being so helpful during the implementation of the program and the booster sessions;

My student assistants: Susan de Haan, Esther Janssen, Yvonne Kuijpers and Chantal Van Ree, for their support during several phases of the project;

The social workers; Jaap Kleve who helped in the pre-pilot phase and Tzippy Harmsen Seffy who supported me tremendously with the implementation process;

Martine Mol for the wonderful help during the final phase of the book preparations; 
My students Annet't Mannetje and Aletta Hendriks for their well written reports on the topic of self-esteem;

Nora Oosting for the beautiful graphic design of the brochure for "I Am The Key';

Valerie Siklie from the "Keshet Beanan Theatre" from the Kibbutz Nir Eliahu in Israel for the beautiful and special puppet designs;

Rinat Hoffer for the wonderfully brilliant cover illustration;

My colleagues from the department of Health Education and Promotion, in particular Dianne Alewijnse, Marlein Ausems, Mirjam Franssen, Helga Happaerts , Leon Kolenburg, Marja Slangen, Josee Trottemant and Ellen Uiters. It was a great pleasure working with them. Their warm and helpful attitude was most valuable;

And all my native English speaking family and friends Anna Cohen, Lisa Cohen, Grit Chiu, Geraldine Craig, Anna Carpendale, Shona Chatten, Shelia Chatten, Sue Hall and Karen Philips for checking and correcting my English.

An important ingredient in every big project is always the extra personal support from family and friends. Such support does not factor in the hectic schedules; the battles for funding; the hours of research and writing; yet it holds the key to how much we can achieve and the well-being of our inner self. I would therefore like to take this opportunity to express my very deep gratitude to these unique people:

An enormous thank you to my mother Judith Mann and my in-laws Shoshana and Meir Cohen. Your love, encouragement and support mean a lot to me.

II would like to thank my big familly and my innumerable friends abroad and in the Netherlands for their endless support. You have all played an important part in encouraging me to complete this challenging mission and have enriched my life in more ways than $I$ can express.

A great thank you to my lovely sons Ron and Gil for your patience and understanding that 'Mum has to finish her book. - I am proud of your great sense of humor, tremendous help and love. 
And last, but by no means least, I would like to thank my husband Eli; for your love, support, help, encouragement, care and true friendship; for being there for me and contributing your knowledge in management, computers and statistics. It is thanks to your great investment that this huge project came through! 


\section{Curriculum vitae}

Michal Mann was born in Petach Tikwa, Israel in 1962. She completed ther high school education at Shimhon Ben Tzvi School in Givataim in 1980. From 1982 to 1985 she attended the Tel-Aviv University, where she received a Bachelor of Arts degree with a double major in Educational Counseling and World Literature. Between 1985 and 1987, Mann earned a Masters degree in Educational Counseling and Special Education at the Tel Aviv University while at the same time gaining a Teaching Diploma in Literature for both primary and secondary schools. During this period she also worked at Tel-Aviv University as an educational assistant in the Special Education department, and as an educational counselor on three prevention programs: Prevention of drug abuse; Rehabilitation of handicapped adolescents; and the 'The challenge of adolescence' life skills program. From 1987 to 1994 she worked for the Ministry of Education in Israel as an educational counselor and a teacher in primary schools at Kiriat Ono. From 1993 she also worked at the Educational Center at Yahud where she guided educational counselors and developed counseling programs. Mann developed several programs in the area of mental health promotion including the programs 'I Am The Key' and 'Coping with stress in war situations', which was implemented in Israel during the Gulf War.

In 1995, Mann moved to The Netherlands and at the end of that year she started the preparations for her study on the evaluation of the "I Am The Key' program in order to pursue her Ph.D. within the department of Health Education and Promotion at Maastricht University. In 1999 Mann started to work as a researcher in this department after receiving a grant from the Dutch Health Research and Development Council (Zorg Onderzoek Nederland). In 2000 Mann also taught in the Creative Therapy and Social Pedagogic Work departments of the Hoge School Limburg. In addition she implemented mental health promotion programs in the International School of Maastricht. 


\section{Appendix}

Articles about the pilot: Arnham Courant (November $25^{\text {th }} 1999$ ) and De Gelderlander (November 23ed 1999).

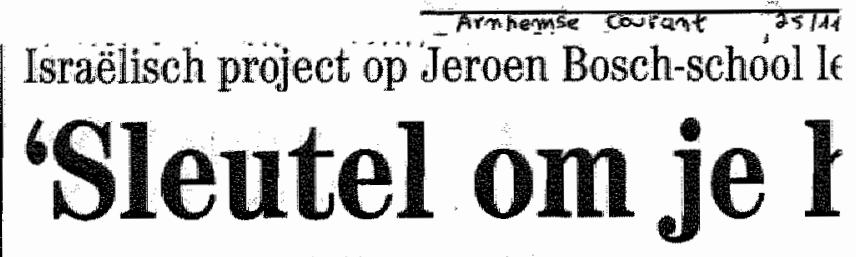

Door MENNO POLS

ARNHEM - Kelly en Sabrina zitten tegren het eind van de les werwoed ve knippien. Ze maken sleu tels"s dat is duidelijk Maar warkoor zifjn dile be doeld? Iedereen maaki zilli, elgen sileutel", legt Kelly wit. .Om je hart te openten "

Vetbluthent, wit de mond van

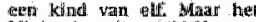
16) Hhat thier gekunisteld Her wro jert "th theb har" laer de lande ven in an hadomitral zae valwasen termen te hankerwo Doxill vatu de methode is kindtic Teni iroer zelfowardering bij te

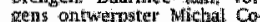
gens aning inen-4han, op lasena leetuld dell

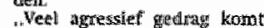

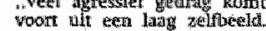
masc ook drugiz en alcoholgepressisey bebben vala $k$ ean linge

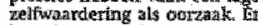
is meel ong

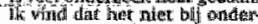

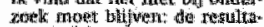

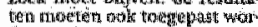

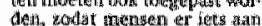

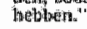

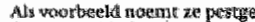
drage van kingereil op bay schiolen. Veel Windwen heb

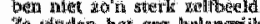

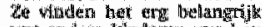
wat where kinideren wan hen

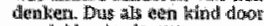
ment levther de rouep gepest

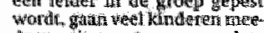

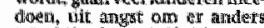
"midur bij the horen". Als kindetren

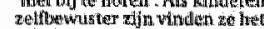

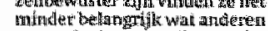

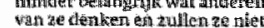

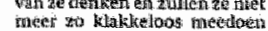

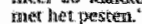

De kouthduren vati groep zever

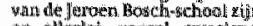
op allertlei. voural creacieve.

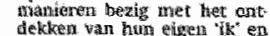

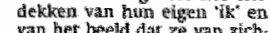
van het beeld dat ze van zinhzell theblen. Whe hiaviselen,

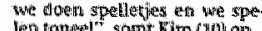

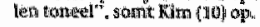

Gehlumen

thots trownt het groweple meis. den de nerslatewer nue nat val hus artheid stang opere

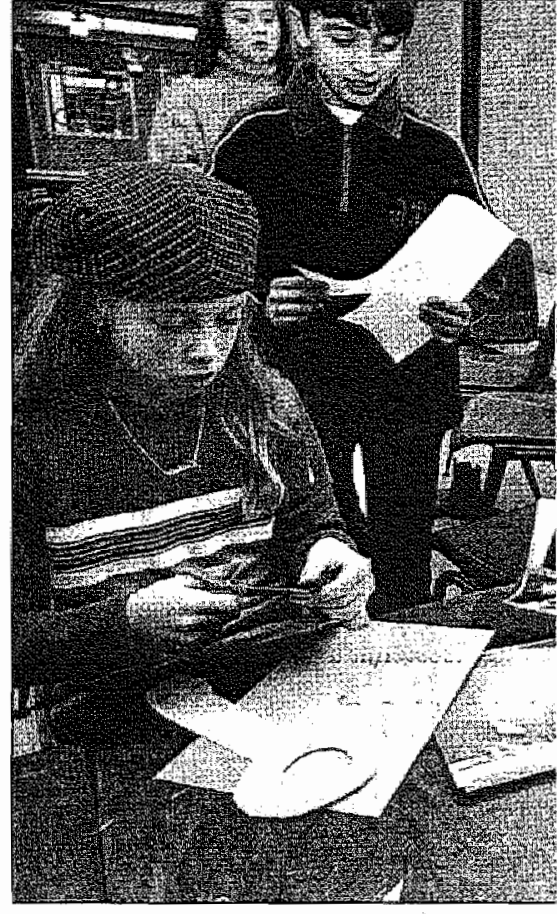

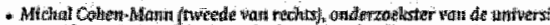

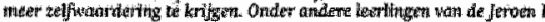

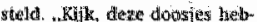

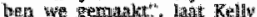

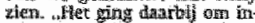

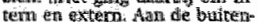

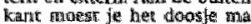

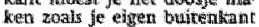

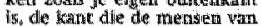
je zier $A$ de thinenkint.

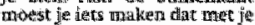

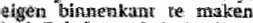
hist. Ik heb asin de buaterikatant:

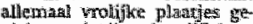

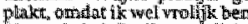

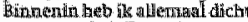

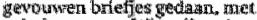
geheimen erop. Wie rriln writer. dinnen zing ers whe stom

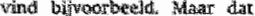

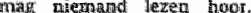
wan daar bun je oot wer mensen mee inversen:"
The heb her" is ofe natam tran ena pongtect dar er op gerrich

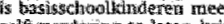

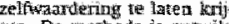

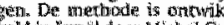

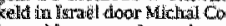
then idwn, ondwrokster

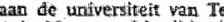

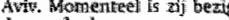
de methole dan tie passien voor do Naderlandse situatie zuf hoopt op dit proiert te pro

We laren bli hed project an andene rnensing ook als te ander wijn" lest

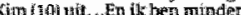

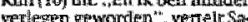

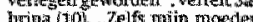




\section{प्राप्र \\ sert kinderen over hun gevoelens te praten lart te openen'}

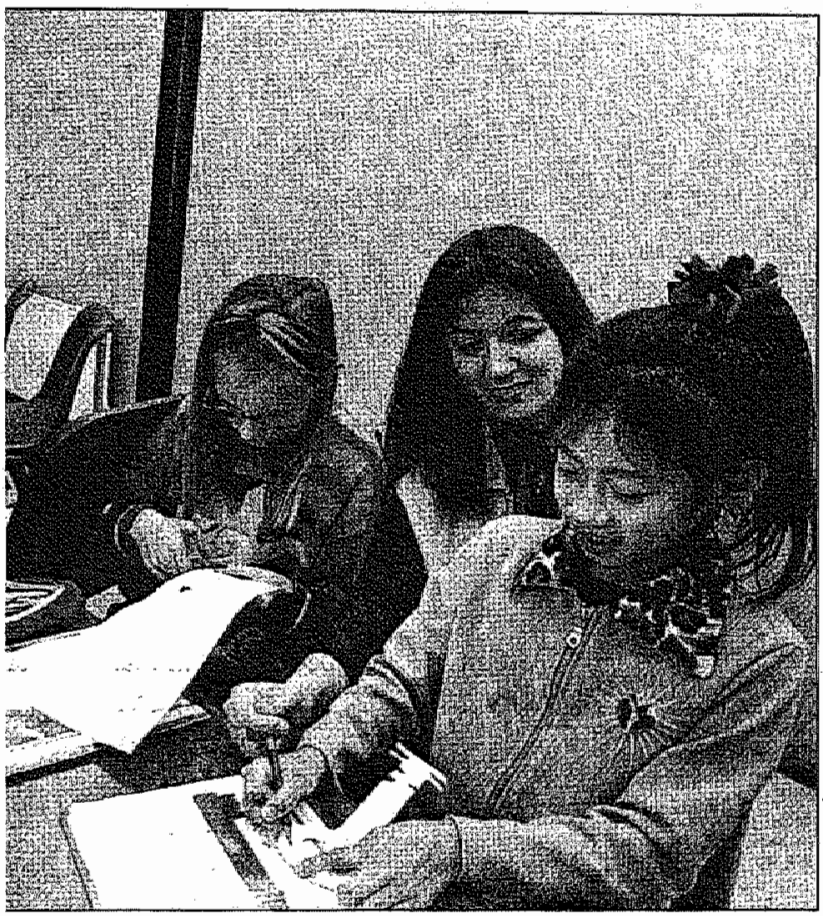

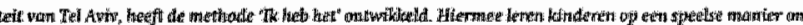

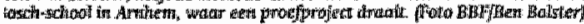

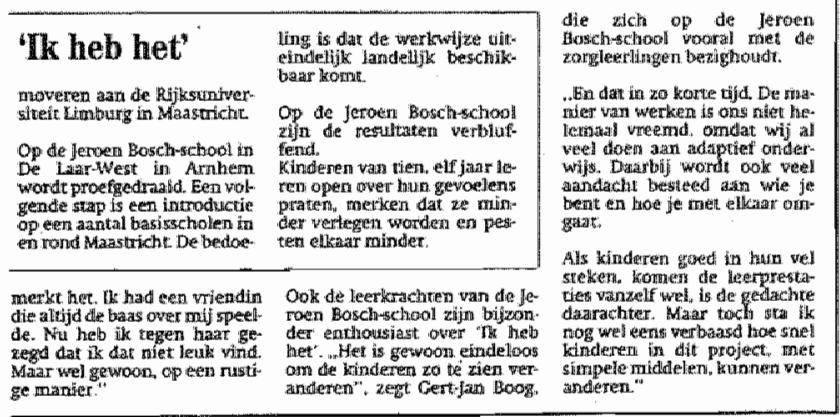




\section{School leert kinderen om}

- Colderlumer 231111949

Kunderen leren lezen. schrijuen en rekenen is niet voldoende, ze moeten ook leren omgan met zichzelf. De Jeroen Boschschool in Arnhem probeent een nicuwe methode uit.

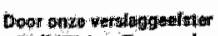

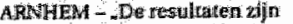

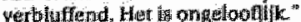

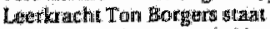

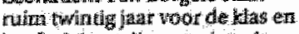

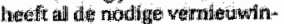
gen metgemalt.

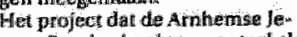
roen Bossheschool momemectil ats wnige Medertandse school wiprobereri, zag hifl dian ook met de nodifge scepsis tegempet. Mati hmidds is de docent raterd:

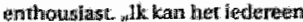
anberelon."

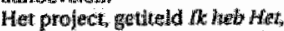

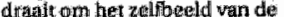
leorlingerm. De kinderen leren le-

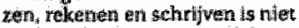
Woldosinde. Ze thoetem ook leren ongatan miet hatiou cigen gavoe. lens en we wan anderen, zo lutht the thasiofie.

Het h heel belarigrilk dat kinde

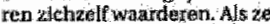

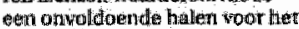

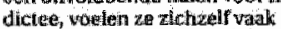
orto mardeloos. We moeten zo: dsudelik makiken dat ze allemal watrut evolle personen zijn.

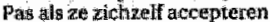
zoals ze zifin kunnern ze andieren accepteren" zong Michall Cohen Mann. de desinumdige uit lis. ratil dite do therio in Nedialland komit uîtedragem: Ze is werbonden alat de Universiteit van Matastrichtit.

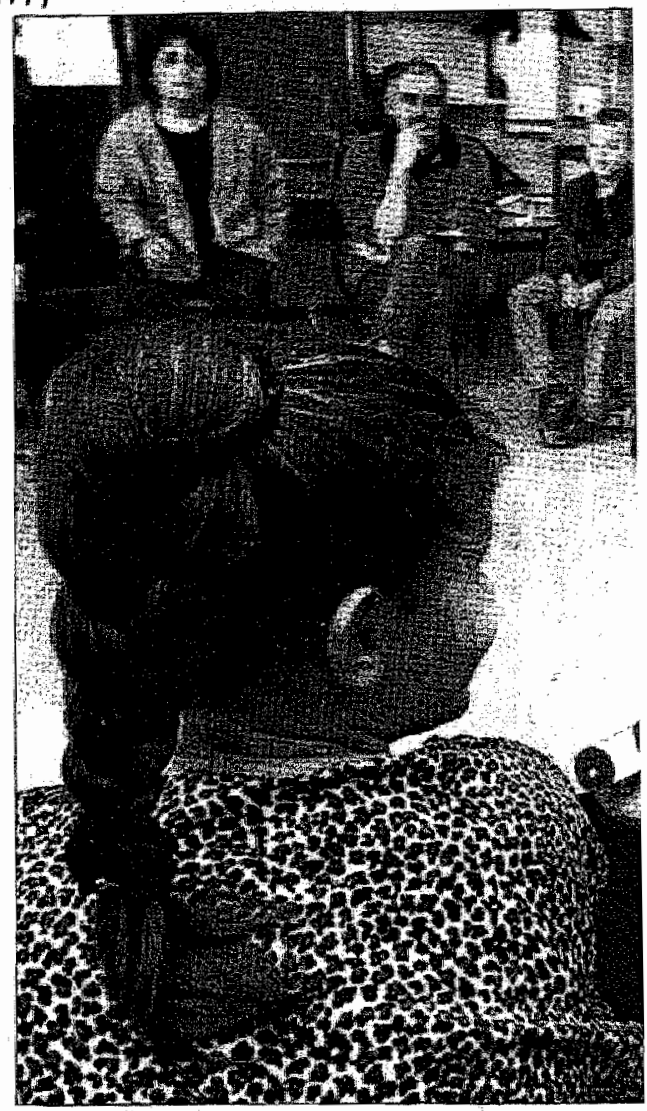

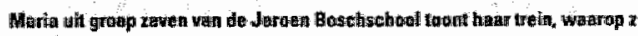

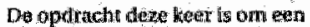

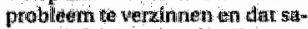
men nut en arudere learling unt

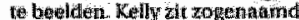
holemanal in de stross ondid zo:

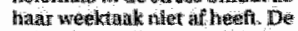

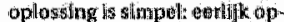

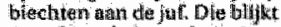

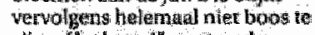

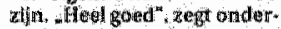

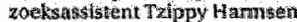

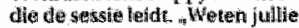

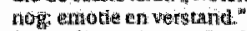
De learlingen kripten hael wat termen re workerken: over the

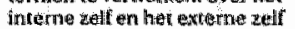
bifoonlbueld end ower thet rede

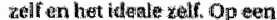
ptast sethe manier verdu dellikt Harms en doze beyripgon. Het

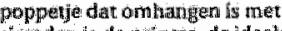
vituraden is de porinses, de ideate zelf van enen noliste dat in her echt nilet 20 this is.

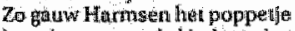

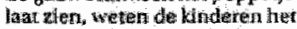

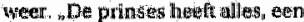

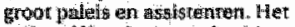

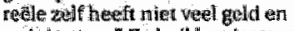
wethig eter." Ze knikkeninstam

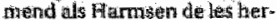

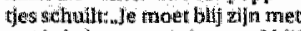

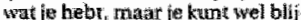
wen dromens over wain liz allemal wow willem."

ook malkten te de anmodi-

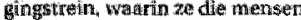
sen pilatioje gaven dise vool heri betangrijk zijn. Enthousinas stelharlit ofe achter that ne poppe 


\section{zich beter te voelen}

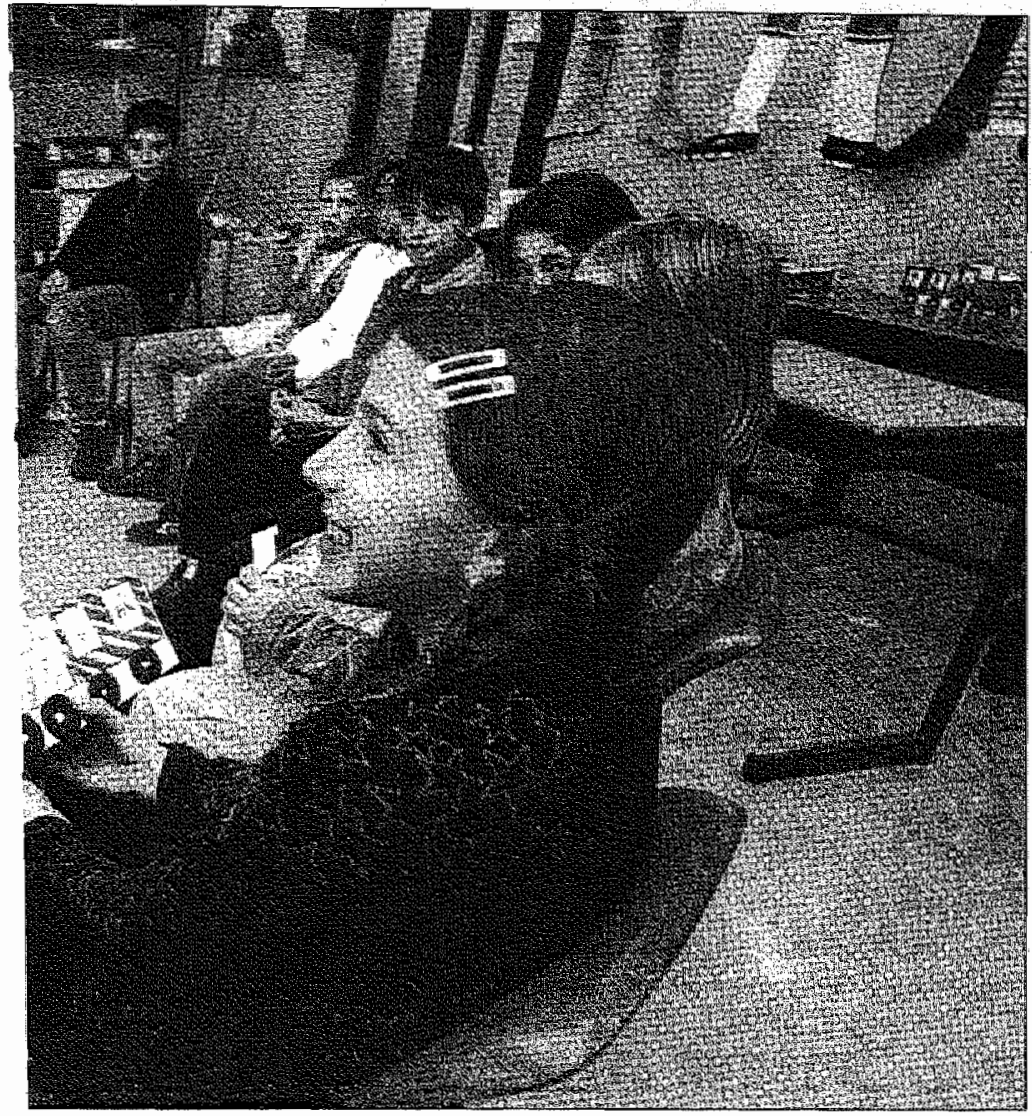

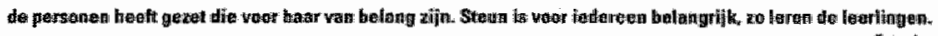

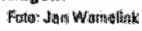

ken de leerlingen hum winger op.

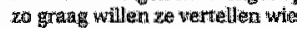
er op hum trefin sitati.

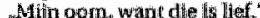

shifin vrienditio want the vertel il allies:"

- Mijn moeder omdat ze mh moeder is:"

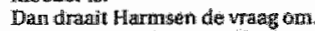
Steunen de leetlingen zellif ond momen? far min moreder for

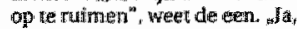
door lers ne verinimen waraloor

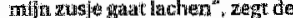
areder. Het we na hell andere voorbedd schuret ze te birnen. We vergeren well eiens on stil te staran bij de pesiltieve dingen ${ }^{*}$

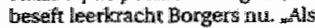

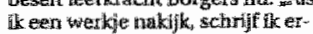

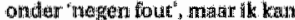

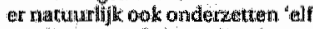
goed'. Bur gente de leerling het gevoel dal hij lets han."

De dacent he erwan orventudigd dat dowor deve beridering de schoolprestatics sialy de lieerlingen omhoog zullen garan. Als ze rich buter woelen an lebler ing twu vel xituen, schipten ade resultagem omtonos.

\section{Tellftedold}

Volgerts Cotien Mantu kan en

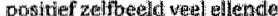

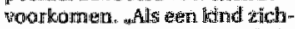
zelf actepreart, wall het makkelijket re druk yan exa groeg kan

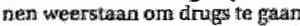
token bijwotroeld of rottligheid wit to haten, "Ciffers on deres

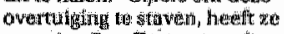
nog nhlet Do effecten vala de mo.

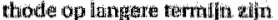
nog miet anderrocht volgent foar cat ar votor het berst in de vakbladen ower wonden gersubill. coterd, ald dius Cohen Malsurt.

Nia de jaarowisselingy gatan ander supervigie wan de urtiversiteit: zestien scholen in Mazustricht het prougramina totepassen. Do Juroen Boschischool zal er zeker moe doorgan, verzekaria Bor-

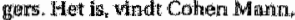
de hoorgre nijd om behatwe an kennis wok aind acht tes betstodien

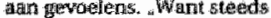
miter mensen stju agresstisif of depressict: 